\title{
A Review of Grain Boundary and Heterointerface Characterization in Polycrystalline Oxides by (Scanning) Transmission Electron Microscopy
}

\author{
Hasti Vahidi ${ }^{1}$, Komal Syed ${ }^{1}$, Huiming Guo ${ }^{1}$, Xin Wang ${ }^{1}$, Jenna Laurice Wardini ${ }^{1}$, Jenny Martinez ${ }^{1}$ \\ and William John Bowman 1,2,* \\ 1 Department of Materials Science and Engineering, University of California, Irvine, CA 92697, USA \\ vahidih@uci.edu (H.V.); ksyed1@uci.edu (K.S.); huimingg@uci.edu (H.G.); xinw15@uci.edu (X.W.); \\ jwardini@uci.edu (J.L.W.); jennypm@uci.edu (J.M.) \\ 2 Irvine Materials Research Institute, Irvine, CA 92697, USA \\ * Correspondence: will.bowman@uci.edu
}

\section{check for} updates

Citation: Vahidi, H.; Syed, K.; Guo, H.; Wang, X.; Wardini, J.L.; Martinez, J.; Bowman, W.J. A Review of Grain Boundary and Heterointerface Characterization in Polycrystalline Oxides by (Scanning) Transmission Electron Microscopy. Crystals 2021, 11, 878. https://doi.org/10.3390/ cryst11080878

Academic Editors: Xialu Wei, Diletta Giuntini and Yanhao Dong

Received: 28 May 2021

Accepted: 19 June 2021

Published: 28 July 2021

Publisher's Note: MDPI stays neutral with regard to jurisdictional claims in published maps and institutional affiliations.

Copyright: (c) 2021 by the authors. Licensee MDPI, Basel, Switzerland. This article is an open access article distributed under the terms and conditions of the Creative Commons Attribution (CC BY) license (https:// creativecommons.org/licenses/by/ $4.0 /)$.

\begin{abstract}
Interfaces such as grain boundaries (GBs) and heterointerfaces (HIs) are known to play a crucial role in structure-property relationships of polycrystalline materials. While several methods have been used to characterize such interfaces, advanced transmission electron microscopy (TEM) and scanning TEM (STEM) techniques have proven to be uniquely powerful tools, enabling quantification of atomic structure, electronic structure, chemistry, order/disorder, and point defect distributions below the atomic scale. This review focuses on recent progress in characterization of polycrystalline oxide interfaces using S/TEM techniques including imaging, analytical spectroscopies such as energy dispersive X-ray spectroscopy (EDXS) and electron energy-loss spectroscopy (EELS) and scanning diffraction methods such as precession electron nano diffraction (PEND) and 4D-STEM. First, a brief introduction to interfaces, GBs, HIs, and relevant techniques is given. Then, experimental studies which directly correlate GB/HI S/TEM characterization with measured properties of polycrystalline oxides are presented to both strengthen our understanding of these interfaces, and to demonstrate the instrumental capabilities available in the S/TEM. Finally, existing challenges and future development opportunities are discussed. In summary, this article is prepared as a guide for scientists and engineers interested in learning about, and/or using advanced S/TEM techniques to characterize interfaces in polycrystalline materials, particularly ceramic oxides.
\end{abstract}

Keywords: oxides; ceramics; polycrystalline; grain boundary; heterointerface; transmission electron microscopy; scanning transmission electron microscopy; energy dispersive X-ray spectroscopy; electron energy-loss spectroscopy; scanning electron nanodiffraction; 4D-STEM

\section{Introduction}

\subsection{Background and Motivation}

Solid-solid interfaces are ubiquitous in materials science and engineering with wideranging properties and applications [1,2]. In polycrystalline bulk materials and thin films, interfaces directly impact mechanical, optical, thermal, magnetic, electrical and (electro)chemical properties due to existence of local heterogeneity in structure, composition, chemistry, and electronic structure down to the atomic scale [1-16]. Ceramics such as oxides $[4,17]$ are particularly prone to GB effects as annealing the GBs out by coarsening the grains usually requires $\geq 1000^{\circ} \mathrm{C}$, which is energy-intensive, costly, and deteriorates device components. Therefore, understanding the basics of interfaces is key in optimization of ceramics for a wide range of applications including electrochemical energy conversion and storage, optical, magnetic, and mechanical applications, thermal applications including thermal/environmental barrier coatings, refractories, etc. [5-7,18-25]. This effect becomes more significant in nanocrystalline ceramics with higher volume fractions of interfaces. 
However, elucidating nanoscopic features of these interfaces is challenging and requires analytical methods offering high spatial resolution [21,26-28]. Among available techniques, modern S/TEMS are uniquely capable of qualification and quantification of structure, composition, and electronic structure down to the atomic scale. For example, cation and anion sublattices can be resolved using high angle annular dark field (HAADF) and annular bright field (ABF) STEM imaging, respectively. HAADF images are formed by thermal diffuse scattering of electrons by nuclei and allow locating cation columns. ABF images [27] are formed by electrons channeled by light atoms, which forward focus the primary beam enabling detection of anions [29,30]. Core-loss electron energy-loss spectroscopy (EELS) can quantify elemental concentrations (sensitivity $\sim 1$ at $\%$ ) and probe electronic structure and bonding, giving information on ion valence, coordination, and defect concentration [7,31-34]. Grain orientation and strain can be mapped in atomic-resolution images, or by precession electron nanodiffraction $[7,31]$. While there are books [35] and review papers [36-39] in the literature describing the role of GBs and interfaces in ceramics, a comprehensive review on the power of S/TEM in characterizing these interfaces is needed. Thus, this article reviews recent progress of interface characterization using $\mathrm{S} / \mathrm{TEM}$ techniques with a focus on ceramics oxides. In addition, major challenges and future perspectives are discussed.

\subsection{Types of Interfaces}

An interface is a planar feature separating two phases or domains of matter and can have properties different from those of the "bulk" material on either side. Here, interfaces between crystalline ceramics, particularly metal oxides, in either single or multi-phase form are discussed. In this context, a grain boundary (GB) is an interface where the two phases comprise the same material (i.e., equivalent stoichiometry and crystal structure). GBs have been studied since at least the 1940s, described by Burgers [40] as a "transition surface" - what we today call a dislocation array (Figure 1).

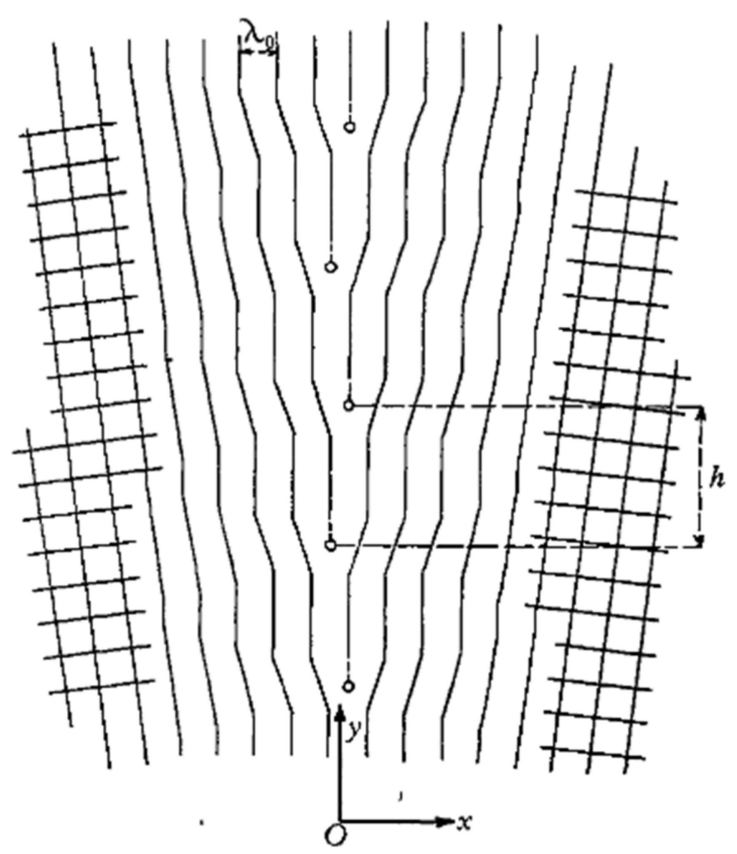

Figure 1. Schematic diagram of a transition surface between two domains, formed by a set of parallel lines of edge dislocations, all situated in the plane $x=0$ [40]. Reprinted from Proceedings of the Physical Society (1926-1948), Geometrical considerations concerning the structural irregularities to be assumed in a crystal, J. M. Burgers, Proc. Phys. Soc. 1940, 52, 23. (C) IOP Publishing. Reproduced with permission. All rights reserved. 


\subsubsection{Heterointerface}

A heterointerface (HI) describes an interface between two phases that differ structurally and/or chemically [4]. Figure 2 contains schematic diagrams and BF-TEM micrographs of GBs and HIs in a single phase and a multiphase polycrystalline oxide. GBs/HIs comprise an approximately two-dimensional "core" or "structural" region where the atomic structure deviates from that of both adjacent crystals over a distance of $\sim 1$ unit cell in the direction normal to the interface plane. A diffuse three-dimensional "space charge zone" or "chemical" region extends up to several nm into adjacent crystals depending on the point defect concentration [40].

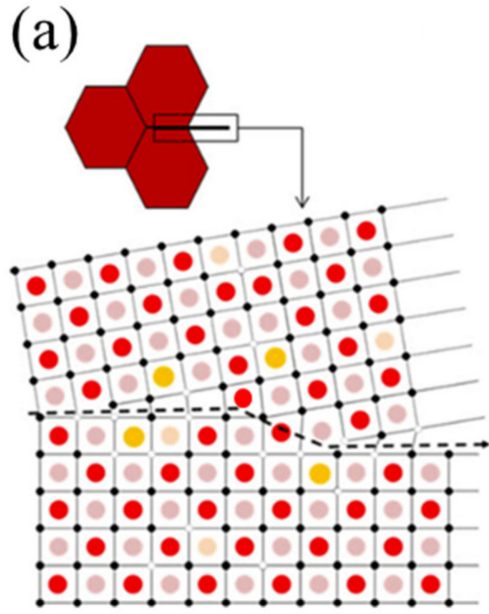

(c)

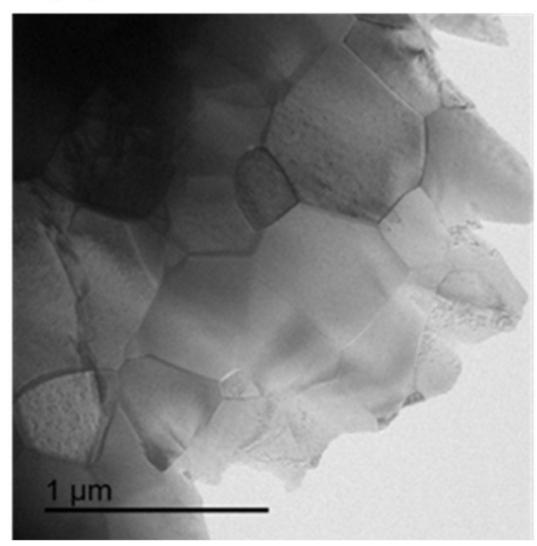

(b)

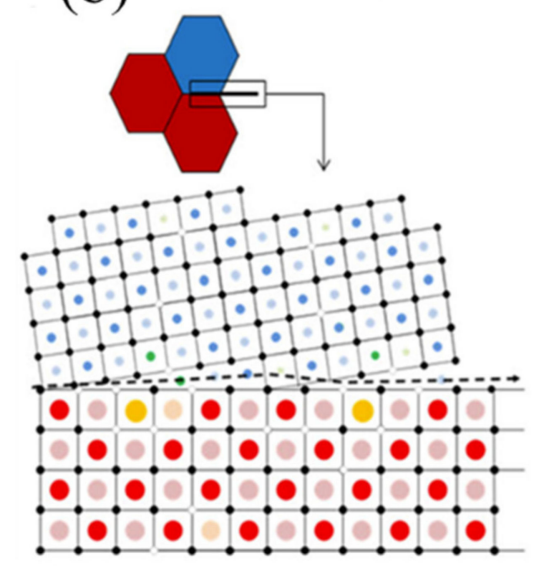

(d)

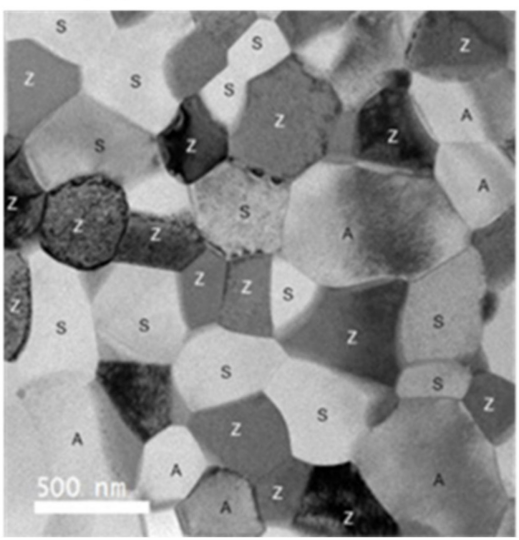

Figure 2. Schematic diagrams of interface between (a) same material (GBs) and (b) different materials (HIs) at atomic scale (c) BF-TEM micrograph of GBs in a polycrystalline Gd/Pr co-doped $\mathrm{CeO}_{2}$ (d) BF-TEM micrograph of $\mathrm{HI}$ and GBs in a polycrystalline $\mathrm{MgAl}_{2} \mathrm{O}_{4}, \mathrm{YSZ}$ and $\mathrm{Al}_{2} \mathrm{O}_{3}$ multiphase oxide. Grains in red and blue in $(\mathbf{a}, \mathbf{b})$ are depicting different materials with different chemistry and crystal structures for demonstration $[2,8,41]$. Figure 2a,b reprinted by permission from Springer Nature Customer Service Centre GmbH: Springer Nature, Journal of Electroceramics, when two become one: An insight into 2Dconductive oxide interfaces, Pryds, N.; Esposito, V.; Dk, N.; Dk, V., Copyright (C) 2016, Springer Science Business Media New York. Figure 2c reprinted from Solid State Ionics, 272, William J. Bowman, Jiangtao Zhu, Renu Sharma, Peter A. Crozier, Electrical conductivity, and grain boundary composition of Gd-doped and Gd/Pr co-doped ceria, 9-17, Copyright (2014), with permission from Elsevier. Figure 2d reprinted from Acta Materialia, 14, Komal Syed, Mingjie Xu, Kenta K. Ohtaki, David Kok, Keyur K. Karandikar, Olivia A. Graeve, William J. Bowman, Martha L. Mecartney, Correlations of grain boundary segregation to sintering techniques in a three-phase ceramic, 100890, Copyright (2020), with permission from Elsevier. 


\subsubsection{Coherent/Incoherent}

When two solids share the same or very similar crystal structures, the atomic columns will be continuous along the interface plane. In this case, the interface will have minimum strain possible and is called coherent. If the mismatch strain associated with a coherent interface is high enough, particularly in presence of large atomic misfits, the total energy of the system increases until the surface is replaced with a more energetically favorable semi-coherent interface, where the excess energy is compensated by generation of misfit dislocations. When atomic structures on both sides of the interface are completely different, there is no possibility of a continuous lattice at the interface. Even when the atomic structures match, the interatomic distances may differ by around $25 \%$ or more. In both cases the interface is called incoherent $[42,43]$.

\subsection{Additional GB Terminology \\ 1.3.1. GB Character}

There are five macroscopic degrees of freedom to describe crystallographic space of GBs, three of which determine relative rotation of two grains, including direction of a rotation axis and rotation angle relative to the axis, and two of them define the interface plane [44-46]. The GB character distribution (GBCD) function $\lambda(\Delta g, n)$ with misorientation $\Delta g$ and plane normal $n$ statistically defines the GB character in polycrystals [46]. Additionally, considering atomic arrangements in crystals, three microscopic degrees of freedom are employed to describe grain translation at the in-planar boundary plane and at the normal GB plane $[47,48]$. The GB energy and properties depend on the degrees of freedom, and it is crucial to link GB energy/properties to degrees of freedom through GB engineering and design $[49,50]$. GBs can be classified into symmetric and asymmetric GBs, depending on whether the GB is a mirror plane (Figure 3a,b) [51]. Tilt, twist and mixed GBs depend on relative position between the rotation axis and the GB plane. For instance, the rotation axis of tilt GBs is normal to the GB plane (Figure 3a,b), while the rotation axis of twist GBs is parallel to the GB plane (Figure 3d). The rotation axis of mixed GBs is neither normal nor parallel to the GB plane (Figure 3c), but commonly they can be resolved into several symmetric special GBs, like symmetric twist boundaries, for analysis [52]. Polycrystalline materials comprise grains in a wide range of crystallographic orientations and therefore characters. Researchers have synthesized and studied bicrystals to manually change the GB character and study its influence on properties $[36,53,54]$. We will discuss experimental examples of bicrystals in the following sections.

\subsubsection{Low Angle GBs}

GBs are categorized based on the orientations of two adjacent grains. The two grains are related to one another by a rotation axis, a rotation angle and meet on a plane. When the misorientation angle is less than $10-15^{\circ}$, the GB is called a low angle boundary $[35,40]$. Tilt and Twist boundaries are in this category and most real GBs are of a mixed type of tilt and twist.

\subsubsection{High Angle GBs}

High angle GBs have misorientation angle is higher than $10-15^{\circ}[35,40]$. They are more disordered and open in structure comparing to low angle GBs. They usually occur in ceramic materials with two or more types of ions which result in perfect dislocations on the oxygen sublattice, as well as stacking faults on anion sublattice [55]. 
(a) STGB

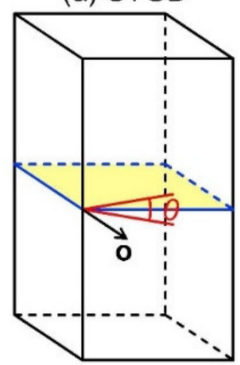

(e)

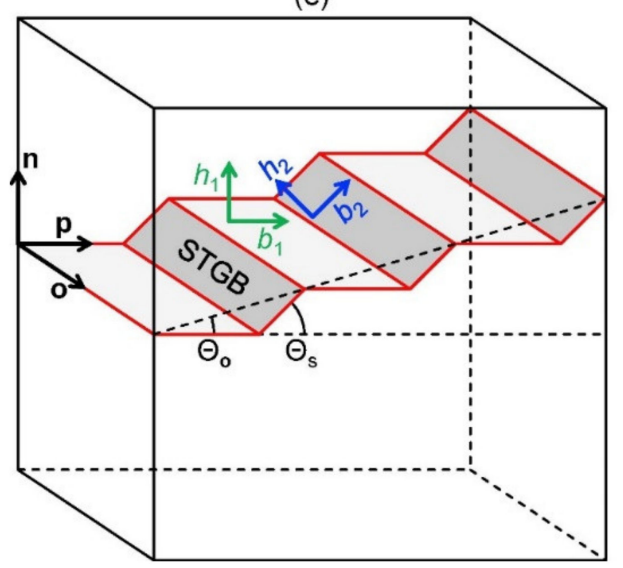

(c) MGB

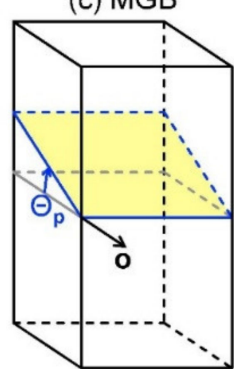

(d) TwGB
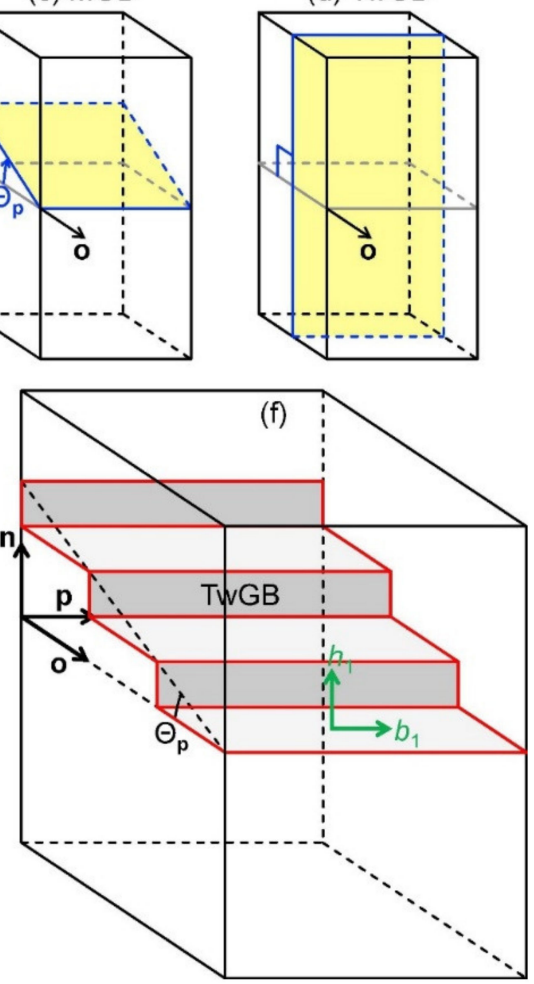

Figure 3. Schematic of macroscopic GB geometry (a)symmetric tilt GB (STGB); (b) asymmetric tilt GB (ATGB); (c) mixed GBs (MGB); (d) twist GBs (twin GB); (e) facet structure of (b); (f) facet structure of (c) [51]. Figure 3 reprinted from Progress in Materials Science, 98, Jian Han, Spencer L. Thomas, David J. Srolovitz, Grain-boundary kinetics: A unified approach, 386-476, Copyright (2018), with permission from Elsevier.

\subsubsection{Special, Twin, and Coincident Site Lattice (CSL) GBs}

The term "special" GB has been used to describe GBs of unique structure, properties, or both. Such special boundaries are often of interest in the field of GB engineering [56]. One example of a special GB is the coincidence-site lattice (CSL). The coincidence-site lattice (CSL) is a well-known model for GBs that was primarily developed from studies of metals by considering the relative misorientation of the adjoining grains. In CSL GBs, two grains are in a relative orientation such that some atomic sites of one grain coincide with the atomic sites of the other grain $[35,56]$. $\sum$ is defined as the degree of fit between the structures of the two grains. The inverse fraction of coincidence sites, $\Sigma^{-1}$, is an important parameter to characterize CSL boundaries and a lower $\sum$ value is an indication of higher order symmetry [40]. Coherent twin boundaries are unique CSL boundaries where the structure mirrors across the GB plane.

\subsubsection{Bicrystals}

Bicrystals are composed of two specific single crystals with controllable interfacial structure. Because many single crystals are and have been commercially available, bicrystals are crucial tools for research on interfaces and have been extensively explored in undoped/doped single phase polycrystalline systems [6,7,54,57-69]. They are often used to analyze individual interfaces at atomic scale, such as CSL boundaries and their relation to properties $[6,33]$. While bicrystals can be used as models on for structure property analysis, they do not fully represent GBs and heterointerfaces in polycrystalline materials, which contain grains with many different orientations $[57,60]$. 


\subsubsection{GB Complexions}

Complexions can be defined as quasi-2D "phases" that primarily occur at interfaces and surfaces $[56,61]$. These interfacial structures can be classified into different categories depending on their composition, structure, and thickness. These categories are: (i) clean/undoped GBs, (ii) sub-monolayer segregation, (iii) bilayer segregation, (iv) multilayer segregation, (v) nanoscale intergranular films, and (vi) wetting films [62].

\subsection{How Do GBs and HIs Form in Polycrystalline Oxides?}

The formation of GBs is accompanied by an increase in Gibbs free energy [40]. The thermodynamic equilibrium is defined as the state with the lowest energy of the crystal, where all GBs are eliminated. Kinetic and geometrical conditions prevent this from happening in reasonable times and therefore, a local equilibrium assumption is defined when analyzing GBs [62]. HIs may exist under thermodynamic equilibrium as the result of a phase transformation. A non-exhaustive list includes four common formation mechanisms: (i) Polycrystalline ceramic sintering yields GBs and HIs; the relative stability of the interface during densification and grain growth dictates which boundaries are likely to form. (ii) Phase transformations, reactions and corrosion can cause the formation of HIs. (iii) Coating processes where one material is applied to a substrate's surface to yield a thick layer $(>1 \mu \mathrm{m})$ or thin film $(<1 \mu \mathrm{m})$, yielding a HI between the materials. (iv) Thick layer coating processes often involve a slurry (ceramic precursor particles suspended in liquid), and include a sintering step, which creates GBs/HIs within the coating material via (i). In thin films-produced by methods such as sputtering [63], molecular beam epitaxy [64], or pulsed laser deposition (PLD) [65-69], GBs/HIs can form within the thin film during growth depending on growth conditions. This review is concerned only with GBs/HIs in polycrystalline oxides formed via (i), (ii), and (iv), and ignores substrate-coating HIs formed via (iii), as there is a very substantial literature on HIs of type (iii) motivated by research and development of oxide thin film and semiconductor devices.

\subsection{How Are GBs and HIs Characterized?}

As mentioned earlier, characterizing individual GBs and HIs is a considerable challenge due to the requisite structural and chemical sensitivity on the length of single unit cells. Moreover, sampling a statistically relevant number of GBs/HIs often requires characterizing many tens, hundreds, or thousands of individual GBs/HIs. The former challenge relates to the spatial resolution of characterization techniques, which limit the suitable techniques to electron microscopy (EM), atom probe tomography (APT), X-ray photoelectron spectroscopy (XPS) [70] on intergranular fracture surfaces, electrochemical strain microscopy (ESM) [71], scanning tunneling microscopy (STM) where the GB intersects the surface, and atomic force microscopy (AFM) for studying GB energy using grooves [72]. As useful as the current characterization techniques are, they are still suffering from a tradeoff between spatial resolution and analyzed sample volume within a reasonable time. Among these techniques, EM techniques have for decades offered significant contributions to interfacial characterization $[73,74]$. For example, TEM phase contrast imaging was the key to the identification of ion-blocking amorphous phases at the GBs, affecting oxygen ion conductivity $[75,76]$. STEM annular bright field (ABF) imaging upgraded with the help of negative Cs STEM aberration correction was used to directly image oxygen and oxygen vacancies. This information helps shed light on the underlying mechanisms driving GB/HI defect chemistry, paving the way for modeling GBs and their properties in future [8].

In addition to EM, APT is useful for quantitative probing of GBs/HIs, owing to its sufficient spatial resolution and chemical sensitivity. APT is a combination of field ion microscope and mass spectrometer, capable of accurately reconstructing the morphology and chemical composition of the specimen in three dimensions at the nanoscale [77]. The detection efficiency (i.e., the ratio of signals detected to signals produced) of APT is around $30-80 \%$, which is reasonable among other techniques (up to $80 \%$ at low count rates for STEM-EELS and $<1 \%$ for STEM-EDXS) [78]. 
The APT technique has been used to measure segregations of defects in oxide GBs in addition to learning about charge density and electrostatic potential [79]. This technique is particularly beneficial in ceramics including oxides due to the combination of surface band bending under high electric field and/or surface defects, which make accumulation of charge on the surface possible, and photons of lower energies can be absorbed [80]. However, data reconstruction can be a limiting factor, as it can potentially create artifacts [81]. APT has been coupled with STEM imaging and spectroscopy to provide a complementary understanding of GB structure and chemistry in Hf and La doped-alumina and Y-doped ceria $[82,83]$. Just like S/TEM, extensive optimization of specimens is necessary to obtain reliable APT results [84]. In a work by Diercks, et al. [79], GB segregation was observed in a $10 \%$ and $30 \% \mathrm{Nb}$-doped ceria (NDC10 and NDC30) using APT. APT is an inherently destructive method, as illustrated by the overlay of TEM micrograph before and after APT shown in Figure $4 a$. The Nd\% map is shown in Figure $4 b$, where fraction of Nd ions is illustrated for clarity. There is an evident increase in the $\mathrm{Nd}$ concentration at the GB compared with the grain bulk. Figure $4 \mathrm{c}$ shows the same volume as in Figure $4 \mathrm{~b}$, except regions containing at least $66 \mathrm{at} \% \mathrm{O}$ are highlighted instead (the boundaries of these regions are referred to as iso-concentration surfaces). This figure illustrates a change in chemistry at the GB, this time a clear decrease in the $\mathrm{O}$ concentration.

\section{(a) before APT}

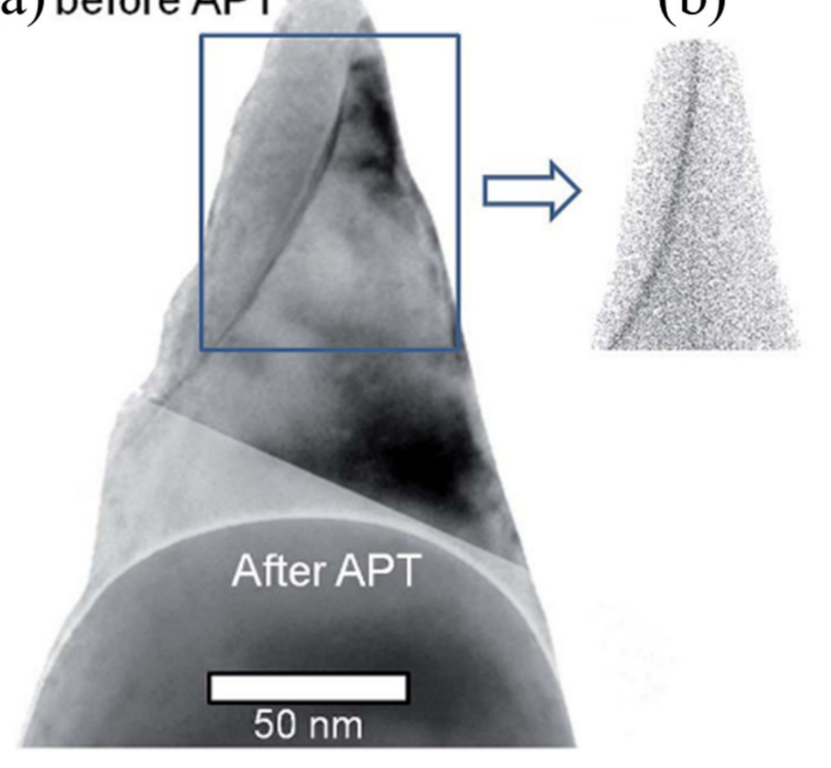

(c)

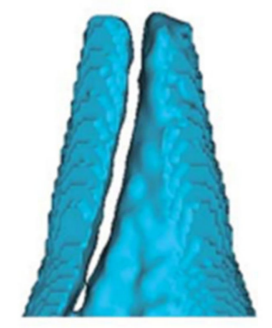

Figure 4. (a) Overlay of transmission electron microscope images of an atom probe NDC10 specimen before and after atom probe analysis. A GB is observed in the before image. The after image indicates that the atom probe analysis encompassed the entire GB region. Atom probe data reconstructions showing (b) $\mathrm{Nd}$, and (c) a 66 at\% oxygen iso-concentration surface [79]. Reproduced from [79] with permission from The Royal Society of Chemistry.

Quantitative 3-D maps of the elements as well as segregation of $\mathrm{Nd}, \mathrm{Al}$ and Si coupled with $\mathrm{O}$ depletion at the GB are presented in Figure 5. This information was used to model the interfaces and correlate them with electrochemical impedance spectroscopy data to yield 3-D potentials at the GBs. At $30 \% \mathrm{Nb}$, local gaps in the 3-D potentials suggest conduction pathways through the potential barrier at the GB [79]. 
(a)

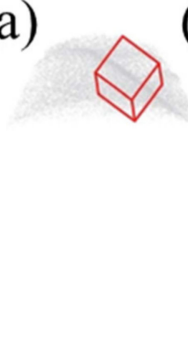

(b)
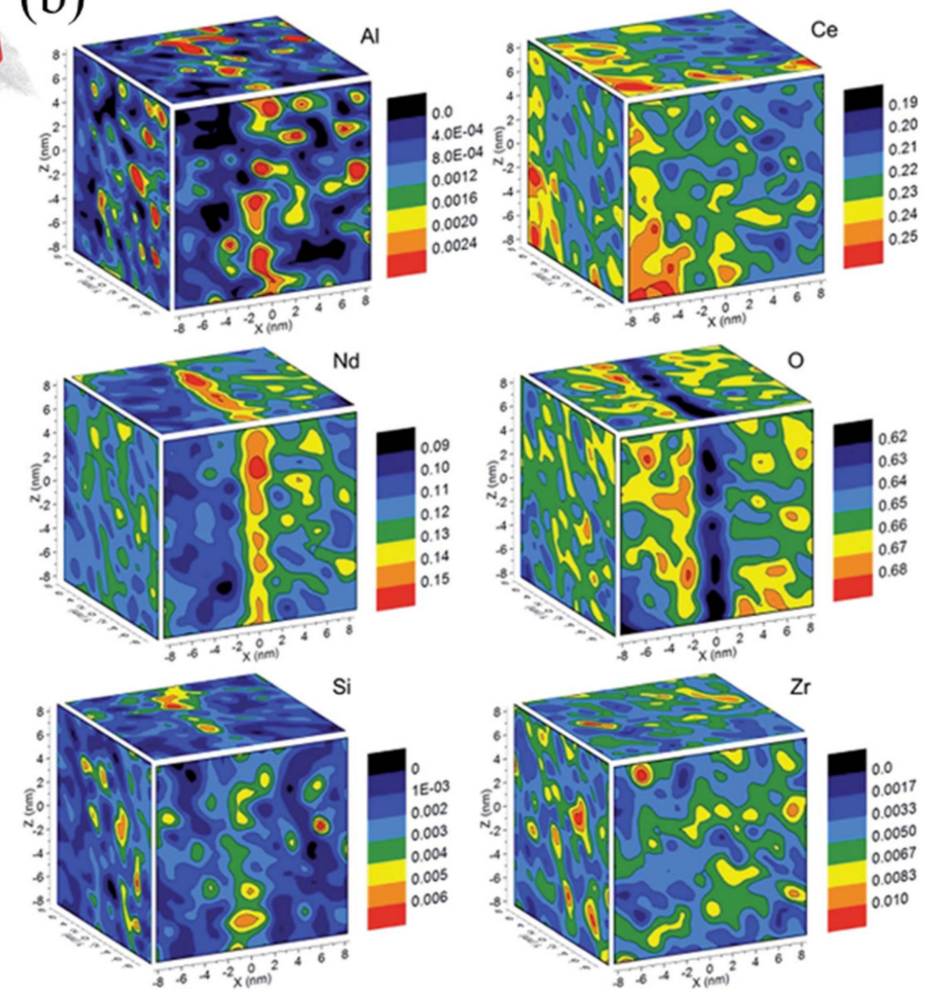

Figure 5. (a) Atom probe data reconstruction for $\mathrm{Nd}_{0.30} \mathrm{Ce}_{0.70} \mathrm{O}_{2}(\mathrm{NCD} 30)$ showing $\mathrm{Nd}$ ions and a 3-D region of interest around the GB extracted for further analysis. (b) 2-D projections of the concentration of each species in at $\%$ from the depicted region of interest. The GB is especially apparent in the $\mathrm{O}$ deficiency and Nd enhancement. There is also evidence of Al and Si enrichment at the GB [79]. Reproduced from [79] with permission from The Royal Society of Chemistry.

GBs in polycrystalline oxides have also been investigated using X-ray photoelectron spectroscopy (XPS) [70], a widely used surface analytical method. Researchers used XPS to analyze the fracture surfaces in Mg-doped alumina to assess Mg GB segregation. The concentrations of $\mathrm{Mg}$ and $\mathrm{Ca}$ at and near the GB are measured and shown in Figure 6. While $\mathrm{Mg}$ has much higher concentration in the bulk comparing to $\mathrm{Ca}$, the segregation of Ca to the GB is more significant.

Scanning probe techniques such as ESM [71] and AFM measure local changes in the surface topography of polycrystalline oxides and have proven useful for quantifying GB energies and mapping functional properties. GB energy plays an important role in segregation phenomena. GB segregation generally occurs to lower the energy of the GBs. Both experiments [85] and simulation [86] studies have shown that GB energies can change with temperature and have a strong effect on microstructure development. A common scanning probe technique that allows measurement of relative GB energy $\left(\Upsilon_{\mathrm{GB}} / \Upsilon_{\mathrm{S}}\right)$ is AFM. When a solid surface is polished and etched, the interfaces are revealed due to preferential removal of material near the GBs [72]. The geometry of the grooves formed by etching can then characterized by AFM and used to measure average GB energy [87]. Many studies have been conducted on single phase oxides for GB energy measurements [88-91]. 
(a)

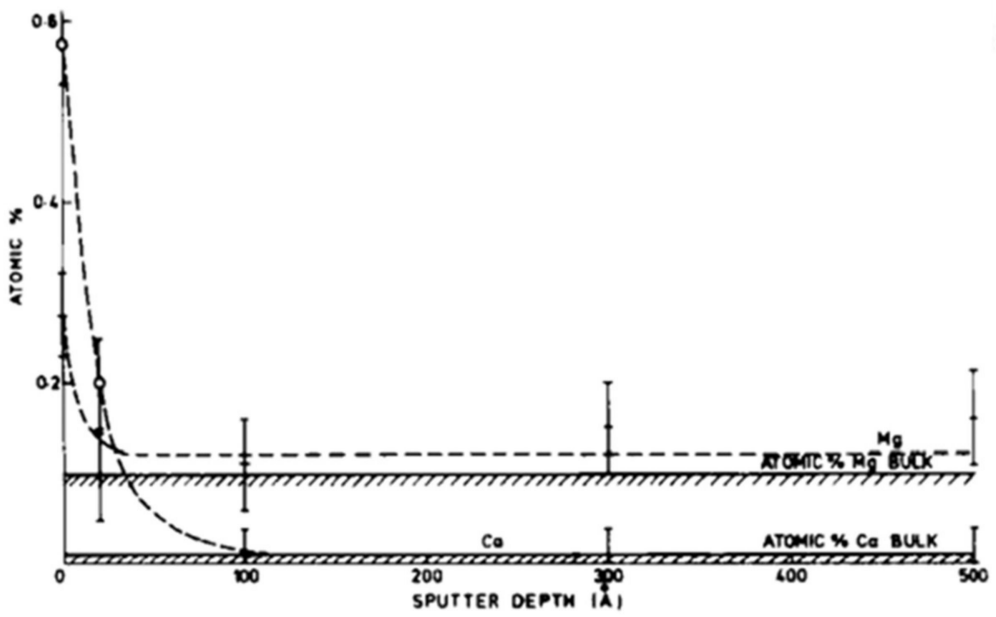

(b)

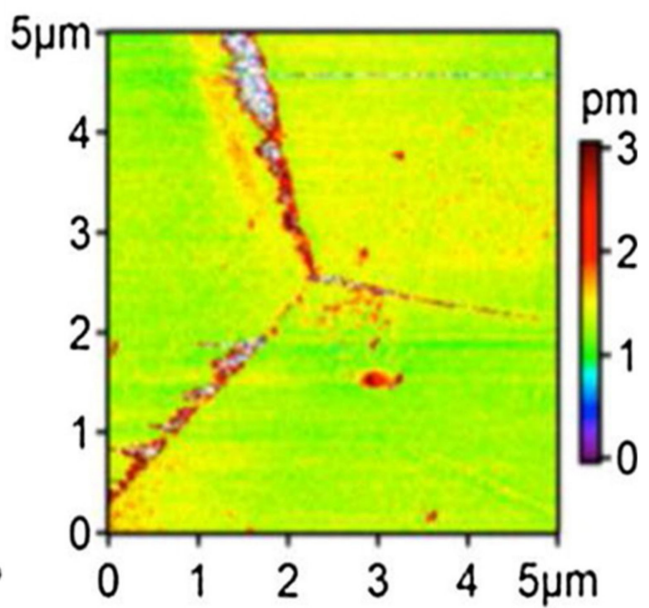

Figure 6. (a) concentration of $\mathrm{Mg}$ and $\mathrm{Ca}$ (at\%) as a function of distance (nm) from the GB [70], (b) Electrochemical strain microscopy (EMS) detecting space charge in a polycrystalline Sm-doped ceria. ESM map of response magnitude for $\pm 3 \mathrm{~V}$ perturbation, revealing increased response in the GB [71]. Figure 6a reprinted from Journal of the American Ceramic Society, 57, Taylor, R.I., Coad, J.P. and Brook, R.J., Grain Boundary Segregation in $\mathrm{Al}_{2} \mathrm{O}_{3}$, 539-540, Copyright (2006), with permission from John Wiley and Sons. Figure 6b reprinted from Progress in Materials Science, 89, Giuliano Gregori, Rotraut Merkle, Joachim Maier, Ion conduction and redistribution at grain boundaries in oxide systems, 252-305, Copyright (2017), with permission from Elsevier.

\section{Characterizing GBs and HIs in S/TEM}

\subsection{A Brief Introduction to TEM and STEM}

The transmission electron microscope (TEM) and scanning TEM (STEM) are powerful tools for directly imaging atomic arrangements, and quantitative chemical analysis down to the atomic scale. Books and review articles are written focusing on TEM [92-97], STEM [98-101], and the various analytical techniques available in both [93,102-105]. A basic introduction to these techniques as they pertain to GB/HI characterization in polycrystalline oxides is provided here. In general, TEMs can be configured to operate in multiple modes. In "TEM mode" (also called conventional TEM) a broad electron beam provides parallel illumination to the specimen. In "STEM mode" the electron beam is converged to a point (or "probe") by pre-specimen electromagnetic focusing lenses and scanned in a raster pattern over the specimen.

Modern S/TEMs routinely demonstrate atomic resolution imaging and chemical analysis in two dimensions, and more recently in three dimensions $[79,80,106]$. TEM development dates to the era of de Broglie overcoming the resolution of a light microscope by electrons [107]. Later, TEM was built and demonstrated by Max Knoll and Ernst Ruska in 1933 [108]. The developments of spherical and chromatic aberration correctors for TEM and STEM in 1998 [109] and 2002 [110], respectively, extended the resolution limit to sub-Angstrom, creating novel opportunities for the accurate characterization of material defects, such as GBs and His [111]. In addition, enhanced electron and spectroscopic signal detection capabilities [112] have increased the ease of use by removing technical barriers such as resolution and signal-to-noise-ratio improvement [113]. Today, a variety of analysis techniques are available to probe important characteristics and functionalities of organic and inorganic specimens in solid, liquid, and gas phases. This review, highlights imaging, diffraction, and spectroscopy techniques suited to characterize interfaces within polycrystalline ceramics, such as atomic resolution imaging, microstructure analyses (e.g., grain orientation mapping), and chemistry mapping (e.g., elemental concentration and chemical segregation). 


\subsection{Imaging and Selected Area Electron Diffraction in the TEM}

Due to the wavelike nature of electrons and periodic arrangement of atoms within a crystalline specimen, electrons scattered from the specimen generate a diffraction pattern that contains rich crystal structure information. From the position and symmetry of the diffraction spots, it is possible to determine the crystal structure, unit-cell parameters, lattice type, and defects such as twinning, while the intensities of the diffraction spots are related to the arrangement of atoms within the unit cell [114]. Selected-area electron diffraction (SAED) is the most used method to acquire this information, and it requires the microscope to operate in "diffraction mode". The ray diagram presented in Figure 7 explains the differences between diffraction and imaging modes in a TEM [92]. As in light optics, ray diagrams are often used in TEM to show how electron lenses control the electron beam by depicting the path electrons take as they traverse the electron column. As can be seen from Figure 7, the information contained in the diffraction pattern is also contained in the image However, the TEM image displays this information in real space while the diffraction pattern represents this information into reciprocal space, the two are related through a Fourier transform. Depending on the application, one or the other representation may prove to be more useful.

(a)

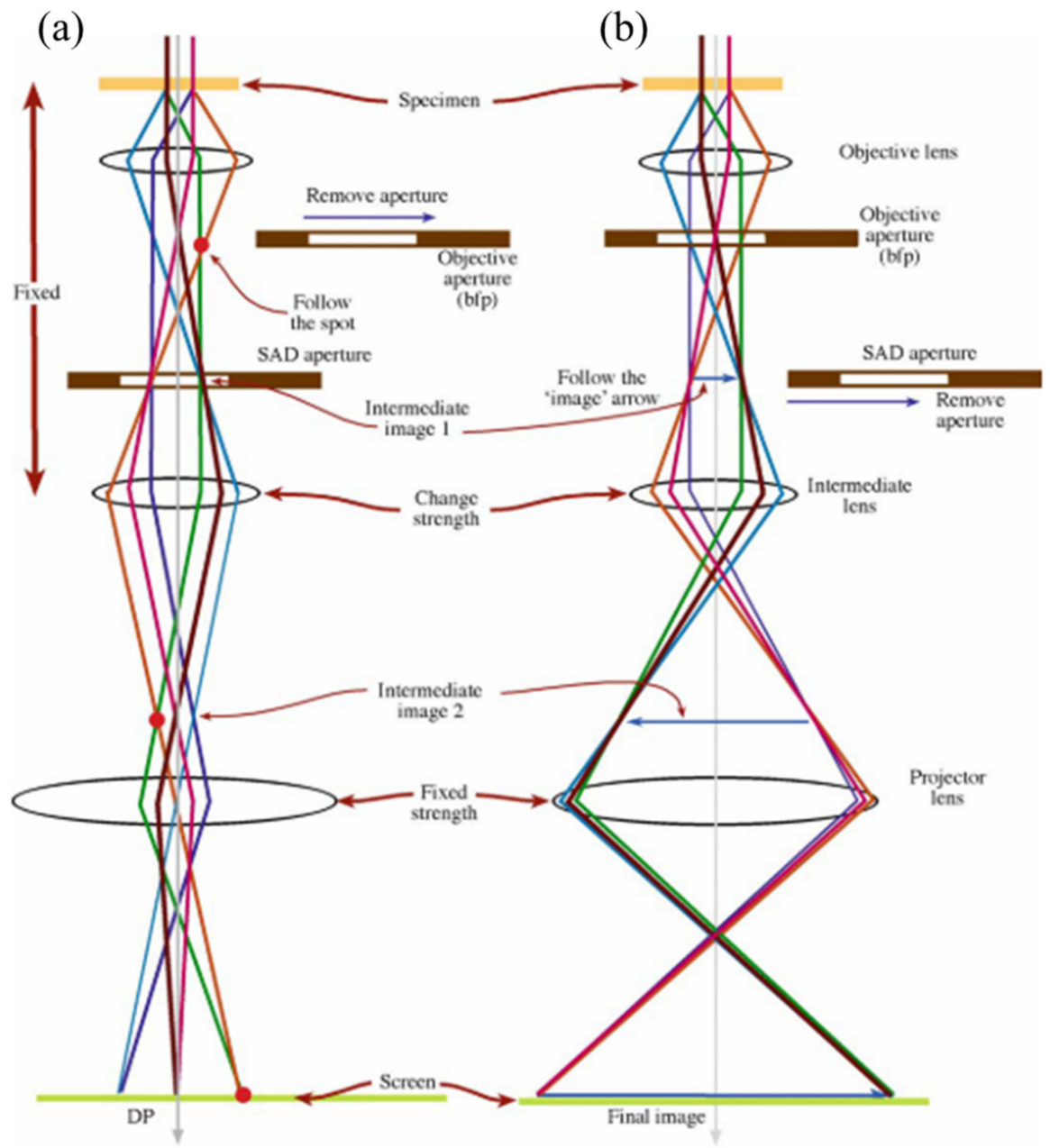

Figure 7. Ray diagrams demonstrating two basic operation modes in a conventional TEM. In (a) diffraction mode, the DP is projected onto the viewing screen and (b) image mode, projecting the image onto the screen [92]. Switching between the modes requires changing the strength of the intermediate lens. Figure 7 reprinted by permission from Springer Nature Customer Service Centre GmbH: Springer Nature, Springer eBook, Diffraction in TEM, David B. Williams, C. Barry Carter, Copyright (C 2009, Springer Science Business Media New York. 
A SAED pattern is acquired by isolating a small area of the specimen for diffraction analysis with an area-limiting aperture (usually 0.1 um or greater). In addition to crystal structure determination, the SAED pattern also contains information about overall sample crystallinity and can be used to establish orientation relationships between multiple diffracting crystals (e.g., between precipitates and a host matrix, or at an interface like GB). Further structural information is encoded into the diffraction pattern through the presence of features such as extra spots, the spot splitting, satellite spots, streaks and diffuse scattering that can indicate the presence of superlattice [115], point defect ordering, or extended defects [3], or can indicate particle shape [92]. Widely used techniques such as bright-field (BF) and dark-field (DF) TEM imaging, demonstrated in Figure 8, rely on filtering information from the SAED pattern to either exclude (BF-TEM) or preferentially select (DF-TEM) diffracted beams for image formation, generating contrast based on whether a particular region does or does not meet the Bragg condition such as examples in [116]. In the case of apertureless imaging, the transmitted and diffracted intensities recombine, and the diffraction contrast is suppressed, while the BF and DF TEM images show much better diffraction contrast due to the coexistence of large intensity in transmitted beam and large loss of intensity in the diffracted beam, and vice versa. For example, heavier phases tend to be darker in BF and brighter in the DF mode. While the BF-TEM helps learn about the morphology of the sample, DF can provide information about nanocrystal size and distribution in addition to defects such as dislocations, stacking faults and twinning.

Another useful technique is weak beam imaging that allows the formation of diffraction contrast in BF and DF modes using a weakly excited beam. The weak beam dark-field imaging (WBDF) approach is popular as it offers advantages over BF, such as having a stronger contrast that is easier to understand using simple physical models. WBDF is routinely used for highlighting the detailed defect structure, and is hence very suitable for lattice defect observation, including dislocations, stacking faults and grain boundaries [117]. Furthermore, high resolution TEM (HRTEM) images demonstrate the atomic arrangement at interfaces and enable observation of individual defects, which can be used to analyze secondary phases or impurities and can probe local crystallinity (degree of structural ordering) at the GBs [118]. One key consideration is that high resolution images require complementary image simulation before the image contrast can be conclusively assigned to an atomic arrangement.

\subsection{Imaging Techniques in the STEM}

In STEM mode, the electron beam is converged to form a probe and scanned across the specimen $[98,99,119]$. Imaging in the STEM is done primarily using elastically and inelastically scattered electrons which have interacted with, and passed through a thinned section of material, usually $<300 \mathrm{~nm}$. The scatter collection angle is critically important for image interpretation. The main imaging modes in STEM are presented in Figure 9 and explained below in the order of high to low scattering collection angles. They are often collected simultaneously and can be coupled with EELS and EDXS analysis. 


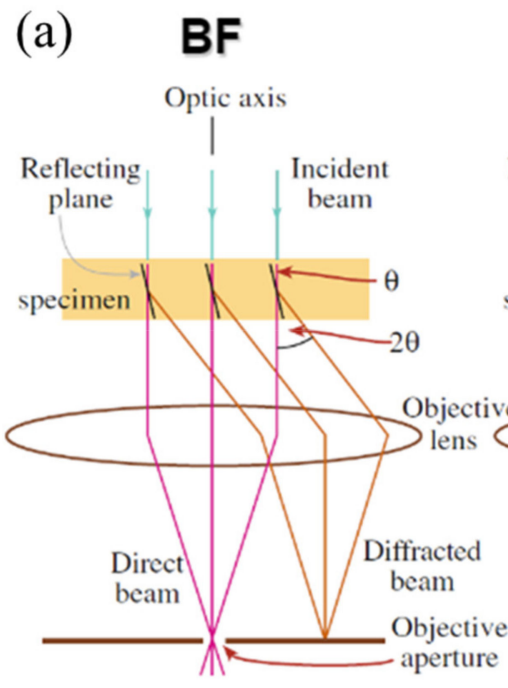

(b) DF

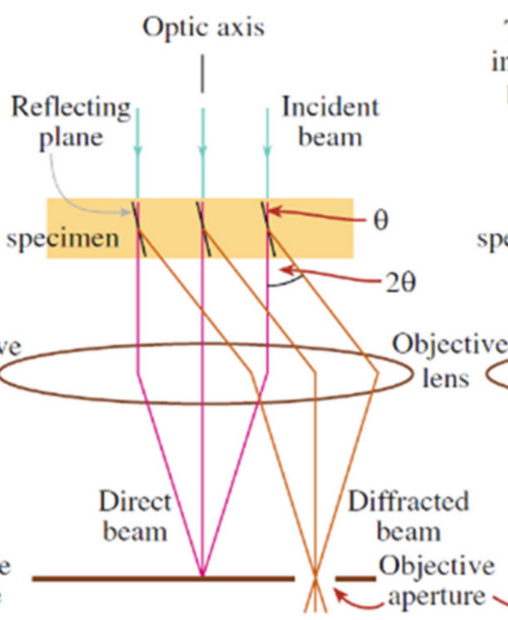

(c) DF Tilted
incident beam

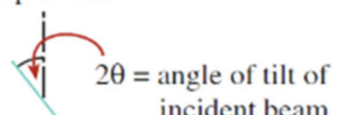
incident beam

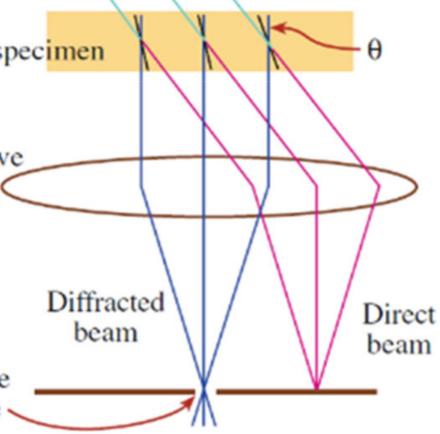

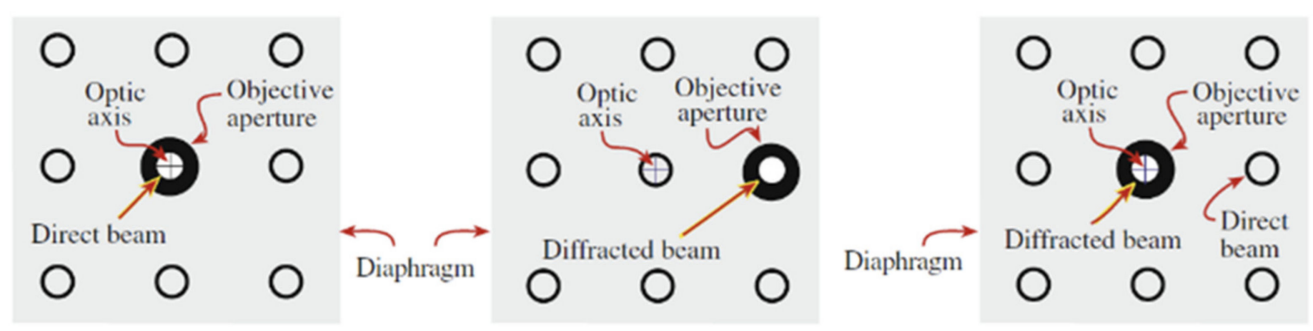

Figure 8. Ray diagrams demonstrating the formation of BF, DF, and centered DF images by selecting specific beams in the diffraction plane with the objective aperture and reforming the filtered image at the imaging plane. (a) BF images are produced by selecting the direct beam while both (b) DF and (c) centered DF images are formed by filtering out the direct beam, using only one or more diffracted beams to form the image. Centered DF images are formed by tilting the incident beam so that the diffracted beam aligns with and is centered on the optic axis, which reduces aberrations. The bottom row shows the region of the diffraction pattern that is selected by the aperture in each case [92]. Figure 8 reprinted by permission from Springer Nature Customer Service Centre GmbH: Springer Nature, Springer eBook, Diffraction in TEM, David B. Williams, C. Barry Carter, Copyright (C) 2009, Springer Science Business Media New York.

When high angle scattered electrons are collected which are incoherent, the image would be a high-angle annular dark-field (HAADF) STEM image. The contrast is generated based on the efficiency of the Rutherford scattering process at that angle of collection, and so is roughly proportional to the square of the atomic number. In addition, atomic positions are very clear since there are no contrast reversals. This technique is the most widely used but is not ideal for imaging light elements since the Rutherford scattering processing is inefficient for light atoms with smaller atomic nuclei.

Medium and or low-angle annular dark-field (MAADF or LAADF) STEM is another commonly used condition that collects lower angle coherent scatter. These images retain some of the characteristics of HAADF images (e.g., no contrast inversion, interpretability of atomic columns over a large focus range) and is also good at showing features that diffract strongly (strained areas such as dislocations, nanosized coherent or semi-coherent precipitates etc.).

Annular bright field (ABF) is when the inner part of the collection disc is collected which is dominated by phase contrast (thickness and defocus dependent). This method works very well with the aid of simulations and seems to show that the outer part of the $\mathrm{BF}$ disc produces images that are more incoherent and reveal all atoms as dark shadows, including light atoms such as oxygen [120] or hydrogen [121]. ABF pairs well with analytical STEM techniques where localized chemical information is desired, typically preferred to operate in STEM mode for chemical analysis. 
(a)

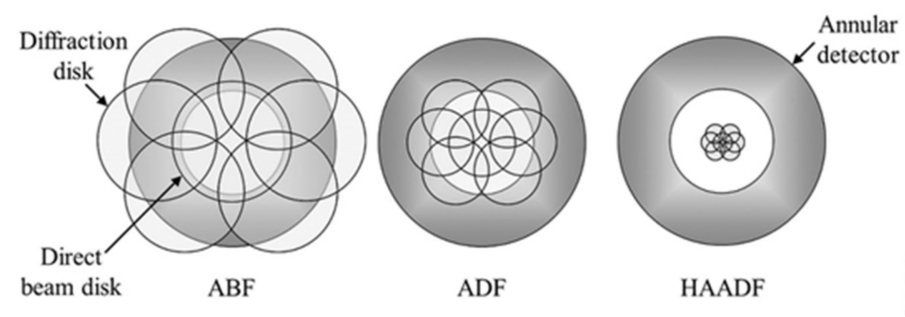

(b)

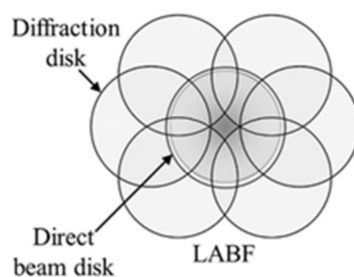

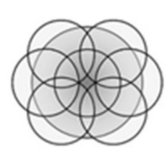

MABF (c)

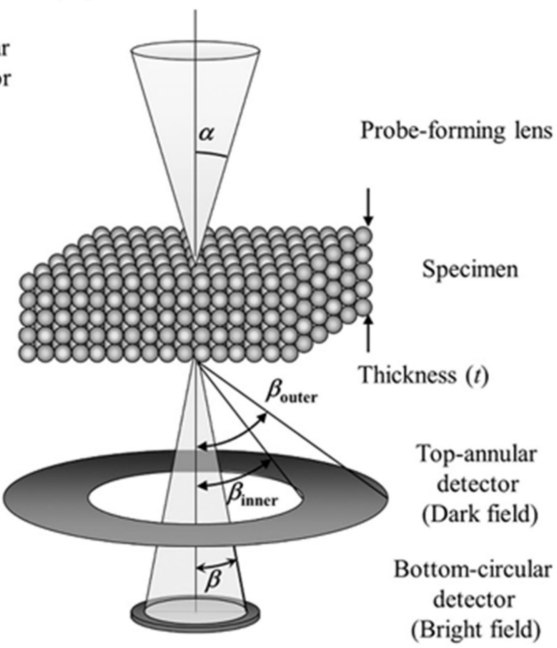

(c)Schematics of double-detector STEM

Figure 9. Schematic configuration of STEM detection set-up. (a) annular DF (ADF) detector under ABF, ADF and HAADF conditions; and (b) circular BF detector under LABF, MABF, and HABF conditions. The camera length is shortened in the order of ABF, ADF, HAADF in DF-STEM imaging, and LABF, MABF, HABF in BF-STEM imaging. (c) Schematic diagram of double-detector STEM imging. The top annular detector and the bottom circular detector are placed with a separating distance [117]. Figure 9 reprinted from Applied Physics Letters, 101, Yasutoshi Kotaka, Direct visualization method of the atomic structure of light and heavy atoms with double-detector Cs-corrected scanning transmission electron microscopy, 133107, Copyright (2012), with permission from AIP Publishing.

Bright-field (BF) STEM is analogous to bright-field TEM images attained in C-TEM. The angle of scatter is small, and the electrons are coherent. Just as in HRTEM, the contrast is critically dependent on sample thickness, microscope defocus and can show contrast inversions. The benefit of BF-STEM compared with HR-TEM is that it can often be collected simultaneously with ADF-STEM images of varying collection conditions (HAADF, MAADF/LAADF).

A comparison of STEM BF, STEM DF and HAADF STEM is given in Figure 10 for Hexoloy SiC.

(a)

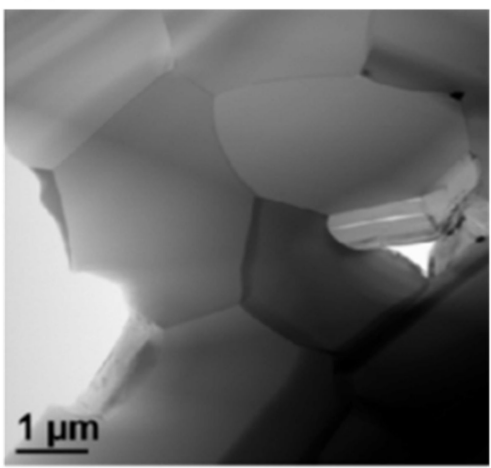

STEM BF (b)

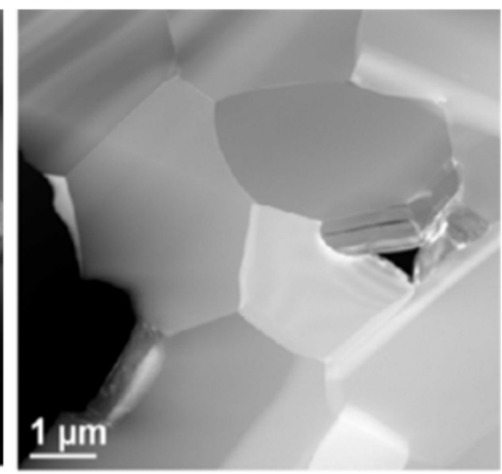

STEM DF (c)

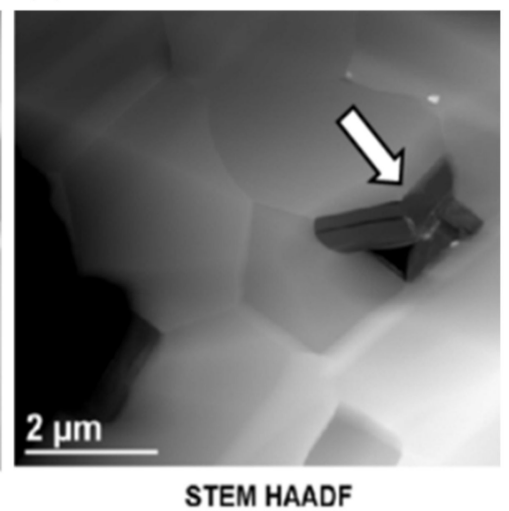

Figure 10. Hexoloy SiC. (a) STEM BF, (b) STEM DF, and (c) STEM HAADF images showing a graphite inclusion (arrow) containing a few smaller oxide inclusions. Figure 10 reprinted from [122] with permission. 


\subsection{Specimen Preparation and Requirements for S/TEM}

As discussed in the introduction, S/TEM specimens are in the form of a thin film or particles typically around $<300 \mathrm{~nm}$. There are several methods for preparing such thin specimens in oxide; the most useful ones are briefly explained below.

\subsubsection{Focused Ion Beam (FIB) Lift-Out and Milling}

A common way of preparing TEM specimens for materials-particularly ceramics and oxides-is using focused ion beams (FIB) [123]. In this method, a thin lamella of a specific thickness is etched and extracted from a specific area of the sample. First, a platinum or carbon layer is deposited on the surface to protect the material during ion milling. Then, an ion beam is used to mill two parallel trenches on both sides of the sample (Figure 11). The FIB is usually equipped with an internal micromanipulator needle for extracting the lamella after milling and transferring to a TEM gird. This process can take place externally using a fine electrostatically charged glass needle. The thin lamella extracted from the bulk is then ready for final thinning and cleaning, before the TEM analysis [124]. To prepare an electron beam sensitive specimen such as biological materials, cryogenic-FIB (cryo-FIB) was developed to allow sample preparation at lower temperatures to reduce redeposition, thermal damages and preserve materials structure for subsequent analyses. Recently, cryo-FIB techniques have been extended to oxides for lithium-ion batteries, for example to characterize lithium dendrites within a frozen liquid electrolyte $[125,126]$.

(a)

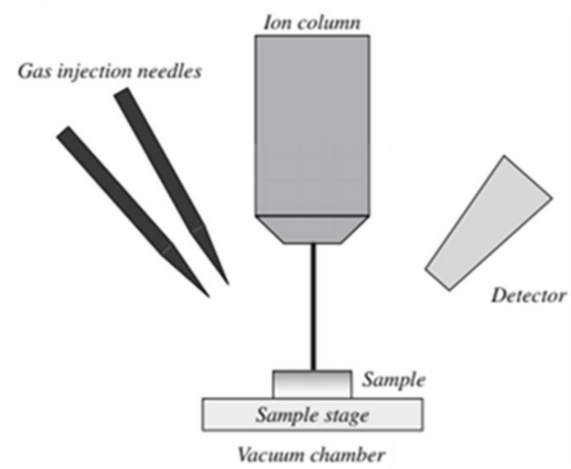

(b)

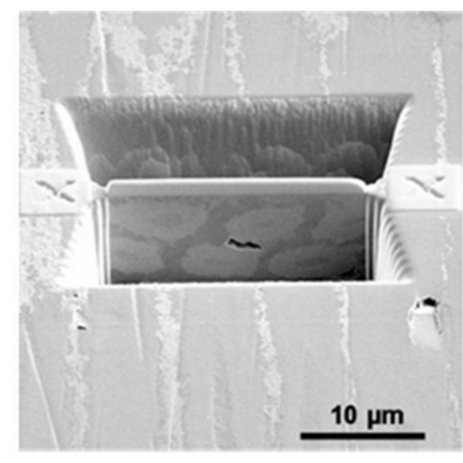

(c)

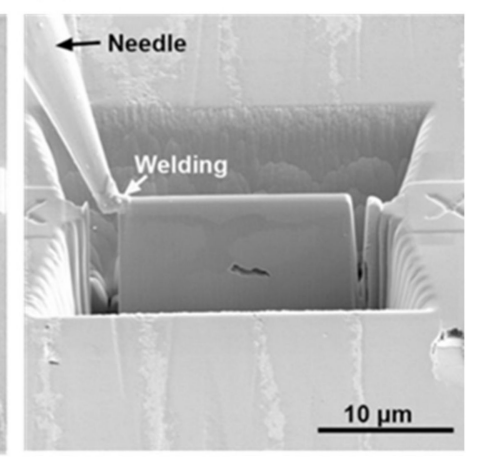

Figure 11. Focused ion beam TEM specimen preparation (a) layout positioning of the ion beam, secondary electron (SE) detector and the metallic source (b) milling trenches with low voltage and weak current. SEM image in secondary electron. (c) welding platinum between the slice and the needle (micromanipulator) [124]. Reprinted from [124] with permission from Springer Science \& Business Media.

\subsubsection{Mechanical Polishing}

This conventional method is still widely used today due to its simplicity and ability to create large areas of electron-transparent specimens. In most cases, mechanical polishing is used to obtain a flat surface in bulk materials, compacts, thin films and even fine embedded particles [124]. However, mechanical polishing needs to be followed by other final thinning methods such as Ar ion milling [127] and twin-jet electropolishing [128] to produce an electron transparent specimen. First, a small disc of $\sim 3 \mathrm{~mm}$ in diameter (i.e., the standard size accepted by TEM specimen holders) is extracted from the material of interest using a tool called a "dimpler". The disc is mounted and polished to a thickness of $\sim 100 \mu \mathrm{m}$ (perpendicular to the disc radius) using a combination of rotary polisher and grinding wheel and turntable (Figure 12). This is followed by either twin-jet electropolishing [128] or Ar ion-milling [127] to produce damage-free, vanishingly thin and electron transparent regions. Twin-jet electropolishing (an extension of electropolishing) is a fast, damage-free and cheap method for preparing TEM specimens from electrically conductive bulk materi- 
als such as metals and alloys. In this method the material is electrochemically removed from both sides of a mechanically thinned disc until sample perforation occurs [129].

(a)

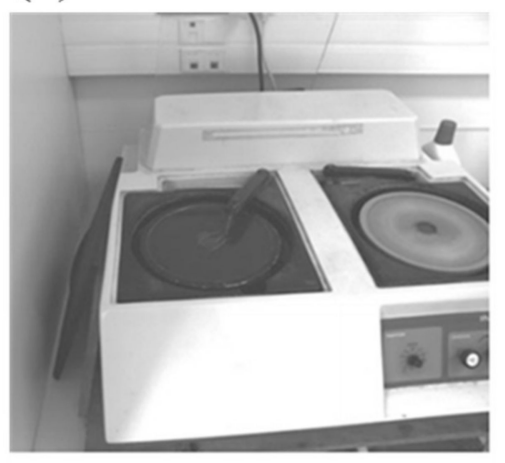

(b)

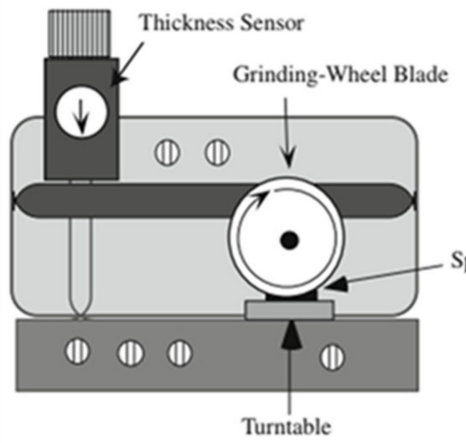

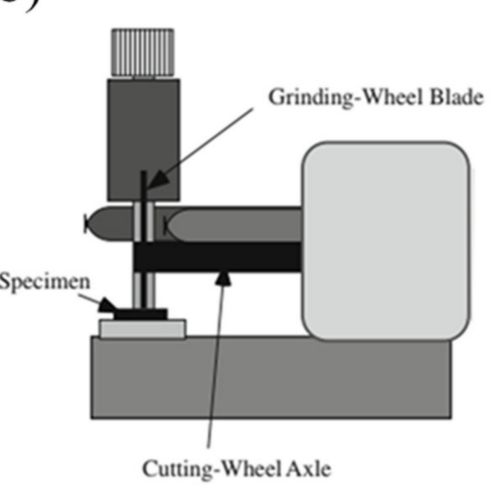

Figure 12. (a) Rotary grinder/polisher, (b) dimpling diagram [124]. Reprinted from [124] with permission from Springer Science \& Business Media.

Ion-milling involves bombarding the sample with relatively low energy (e.g., $<1-2 \mathrm{keV})$ ions or neutral atoms to remove material from the surface until a very thin electron transparent specimen is formed. Variables including accelerating voltage, ion energy and incident angle of irradiation can be changed depending on the specimen requirements and polishing rate. Ar is widely used in ion milling due to its inert and heavy nature, though other ions are utilized. While ion milling is a common and useful technique, it is good to be aware of its artifacts and possibilities of redepositing material from one side to the other side of your specimen.

\subsubsection{Ultramicrotome}

The ultramicrotome technique uses a sharp diamond or glass knife to produce a nanoscale cross-section through manipulating six degrees of freedom (X-axis, Y-axis, rotational angle and clearance angle of the knife holder, the pitch and rotation of the block sample). Thereby, the knife-block relative position can be accurately regulated and adjusted according to the observation from the stereomicroscope attached at the ultramicrotome [130]. To obtain desired a TEM specimen, the sample requires to be sheared off by a clean single-side razor blade to form a trimmed surface (generally $<1 \mathrm{~mm}^{2}$ ). Then, the well sheared sample goes through trimming and sectioning at high and/or low speeds, to acquire ultra-thin slices $(40-100 \mathrm{~nm}$ ) which are easily transferred to TEM grids by a loop [131]. Figure 13 presents a schematic of ultramicrotome and images showing the sample cross sectioning. Due to the need to mechanically slice the specimen, it is not as practical in hard materials, where slicing can potentially lead to breaking and failure.

\subsubsection{Nanomilling}

Nanomilling is an effective tool for final thinning and cleaning of TEM specimens following other preparations by low voltage $\mathrm{Ga}^{+}$FIB milling or mechanical polishing. Nanomilling uses a focused Ar beam to polish both sides of the TEM specimen [54,133]. The spot size of an Ar beam is as small as $1 \mu \mathrm{m}$-smaller than the size of TEM lamella-so there will be no milling or redeposition of the specimen grid material (e.g., copper or molybdenum) if correct milling procedures are used [134]. Nanomill operates at sub-kV acceleration voltage and low current $(<150 \mathrm{pA})$ under liquid $\mathrm{N}_{2}$ environment to reduce ion beam damage and achieving effective thinning and cleaning [135]. Therefore, as a post-FIB processing step, nanomilling can not only remove a surface amorphous layer and implanted $\mathrm{Ga}^{+}$layer effectively but avoids additional damage and contamination [136]. The final TEM specimen will be clean, thin $(<100 \mathrm{~nm})$, and flat $[137,138]$. Figure 14 shows a clear comparison between two TEM specimens with and without the nanomilling as post-FIB processing step. The specimen that went through $500 \mathrm{~V}$ nanomilling exhibited 
clear lattice fringes even at the edge of the sample, while the specimen that went through $5 \mathrm{kV}$ FIB polishing showed obvious redeposition and damaged layers which impeded imaging and energy spectrum analysis [134].

(a)

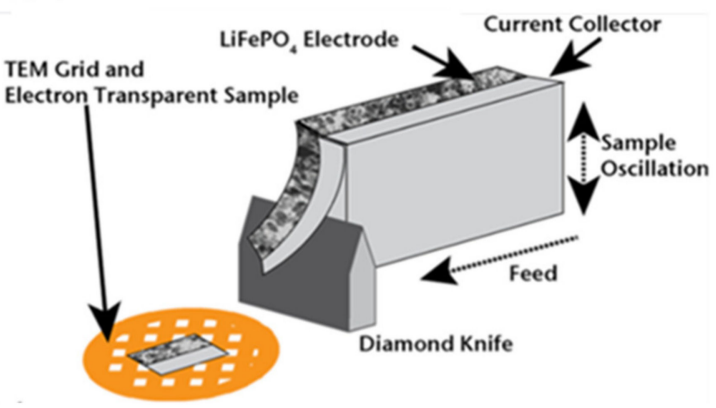

(b)

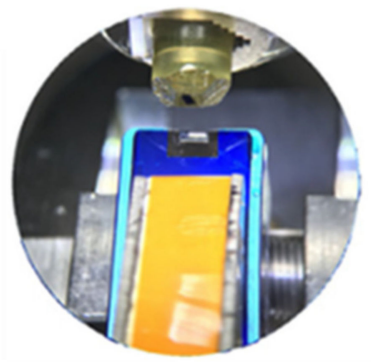

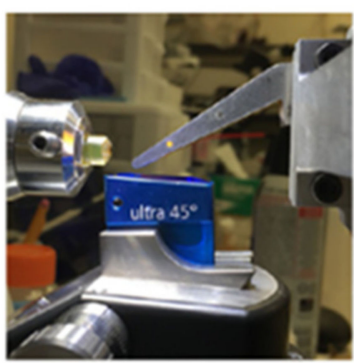

Figure 13. (a) Schematic of ultramicrotome and (b) images illustrating the ultramicrotome cross-sectioning and slices (the cutting direction is parallel to the desired surface and the slice is with nanoscale thickness and wide dimension) [132]. Figure 13a reprinted from Journal of Power Sources, High-resolution chemical analysis on cycled $\mathrm{LiFePO}_{4}$ battery electrodes using energy-filtered transmission electron microscopy, Joshua D.Sugar, Farid El Gabaly, William C. Chueh, Kyle R. Fenton, Tolek Tyliszczak, Paul G. Kotula, Norman C. Bartelt, 246, 512-521, with permission from Elsevier (2013). Figure 13b reprinted from [130] Methods in Cell Biology, 152, Valentina Baena, Richard Lee Schalek, Jeff William Lichtman, Mark Terasaki, Serial-section electron microscopy using automated tape-collecting ultramicrotome (ATUM), 41-67, Copyright (2019), with permission from Elsevier.

(a)

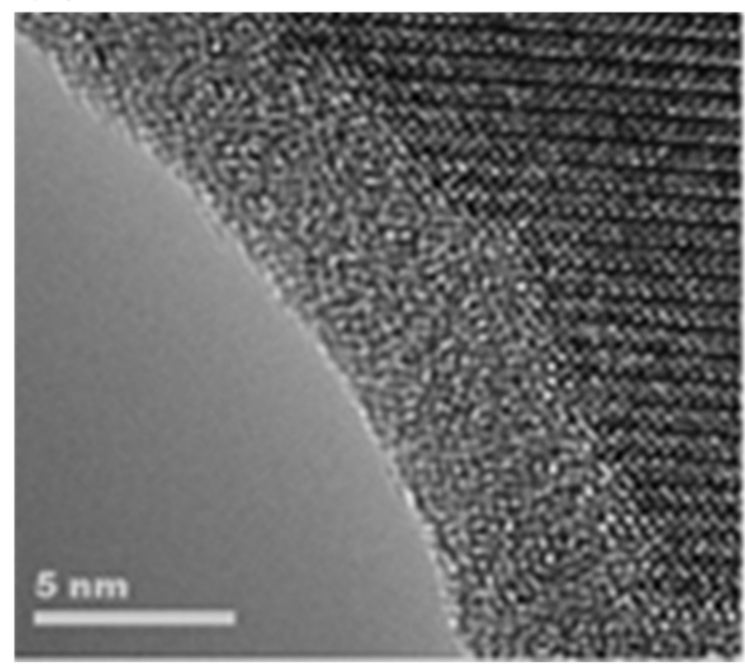

(b)

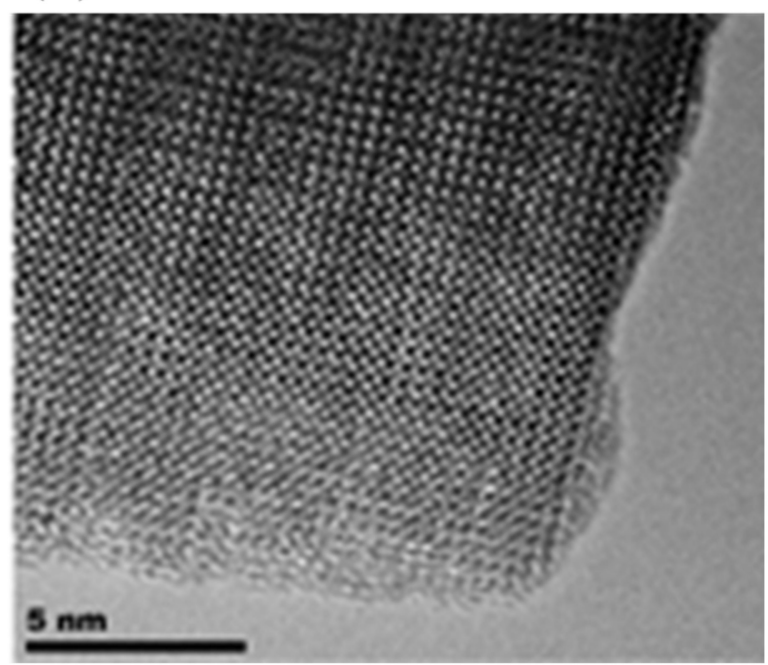

Figure 14. HRTEM images of $\mathrm{La}_{0.29} \mathrm{Sr}_{0.7} \mathrm{Al}_{0.65} \mathrm{Ta}_{0.35} \mathrm{O}_{3}$ substrate with nickelate and aluminate heterostructures below the surface. (a) specimen polished with $5 \mathrm{kV}$ FIB. (b) specimen went through nanomilling at $500 \mathrm{~V}$ as a final treatment step. The lattice fringes are clear even at sample edge [134]. Reprinted from Ultramicroscopy, Practical aspects of the use of the $X^{2}$ holder for HRTEM-quality TEM sample preparation by FIB, Willem van Mierlo, Dorin Geiger, Alan Robins, Matthias Stumpf, Mary Louise Ray, Paul Fischione, Ute Kaiser, 147, 149-155, Copyright (2014), with permission from Elsevier.

\subsection{Specimen Contamination in S/TEM}

Residual hydrocarbons in the microscope column coming from pump oil, specimen air lock or even user contact with holder can be a resource of contamination [92,139]. Carbonaceous materials then deposit on the surface of perfectly thinned specimen and significantly affect high resolution imaging and microanalysis. This can be minimized by heating the specimen to $>100{ }^{\circ} \mathrm{C}$ in a heating holder to burn off the carbonaceous 
contamination or cooling the specimen to liquid- $\mathrm{N}_{2}$ temperature in a cooling holder. Plasma cleaning of specimen and holder prior to operation is a very successful approach in reducing contaminations [140].

\subsection{Analytical Techniques in TEM/STEM}

\subsubsection{Energy Dispersive X-ray Spectroscopy (EDXS)}

EDXS is a powerful qualitative and quantitative analytical technique available in $\mathrm{S} / \mathrm{TEM}$ used for chemical analysis of a desired specimen. The technique relies on the $\mathrm{X}$-rays generated in the microscope due to the interaction between the electron beam and sample. Two different types of X-ray signals are generated: Bremsstrahlung X-rays and Characteristic X-rays. Bremsstrahlung or braking radiation results from the deceleration of primary beam electrons when deflected by the atomic nuclei in the sample. The characteristic X-rays are a result of sample atoms being ionized by the primary electron beam. Simply, a core-shell electron is excited and ejected from the atom, while an outer-shell electron replaces it; this energy difference is released as an X-ray. These characteristics $\mathrm{X}$-rays are like fingerprints for each element and as a result, EDXS spectra are very useful to determine elemental composition of any sample [102]. Figure 15 exhibits a summarized illustration of X-ray signal generation, collection, data display and resulting quantification [102]. The methods for quantitative analysis of EDXS data is discussed below.

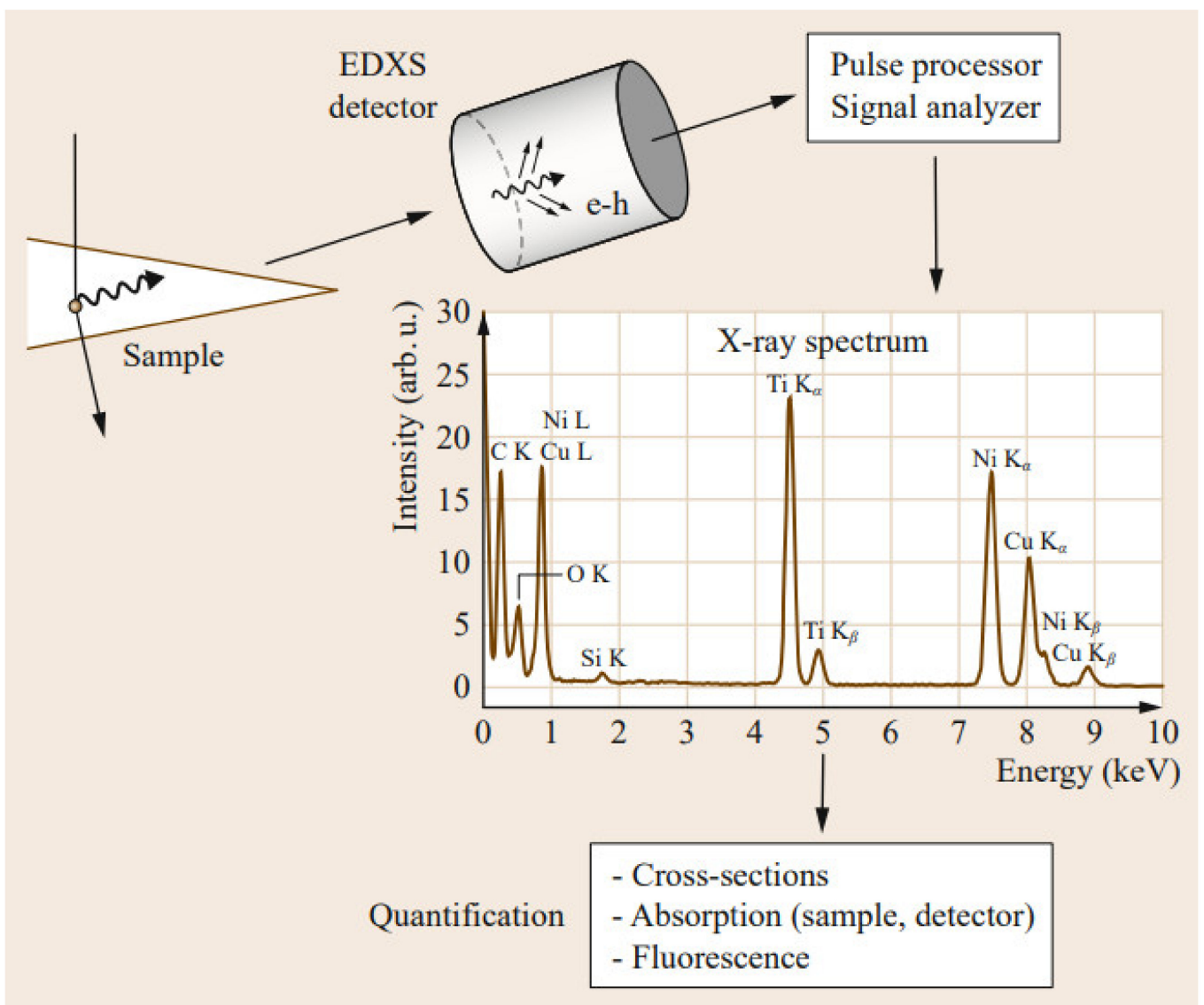

Figure 15. Schematic diagram showing the generation of X-rays in the sample, detection of the X-rays by the detector (using generation of electron and hole pairs), pulse analysis and quantification process of the spectrum to derive the composition of the sample [102]. Reprinted from Science of microscopy, Scanning Transmission Electron Microscopy, Peter D. Nellist, New York, NY, 2007, 65-132. Springer, Copyright (2007), with per-mission from Springer Science+Business Media, LLC. 
EDXS is a standard analytical technique in S/TEM for determining elemental concentrations in each sample. However, the quantification of low $\mathrm{Z}$ elements, including oxygen and lighter elements, has been widely known to be challenging in EDSX. This has to do with poor detection efficiency of these elements, severe absorption of X-rays within the specimen etc. Thus, even with very thin TEM samples, absorption and fluorescence, correction cannot be ignored for lighter elements. However, with detector advancements in recent years, particularly use of multiple silicon-drift detectors (SDDs), improved efficiency in signal collection, etc., it has become possible to quantify elements like oxygen with good accuracy $[6,141]$.

\subsubsection{Electron Energy-Loss Spectroscopy (EELS)}

EELS is the analysis of the energy distribution of electrons that have lost energy through inelastic scattering while passing through an electron transparent sample [98,142-144]. There are two general types of EELS in S/TEM, both of which rely on the facts that inelastically scattered electrons have kinetic energy corresponding to the energy lost, and that they can be dispersed in space by passing through a magnetic field, i.e., an energy-loss spectrometer. The first is energy-filtered imaging, known as energy-filtered TEM (EFTEM) [145], in which electrons having lost a relatively narrow range of energy (e.g., $\sim 5 \mathrm{eV}$ ) are filtered out of the transmitted beam and used to form a real space image. The specific amounts of energy form a real space image. The second is parallel EELS, where all electrons having lost a relatively large range of energy (e.g., $<2000 \mathrm{eV}$ ) are dispersed onto a detector plane and typically analyzed further in terms of a one-dimensional spectrum of counts versus energy loss. Both provide spatially resolved information about chemical composition and electronic structure, though parallel EELS is currently more commonly used because an entire EEL spectrum can be recorded at specified locations in a S/TEM specimen, potentially providing a rich set of data containing information about specimen thickness, chemical composition, and electronic structure of multiple elements simultaneously.

EELS is now incorporated into S/TEMs that typically operate using high energy electron $(60-300 \mathrm{kV})$ sources. The interactions between electrons and matter are either elastic (approximately zero energy loss) or inelastic (finite energy loss), providing various information about the sample. Elastic scattering involves Coulomb interactions with the atomic nuclei, while inelastic scattering refers to the interactions between a fast incident electron and the atomic electrons that surround the nucleus. Inelastic processes can be understood in terms energy band theory. Figure 16 shows the energy level diagram in a solid and several signals generated after electron interaction and excitation in the specimen [142].

The energy loss spectrum consists of three main components: (i) the zero-loss or "elastic" peak (ZLP), (ii) the low energy-loss region $(\Delta \mathrm{E}<50 \mathrm{eV})$ where optical information can be determined by examining excitations into low-lying states above the Fermi energy [98], and (iii) the high energy-loss or core-loss region, where compositional and electronic information can be obtained from the electron beam interaction with deep core states $(\Delta \mathrm{E}>50 \mathrm{eV})$. These regions are indicated in Figure 17 for $\mathrm{YBa}_{2} \mathrm{Cu}_{3} \mathrm{O}_{7}$.

Electron energy-loss spectrum of $\mathrm{YBa}_{2} \mathrm{Cu}_{3} \mathrm{O}_{7}$ is a high-temperature superconductor. The electron intensity is depicted on a logarithmic scale, showing zero-loss, plasmon peaks and ionization edges arising from each element [142,146]. 


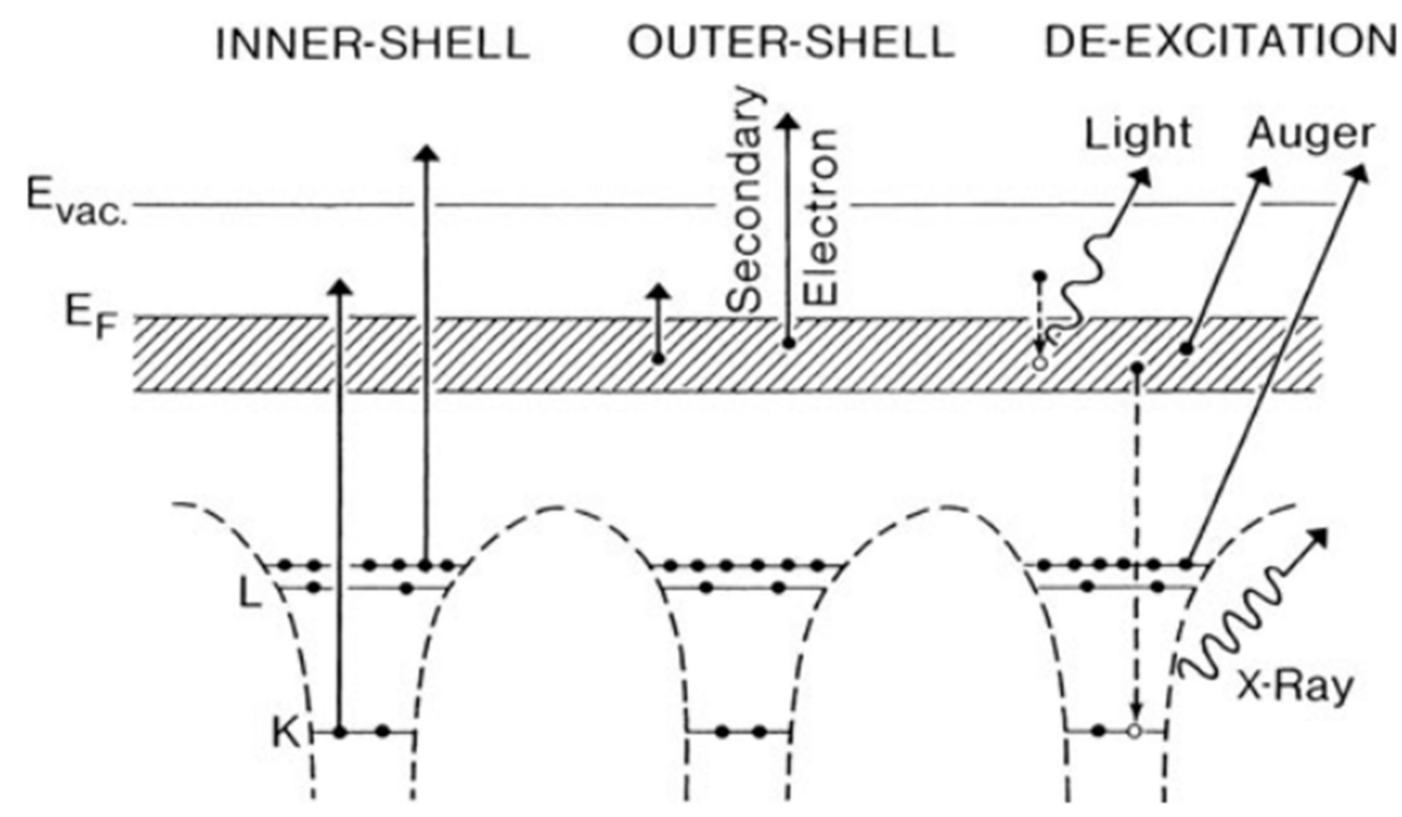

Figure 16. Energy-level diagram of a solid depicting $K$ and $L$ Shell and the valence band $E_{f}$ is the Fermi level and $E_{v a c}$ is the vacuum level. The primary process of inner and outer shell excitation is shown on the left, the secondary processes from phonons and electrons on the right. [142]. Figure 16 reprinted by permission from Springer Nature Customer Service Centre GmbH: Springer Nature, Springer eBook, An Introduction to EELS, R.F. Egerton, Copyright @ 2011, Springer Science Business Media New York.

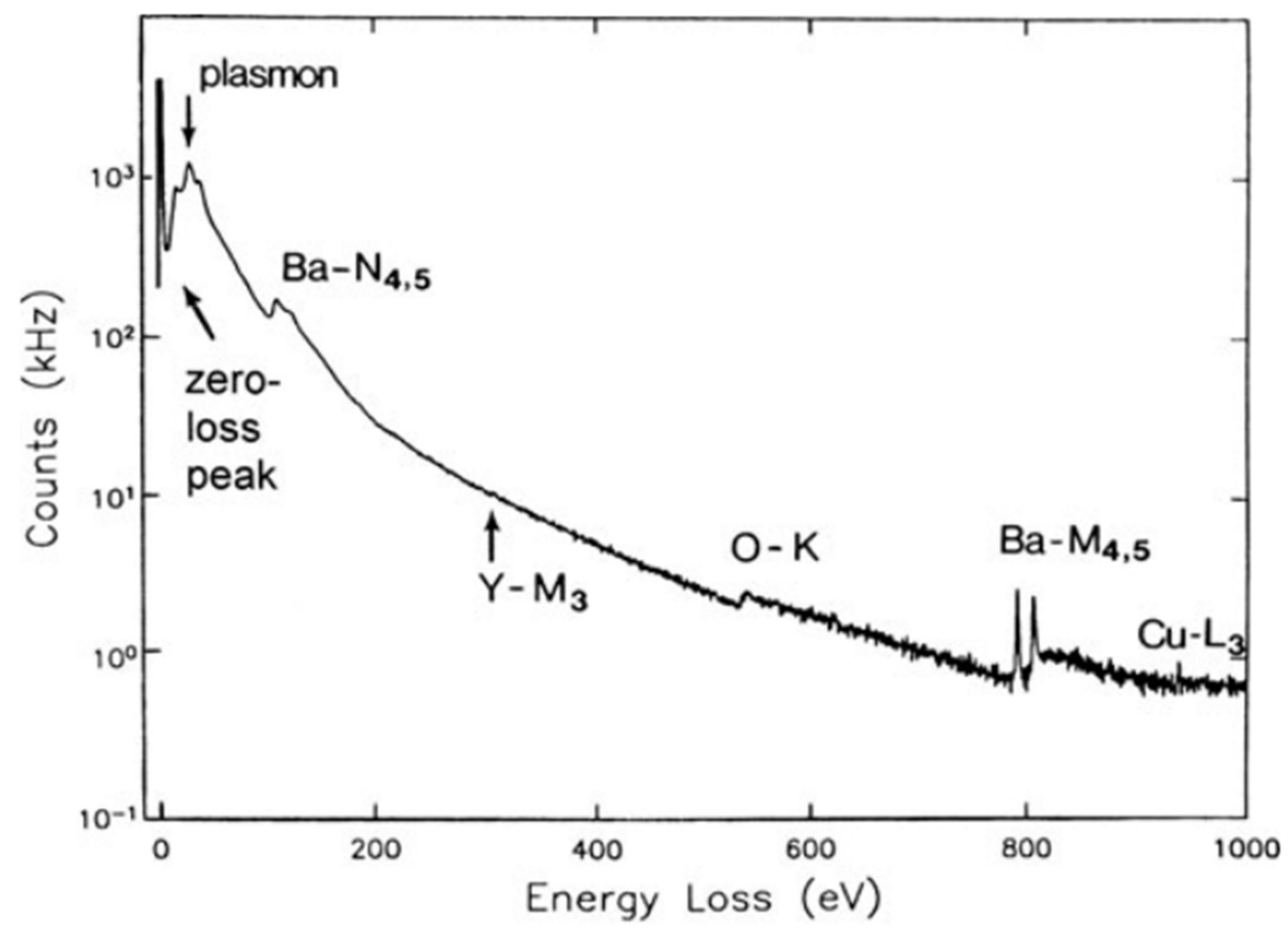

Figure 17. Electron energy loss spectrum (EELS) core loss edges of $\mathrm{YBa}_{2} \mathrm{Cu}_{3} \mathrm{O}_{7}$ [142]. Figure 17 reprinted by permission from Springer Nature Customer Service Centre GmbH: Springer Nature, Springer eBook, An Introduction to EELS, R.F. Egerton, Copyright (C) 2011, Springer Science Business Media New York. 
The ZLP represents electrons that are transmitted without losing measurable energy, including electrons scattered elastically and those that excite phonon modes, for which the energy loss is less than the experimental energy resolution (in conventional EELS systems). While the ZLP does not contain spectroscopic information about the specimen, it is useful for energy calibration of the loss spectrum, deconvolution of plural scattering in thicker specimens and determining local thickness $[145,147]$. The width of the ZLP is related to the energy spread of the incident beam emitted from the electron source and is typically $0.25-1 \mathrm{eV}[148,149]$. These spreads are sufficient for applications such as core-loss elemental mapping, bulk plasmon analysis and analyses of wide-band gap materials but can mask multiple narrow excitations such as surface plasmons, near-edge fine structures, or vibrational excitations at very low losses. The tails of the ZLP ultimately define the spectral resolution and can obscure the optical excitations [150-155]. Spectral resolution can be improved to less than $10 \mathrm{meV}$ in advanced monochromated electron microscopes that include specialized equipment to reduce the electron energy spread of incident beam [148]. In a typical monochromator, the electron beam is dispersed by energy (like a pre-specimen EEL spectrometer) and a narrow band of the dispersed beam is selected by an energyselecting slit which defines the energy spread of the electron beam, which is incident on the specimen. This technique has proven to be useful in high spatial resolution vibrational and low-loss spectroscopy in the electron microscopy, with monochromated STEMs having now provided impressive results for several years [92,149,154-159].

The lower loss energies $(<50 \mathrm{eV})$ are related to the formation and destruction of phonons and electrons of the outermost orbitals, including both single and collective collections, which are plasmons and electrons transmitting from valence band to empty conduction band, allowing band gap energy measurements (Figure 18) [160,161]. The most common application of energy losses in this low range is the measurement of sample thickness, simply by comparing zero loss intensity with inelastic scattering intensity.
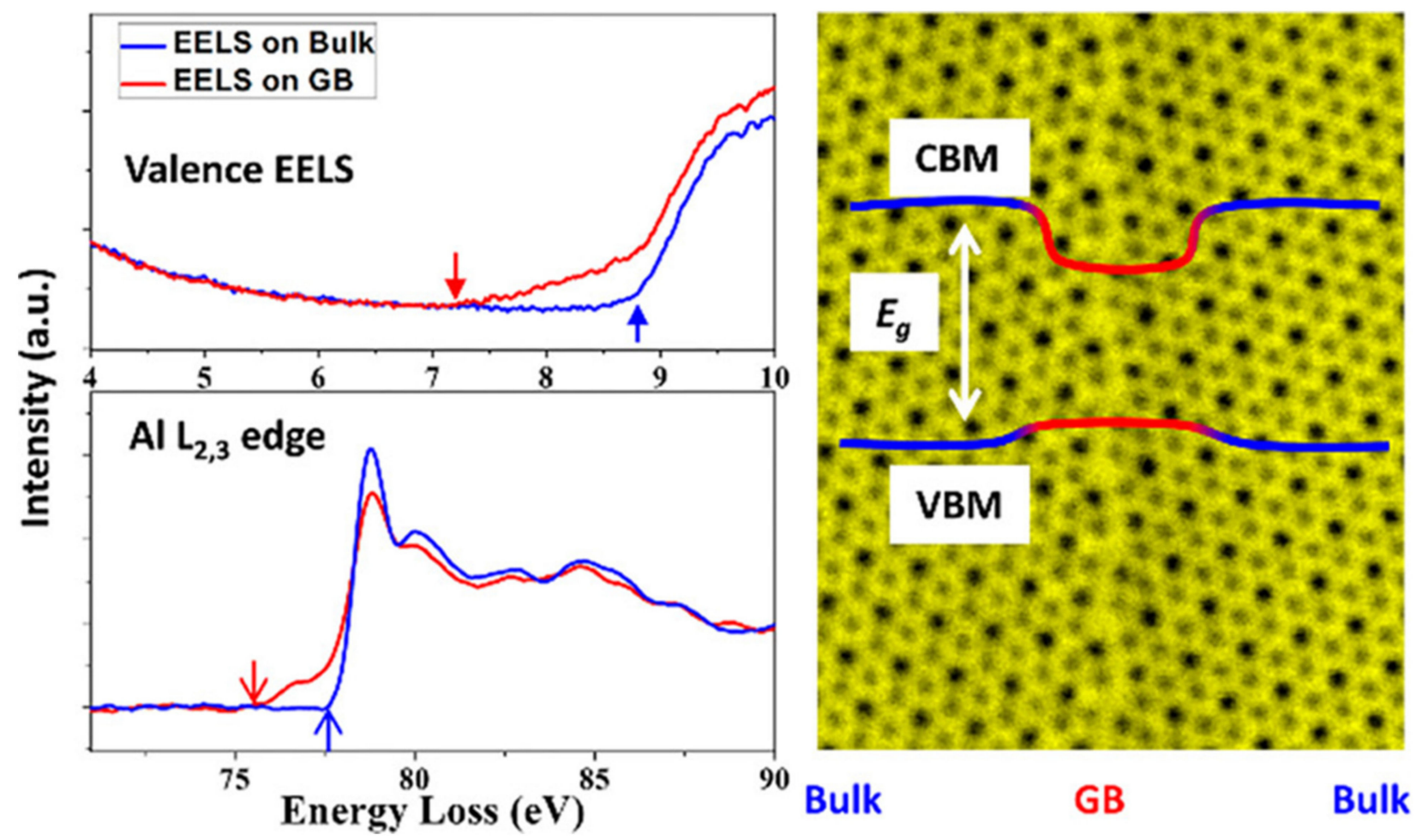

Figure 18. Valence EELS and Al- $\mathrm{L}_{23}$ for bulk and GB. Difference between bang gap in the bulk and at the GB [161]. Reprinted with permission from Copyright (C) 2020 American Chemical Society. 
The high-loss electrons are related to the core binding energy, and therefore provide both qualitative and quantitative chemical information, as the intensity of each edge corresponds to the quantity of electrons generating a specific energy. In addition to the core-loss edges, the first 30-40 eV beyond each edge is related to the change in density of unoccupied states, which affects the electron loss near edge structure (ELNES), or fine structure [162-164].

The detection efficiency of EELS is generally much higher (up to $80 \%$ at low count rates) than EDXS systems $(<1 \%)$ [78]. This is because a large proportion of inelastically scattered electrons are forward scattered into the EEL spectrometer, whereas X-ray emission is isotropic and only a small fraction is intercepted by finite-sized detectors; in recent years, additional (e.g., 4) X-ray detectors have been introduced to the S/TEM column to enhance efficiency. Remember that the detector efficiency will be affected by the specimen thickness, the probe current, and the solid angle of collection of the detector. In EELS, a thin specimen is preferred as more electrons transmit the specimen and can pass through the spectrometer entrance aperture, which can be expanded in diameter to increase collection efficiency.

The first step for analyzing EELS data is to subtract the background and any potential plural scattering effects that occur in a thick specimen when a significant fraction of incident electrons passing through a sample scatter inelastically more than once [158,165]. When the background is removed, intensities of elements can be converted to concentrations.

STEM-EELS analysis on an interface in a Y-doped $\mathrm{ZrO}_{2}$ bicrystal is shown in Figure 19 [166]. In this case, STEM was used to observe the interface (Figure 19a) and EELS was used to generate signal maps of each element relative to the bulk (Figure 19b-d). The line profile of elemental signals is shown in Figure 19e that shows depletion of $0.5-1 \mathrm{~nm}$ for $\mathrm{O}$ and $\mathrm{Zr}$ and enrichment of $\mathrm{Y}$ at this synthetic interface. Therefore, the combination of STEM with EELS is a powerful method, allowing the investigation of defect chemistry at atomic level, paving the way for understanding the relationship between GB and ionic conductivity [166].

\subsection{Other Emerging Techniques}

\subsubsection{Cathodoluminescence (CL) in S/TEM}

In an electron microscope, the energy of electrons is transferred to specimen, bringing it to an exited state. As the excited electrons relax to the ground state, they release both high and low energy photons. The higher energy core-shell transitions generate X-ray emission, while the lower energy photons that are associated with valence band energy states and transitions between free electrons, generate cathodoluminescence (CL) which has applications in S/TEM (CL-S/TEM), particularly in the semiconductors, where an incident electron beam generates electron-hole pairs during the imaging mode. It is possible to separate electron hole pairs using an external voltage to generate a signal of electron charge pulse onto the STEM screen. The strength or weakness of the signal is related to the status of electron-hole pairs. When electron-hole pairs are separated, the signal is strong and when they recombine in presence of defects such as dislocations, the signal is weak. If the electron-hole recombines, they give off visible light in form of a spectrum which contains information about band gaps and dopants of the system. According to a recent study [167], it is impossible to interpret the emitted light spectrum to the transitions excited by the electrons directly. This is due to the existence of Cherenkov effect [168] in addition to ratio-induced transitions in the spectra. Therefore, the spectra need to be corrected for each sample shape, geometry, thickness, and beam energy. 

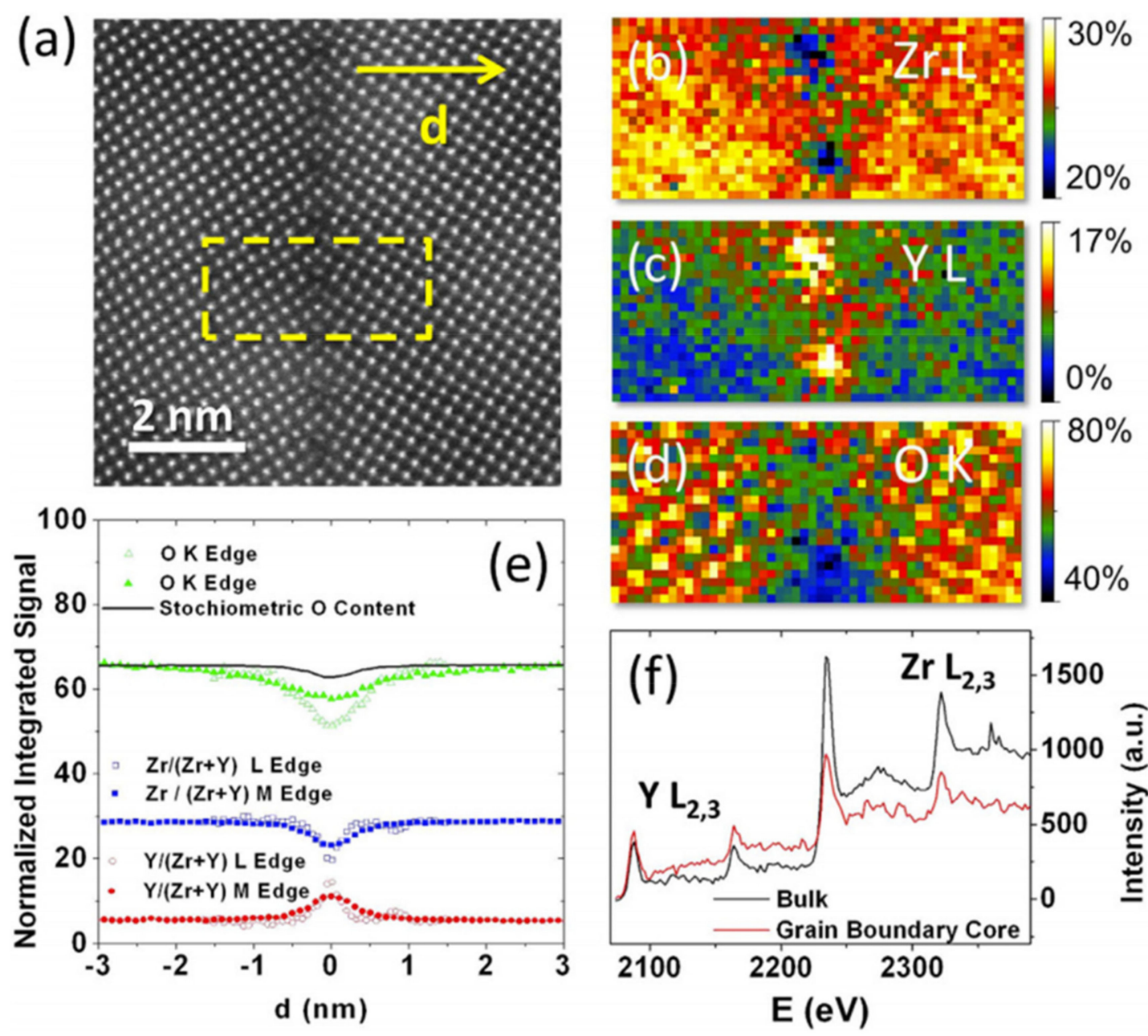

Figure 19. STEM-EELS of a YZS bicrystal. (a) Z-contrast image at the GB obtained in Nion UltraSTEM 200 operated at $200 \mathrm{keV}$, the yellow dashed box marks the area where an EELS spectrum was acquired. (b-d) atomic resolution, integrated signal maps of $\mathrm{Zr}-\mathrm{L}_{23}, \mathrm{Y}-\mathrm{L}_{23}$ and $\mathrm{O}-\mathrm{K}$ edges, respectively, normalized to the bulk concentration. (e) normalized integrated signal profiles based on the analysis of the $\mathrm{O}-\mathrm{K}, \mathrm{Zr}$ and $\mathrm{Y}-\mathrm{L}_{23}$ edges in (d). solid symbols result from quantification performed on a spectrum image including the $\mathrm{O}-\mathrm{K}$ and $\mathrm{Zr}$ and $\mathrm{Y}-\mathrm{M}_{23}$ edges instead. The black line represents the stoichiometric $\mathrm{O}$ content that would be expected from measured $\mathrm{Zr}$ and $\mathrm{Y}$ signals. (f). averaged $\mathrm{Y}-\mathrm{L}_{23}$, and $\mathrm{Zr}-\mathrm{L}_{23}$ EELS spectra from the bulk (black) and the dislocation core (red). Figure 19 reprinted from [166] under the terms of the Creative Commons CC BY license.

\subsubsection{Electron Beam Induced Current (EBIC-S/TEM)}

In EBIC, high energy electrons induce a current that is scanned across the specimen surface and variations in the EBIC induced current are used to map the electronic activity of the specimen. In this technique, the specimen needs to be coated to create ohmic contacts for applying an external voltage. EBIC has been used to identify defects such as GBs [169] or minority carrier properties [170] in semiconductors. It has also proven useful in characterizing oxides such as GBs and structure of zinc oxide varistors [171-173].

\subsection{Scanning Electron Diffraction Techniques}

\subsubsection{Precession-Electron Nano Diffraction (PEND)}

PEND was introduced in 1944 by Vincent and Midgley [165]. This technique has become a major crystallographic investigation tool to identify crystal structure and relevant parameters down to the nanometer fine scale. It is also used to map the local orientation to investigate crystal texture, rotation and strain and virtual STEM imaging at the nanometer scale, in connection with the scanning system of the microscope [166]. In this system, the incident electron beam is tilted and precessed using the pre-specimen optics to form a coni- 
cal electron probe. The result of this process is a higher number of spots in the diffraction patterns acquired and integrated over the precession cycle (Figure 20). Compared to the case for an unprecessed beam, these PEND reflections have intensities that are determined by integrating through the Bragg condition of each reflection. Therefore, PEND enables better indexing of high order diffraction patterns, allowing complementary studies to X-ray diffraction, especially in multi-phase samples, disordered crystals or other systems that are not suitable for conventional X-ray crystallographic analysis [174].
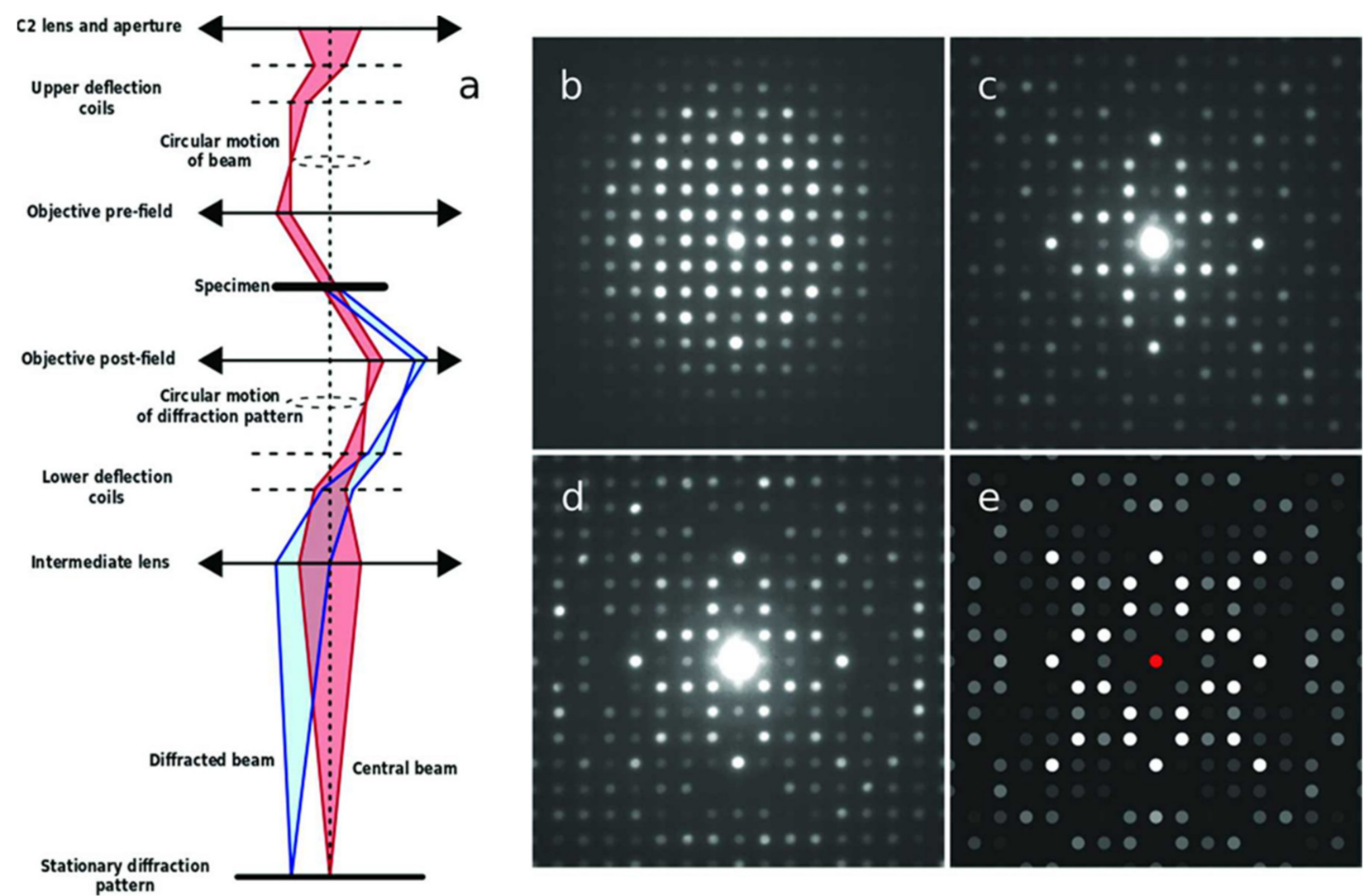

Figure 20. (a) A schematic ray diagram for precession electron diffraction (PED), illustrating the rocking/de-rocking action of the beam before and after the specimen. (b-e) Illustrations of how precession alters the recorded diffracted intensities, here from the [001] zone axis of $\mathrm{Er}_{2} \mathrm{Ge}_{2} \mathrm{O}_{7}$ : (b) without precession, (c) with a precession angle of $20 \mathrm{mrad}$, (d) with a precession angle of $47 \mathrm{mrad}$. The pattern of diffracted intensities seen in (d) is similar to that seen in the kinematic simulation shown in part (e). Figure 20 reprinted from [174] under the terms of the Creative Commons CC BY license.

PEND is now a powerful tool for looking at the twinning behavior in hexagonal alloys [149] and phase changes in oxide structures like Ni-YSZ electrodes during reduction and oxidation [146]. The sensitivity of this technique to local orientations has been the key to strain analysis in semiconductors [157].

\subsubsection{D-STEM}

In this method, the probe is scanned over the specimen in a two-dimensional (2D) array and at each probe position a 2D diffraction pattern is recorded, thus generating $4 \mathrm{D}$ data that can be further analyzed. This technique enables orientation, strain, and phase mapping down to the atomic scale, as well as virtual STEM imaging. Due to the volume of obtained data during 4S-STEM, data analysis can be complicated via requiring capable algorithms and simulation, though these are expected to become more automated over the next few years. In addition to providing spatially resolved diffraction patterns, 4D-STEM data can also be used for STEM imaging using "virtual" detectors. This is accomplished in post processing by integrating the scattered intensity within arbitrary segments of the diffraction 
pattern at each probe position, thus recreating a STEM image [175]. Figure 21 [175] shows imaging of Y-doped $\mathrm{ZrO}_{2}$ using 4D-STEM. Two methods of image interpretation are shown: (i) generation of a virtual detector and (ii) selecting diffraction patterns from various regions of constant contrast over the probe position in the real space. As all the diffraction patterns for each position in the raster scan are stored, a comprehensive analysis of the GB crystallography in addition to local strain mapping can be performed (Figure 21a). Additionally, virtual STEM images can be created, such as BF, ADF and HAADF can be reconstructed from a single dataset showing in a by selecting angular ranges of interest (Figure 21b).

(a)

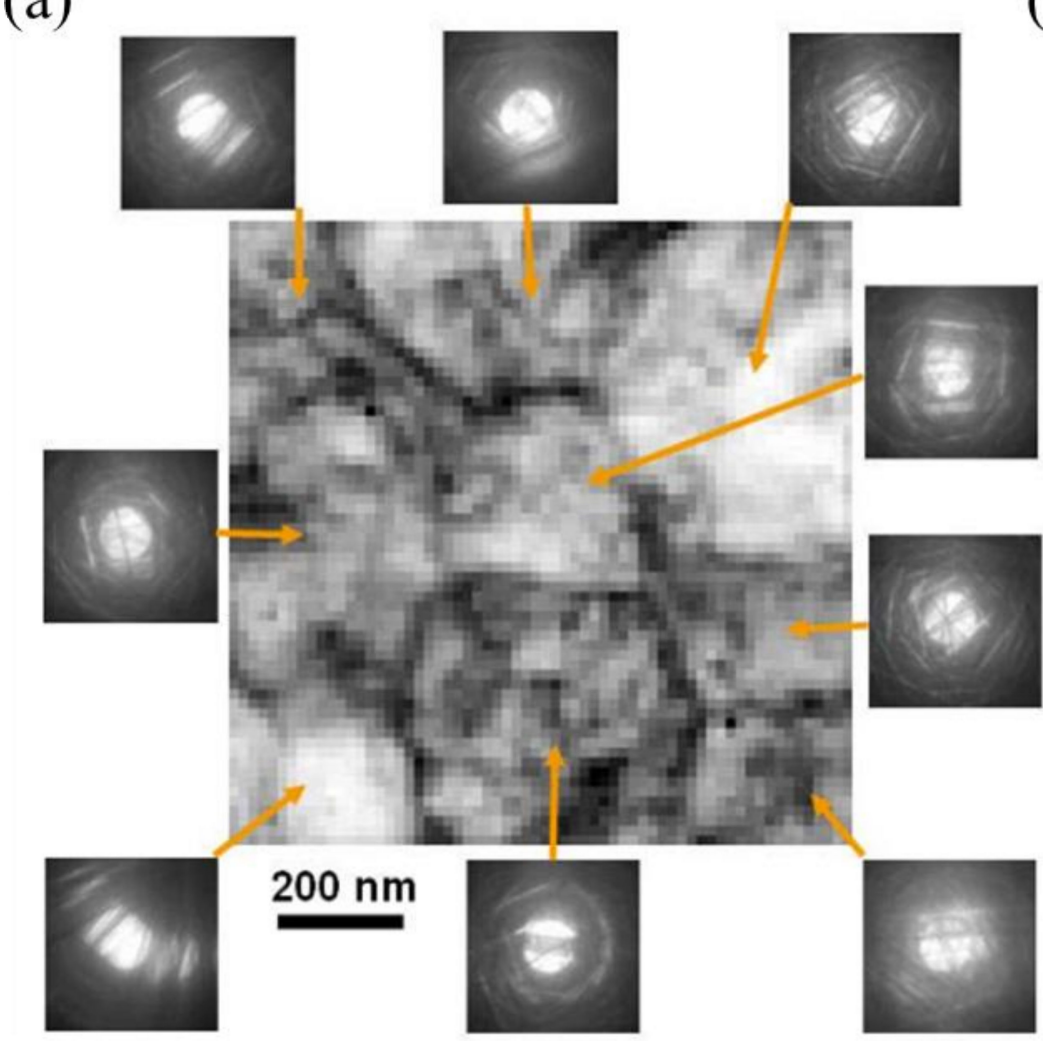

(b)

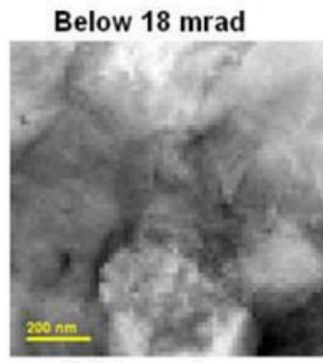

$37-81 \mathrm{mrad}$

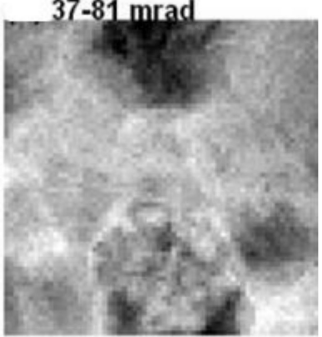

18-37 mrad

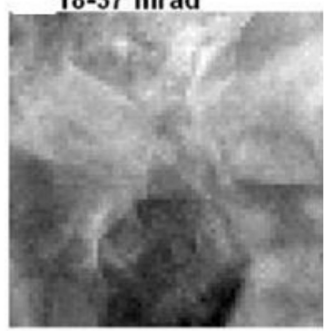

Figure 21. (a) Grain map from a Y-doped $\mathrm{ZrO}_{2}$ thin-specimen. (b) Series of STEM images, reconstructed by selecting the following angles from the STEM dataset in a. below $18 \mathrm{mrad}, 37-81 \mathrm{mrad}$ and 18-37 mrad [176]. Figure 21 reprinted by permission from Cambridge University Press, Development of Diffraction Imaging for Orientation Analysis of Grains in Scanning Transmission Electron Microscopy, M Watanabe and D Williams, Copyright (C) 2007.

For this purpose, computer image processing methods are used to classify the crystal orientations automatically, which is called "automated crystal orientation mapping" (ACOM). This method allows tracking orientation changes of hundreds of grains simultaneously and has been used significantly for in-situ mechanical testing measurements in nanocrystalline metals [177-179]. In a work by Garner, et al. [180], the orientation map of monoclinic zirconia reveals a fine level of detail with grains as small as $5 \mathrm{~nm}$ in the outer region. This was also done for tetragonal zirconia grains and therefore can be used for mapping any type of phase distribution [180].

\subsection{In-Situ S/TEM}

In-situ S/TEM is a technique where an electron microscope is used to watch and capture specimen's response to one or more external stimuli in real time. Operando S/TEM is an extension of in-situ analysis whereby specimen properties are measured in addition to simultaneous direct observation, thus shedding light on the specimen functionality. 
Both techniques have emerged as a powerful field of nanomaterials characterization. Now, previously mysterious reactions and processes can be dynamically monitored under realistic or close-to-realistic conditions. The past decades have witnessed continuous development in both in-situ technology and the applications in a wide field of research, particularly in catalysis, energy storage and conversion [181,182], gas-solid interactions, semiconductor growth, nanomechanical testing, electrical properties and phenomena, and corrosion [183] (Figure 22).

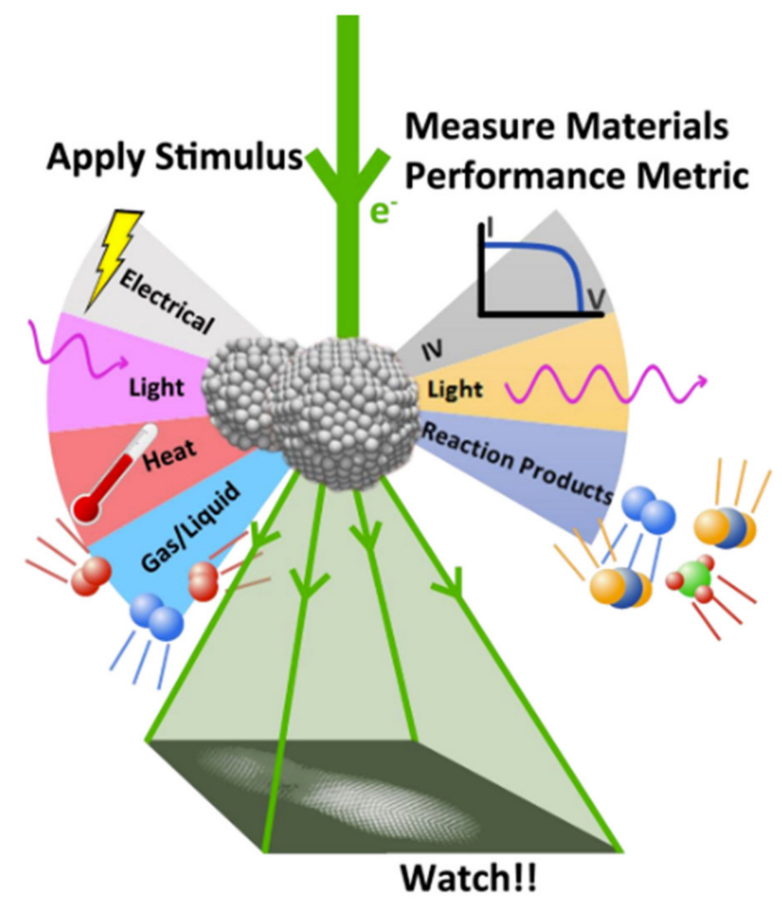

Figure 22. In-situ S/TEM involves direct specimen observation while applying stimuli, and operando S/TEM includes measuring a performance metric of the material [184]. Reprinted from Controlled Atmosphere Transmission Electron Microscopy, Spectroscopy of Solids, Gases, and Liquids in the ETEM, Crozier, Peter A., and Benjamin K. Miller, 2016, 95-141, Copyright (2016), with permission from Springer International Publishing Switzerland 2016.

\subsection{Electron Beam Damage}

The bombardment of thin TEM specimens by intense electron beams can result in irreversible atomic displacements and chemical reactions generally termed "electron beam damage". This can particularly affect any quantitative analysis performed on samples exposed to such intense, energetic electron beams $[185,186]$. The beam damage in S/TEMs can be a result of inelastic scattering caused due to the interaction between the energetic incident electrons and sample atoms/electrons. This beam damage can thus result in various phenomena in TEM samples including mass loss, phase decomposition, crystallization, amorphization, atom transport, etc. [185].

Two main mechanisms of radiation damage in TEMs are knock-on damage (elastic beam-atom collision) and radiolysis (ionization damage), or a combination of both $[185,186]$. In knock-on beam damage, the sample-beam interactions can cause preferential surface sputtering in oxides, while radiolysis can generate point defects and break chemical bonds, etc. [185] While radiolysis mainly occurs in insulating oxides, knock-on damage can occur in both conducting and insulating oxides. Furthermore, knock-on damage is significant during prolonged exposure to e-beam and can become predominant at higher accelerating voltages $\geq 200 \mathrm{kV}$. Other mechanisms include thermal effects for phonon excitation and electric-fielddriven migration [185]. Jiang [185] reviewed that while majority of the observed TEM/STEM beam damage in reported studies have been interpreted as knock-on damage or radiolysis, 
most observations appeared to involve collective atomic displacements in which atoms of the same element move together in synchronization.

The electron beam damage phenomena have been studied extensively in different oxides, both for bulk and GB characterization, such as spinel [187-189], alumina [190,191], perovskites [192-194], etc. In oxides, electron beam damage phenomena are often noticeable when using aberration-correction STEMs, which by design provide very small and intense. With EDXS particularly, longer acquisition times are preferred for better counting statistics, but this increases the likelihood of e-beam damage, as well as contamination [195]. This makes it difficult to interpret any chemical information obtained from an area damaged by e-beam. Electron beam damage was shown to influence the oxidation state of cations such as $\mathrm{Ce}^{4+}$ and reduce it to $\mathrm{Ce}^{3+}$, particularly near GBs, providing a methodology for further investigating oxygen-vacancy concentrations in solid oxide solutions [196]. Figure 23 shows the $\mathrm{Ce}^{3+}$ fraction across two GBs in Gd- and Fe-doped ceria. In both plots, the bulk contains larger than expected amounts of $\mathrm{Ce}^{3+}$ due to the e-beam damage $(30 \%$ and $20 \%$, respectively). The $\mathrm{Ce}^{3+}$ drops to zero or negative values, with a slight rise at the GB plane followed by another drop near the GB on the other side. After that, $\mathrm{Ce}^{3+}$ increases again to high values in the bulk. It is noteworthy that the slight increase of $\mathrm{Ce}^{3+}$ at the $\mathrm{GB}$ can be due to the beam damage, intrinsic boundary properties or both.

(a)

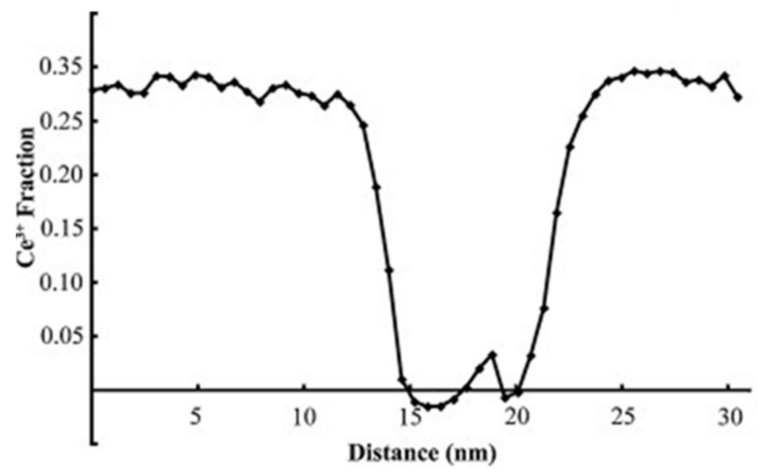

(b)

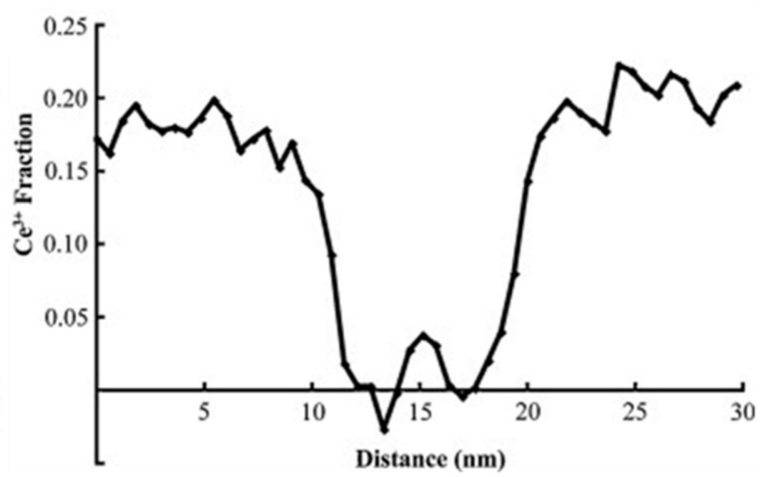

Figure 23. Plots of the $\mathrm{Ce}^{3+}$ fraction from STEM-EELS line profiles across grain boundaries in cerium oxide doped with Gd and Fe with around (a) 30\% and (b) $20 \% \mathrm{Ce}^{3+}$ in the bulk [196]. Figure 23 reprinted from Journal of the European Ceramic Society, 34, J.P. Winterstein and C.B. Carter, Electron-beam damage and point defects near grain boundaries in cerium oxide, 3007-3018, Copyright (2014), with permission from Elsevier.

\section{Applications of TEM to Oxide GBs and HIs Characterization}

\subsection{Imaging Atomic and Nano Structures}

Atomic and nanoscale imaging by HRTEM is a common approach to assess GBs in many oxide systems, such as alumina [197-200], zirconia [74,201,202], spinel [203,204], ceria [76,205], etc. [206-208] In addition, aberration-corrected TEM is widely used in oxides [27,209-211]. HRTEM micrographs and schematic models of GBs in a rare-earth (RE) doped alumina and a pure alumina are shown in Figure 24 [195]. Lattice fringes joining at the interface are observed in the RE-doped GB. This can indicate relaxation in the crystallographic structure near this GB and is consistent with observations of interface broadening in RE-doped GB, which itself is consistent with observations of interface broadening in RE-doped GBs and bicrystals compared to pure ones. It is concluded from the micrographs that the segregants are confined in a $\sim 1 \mathrm{~nm}$ region at the GB and that the GB structure is sensitive to GB type/character. 

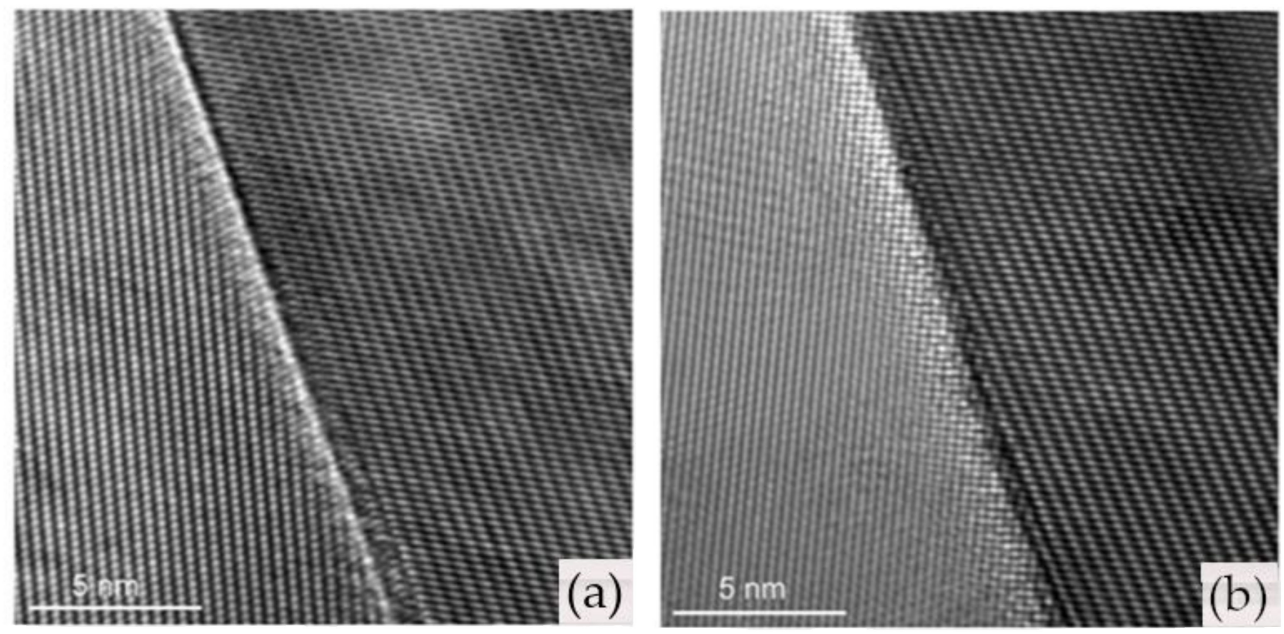

(c) (d)
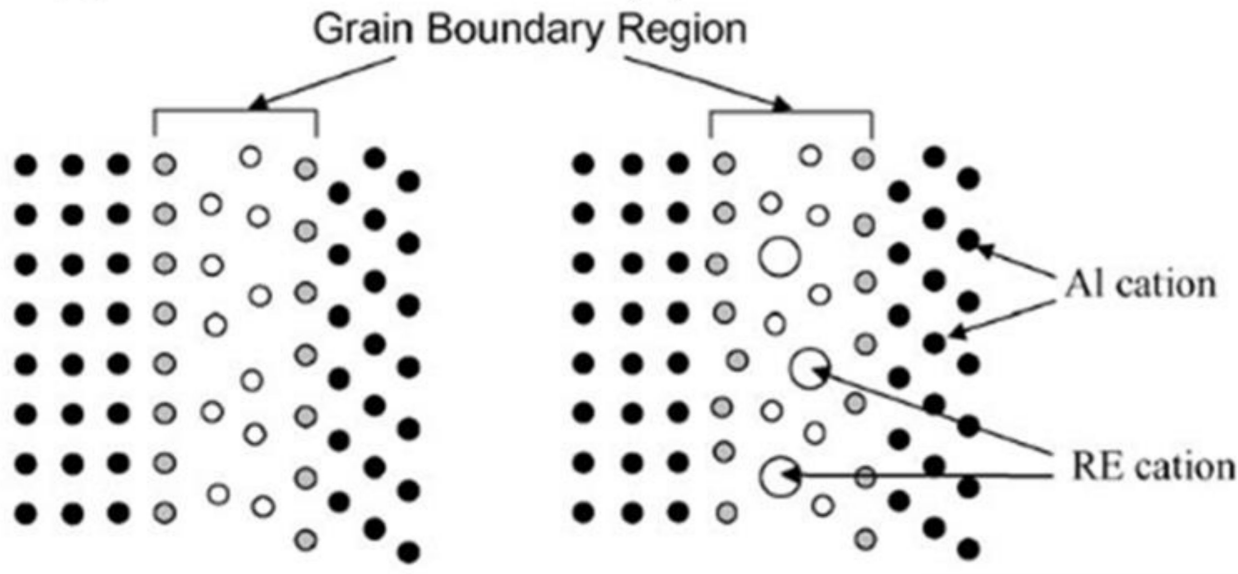

Figure 24. HRTEM micrographs of (a) un-doped and (b) La-doped alumina GBs viewed edge on. Schematic models of (c) un-doped and (d) RE doped GB in alumina [195]. Note the wider GB region in RE doped alumina shown in (b,d). Figure 24 reprinted by permission from Springer Nature Customer Service Centre GmbH: Springer Nature, Journal of Materials Science, Characterisation of fine-grained oxide ceramics, West, G.D.; Perkins, J.M.; Lewis, M.H., Copyright $\odot 2004$.

Spherical aberration (Cs)-corrected scanning transmission electron microscopy (STEM), with a sub-angstrom-sized electron probe can is another powerful technique for understanding structures of interfaces and segregation of dopants [212-215]. In a study by Schustertisch, et al. [215], HR-STEM, complementary EELS analysis and density functional theory (DFT) were used to accurately determine GBs structures in $\mathrm{TiO}_{2}$ at atomic scale (Figure 25). The existence of a unique nanoscale phase like bulk anatase $\mathrm{TiO}_{2}$ was discovered in a fabricated $\Sigma 13$ (221) [11̄0] rutile $\mathrm{TiO}_{2}$ bicrystals. This work show that it is possible to embed regions of $\mathrm{TiO}_{2}$ anatase in rutile $\mathrm{TiO}_{2}$ structure by GB fabrication and design. In other words, the power of GB analysis and engineering in oxides allows for further tuning the GB structure and properties in such materials. 
(a)

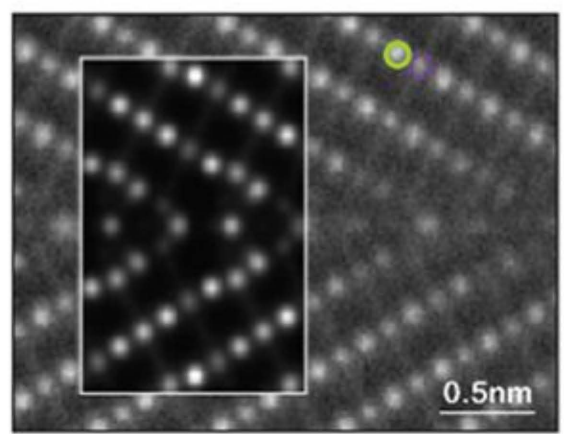

$\langle 1 \overline{1} 0\rangle=\langle 11 \overline{4}\rangle$

(d)

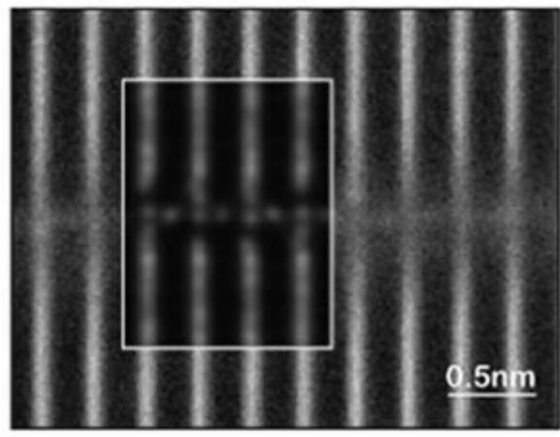

$\langle 11 \overline{4}\rangle \rightarrow\langle 1 \overline{1} 0\rangle$ (b)

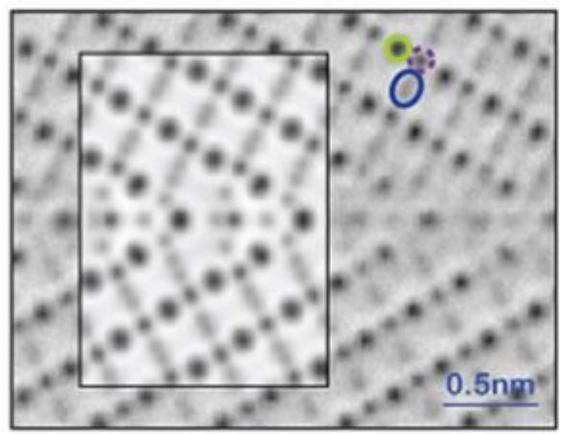

- $T i+O \because T i \bigcirc O$

(e)

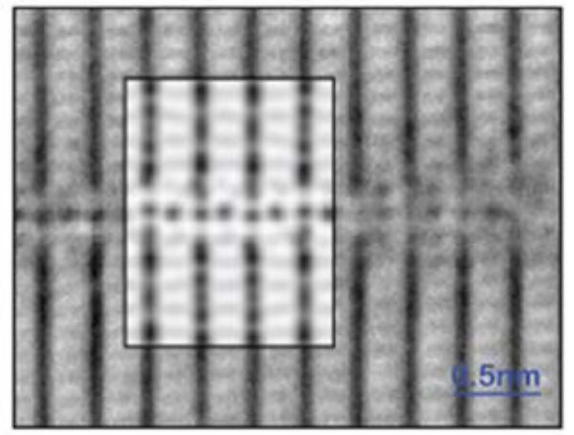

(c)

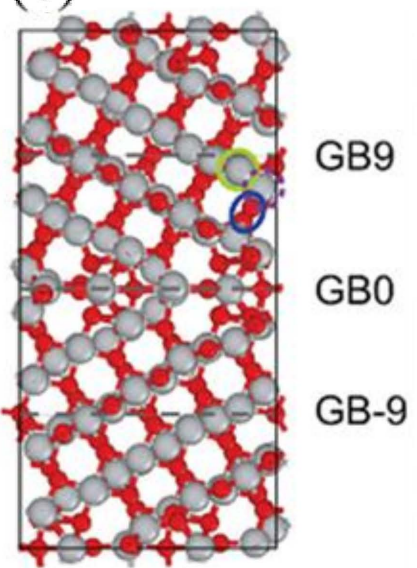

(f)

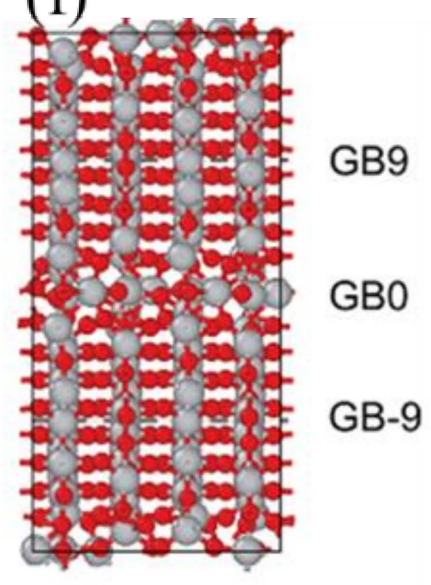

Figure 25. Atomic resolution HAADF, ABF STEM images and the DFT atomic structure of the $\Sigma 13$ bicrystal along the $(\mathbf{a}-\mathbf{c})[1 \overline{1} 0]$ and $(\mathbf{d}-\mathbf{f})[11 \overline{4}]$, respectively. Image simulations based on the atomic structure of rutile are shown as insets in the experimental HAADF and ABF STEM images. Gray and red spheres represent Ti and $\mathrm{O}$ atoms, respectively. Columns of $\mathrm{Ti}+\mathrm{O}, \mathrm{Ti}$, and $\mathrm{O}$ atoms are marked by solid green circles, dashed purple circles, and blue ellipsoids, respectively [216]. Figure 25 reprinted from https:/ / pubs.acs.org/doi/full/10.1021/acs.nanolett.0c04564 (accessed on 27 May 2021) under the terms of the Creative Commons CC BY license. Further permissions related to the material excerpted should be directed to the ACS.

Most ceramics are composed of a mixture heavy and light element, the latter of which are hard to detect. Annular bright-field (ABF)-STEM combined with HAADF imaging is a powerful tool for imaging both light and heavy elements. Such studies shed light on the origin of structure property relationships in oxides and improve even more through the incorporation of theoretical calculations [122,217]. This technique was proved to be useful in imaging cation and oxygen sublattices in a (210) $\Sigma 5 \mathrm{CeO}_{2} \mathrm{~GB}$ with a tilt axis of [001] (Figure 26) [33]. In addition, the oxygen non-stoichiometry used to reveal the role of the oxygen vacancies on the GB atomic structure. Modeling of the GB structure in this case was done using a static lattice calculation with the GULP program [218]. Figure 26a,c shows HAADF and ABF images taken from this GB, along with simulated HAADF and ABF images of the following in Figure 26b,d.

The bright spots in the HAADF image correspond to Ce column locations and the black and gray spots in $\mathrm{ABF}$ correspond to $\mathrm{Ce}$ and $\mathrm{O}$ column locations, respectively. The presence of $\mathrm{O}$ columns in the GB shown by the gray contrast is weaker compared to the $\mathrm{O}$ columns in the bulk. This is reasonable due to lower density of O column in GB compared to the bulk region. 
(a)

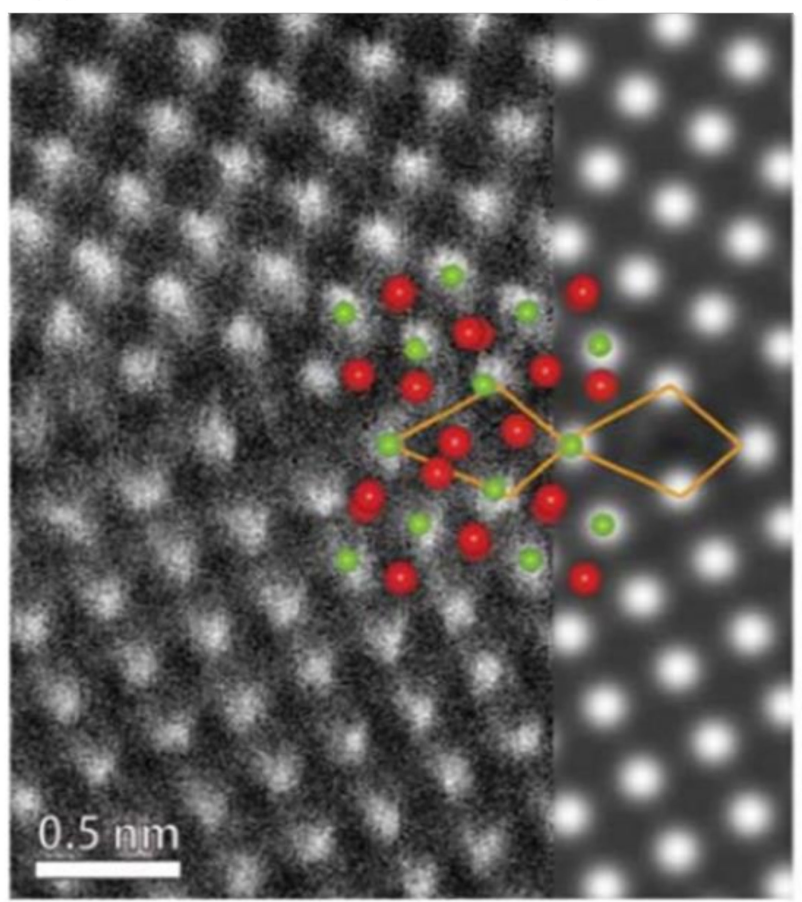

(c)

(d)

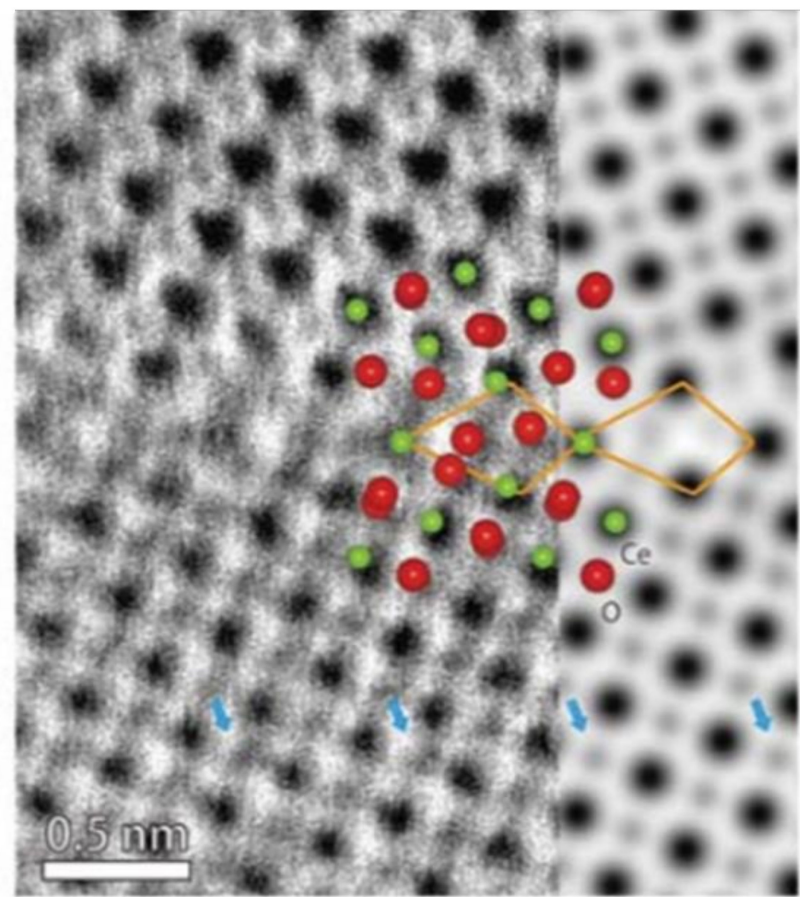

Figure 26. (a) HAADF, (b) simulated HAADF, (c) ABF image and (d) simulated ABF of a [001] (210) $\Sigma 5 \mathrm{~GB}^{\text {in a } \mathrm{CeO}_{2}}$ thin film. Simulated images are from a non-stoichiometric GB model structure. The structural units of each boundary are indicated by the polygons. A noise-reduction procedure was applied to the ABF image by a background subtraction filter [34]. The structural units of each boundary are indicated by polygons. Figure 26 reprinted with permission from Copyright (C) 2011, Oxford University Press.

\subsection{Measuring GB Character}

To determine the GB character in oxides, grain orientation mapping with a spatially resolved transmission electron diffraction techniques are used. In cases where the character of many GBs is of interest, researchers measure the GB misorientation angle distribution, which indicates the fractional length of boundaries with a given misorientation angle between adjacent grains. Such technique can employ PEND, 4D-STEM, or atomic resolution imaging to quantify GB character and orientation by automated acquisition and indexing of the diffraction data sets $[7,147,219]$. Figure 27 shows a of grain orientation overlay map on the BF-TEM image in polycrystalline Pr and Gd doped-ceria. Each grain is colored based on the crystallographic direction oriented parallel to the electron beam direction (see the color-coded stereographic inset). The misorientation angle distribution measured agrees well with polycrystalline cubic structures full of randomly oriented grains [220].

\subsection{Chemical Analysis by EDXS and EELS}

Analytical electron microscopy (AEM) techniques such as EDXS and EELS are powerful methods for qualitative and quantitative chemical and electronic structural analysis of the interfaces in oxides down to atomic scale. Modern AEMs readily provide spatially resolved spectroscopic data from points, lines, and 2D areas (also called "maps"). These methods have been applied readily for several decades, as described in books and reviews [99,103-105,142]. STEM-EDXS is used to characterize GB and HI segregations in YSZ- $\mathrm{Al}_{2} \mathrm{O}_{3}-\mathrm{MgAl}_{2} \mathrm{O}_{4}$ ceramic oxides (Figure 28) and correlate them with thermal properties of these composites [41]. 

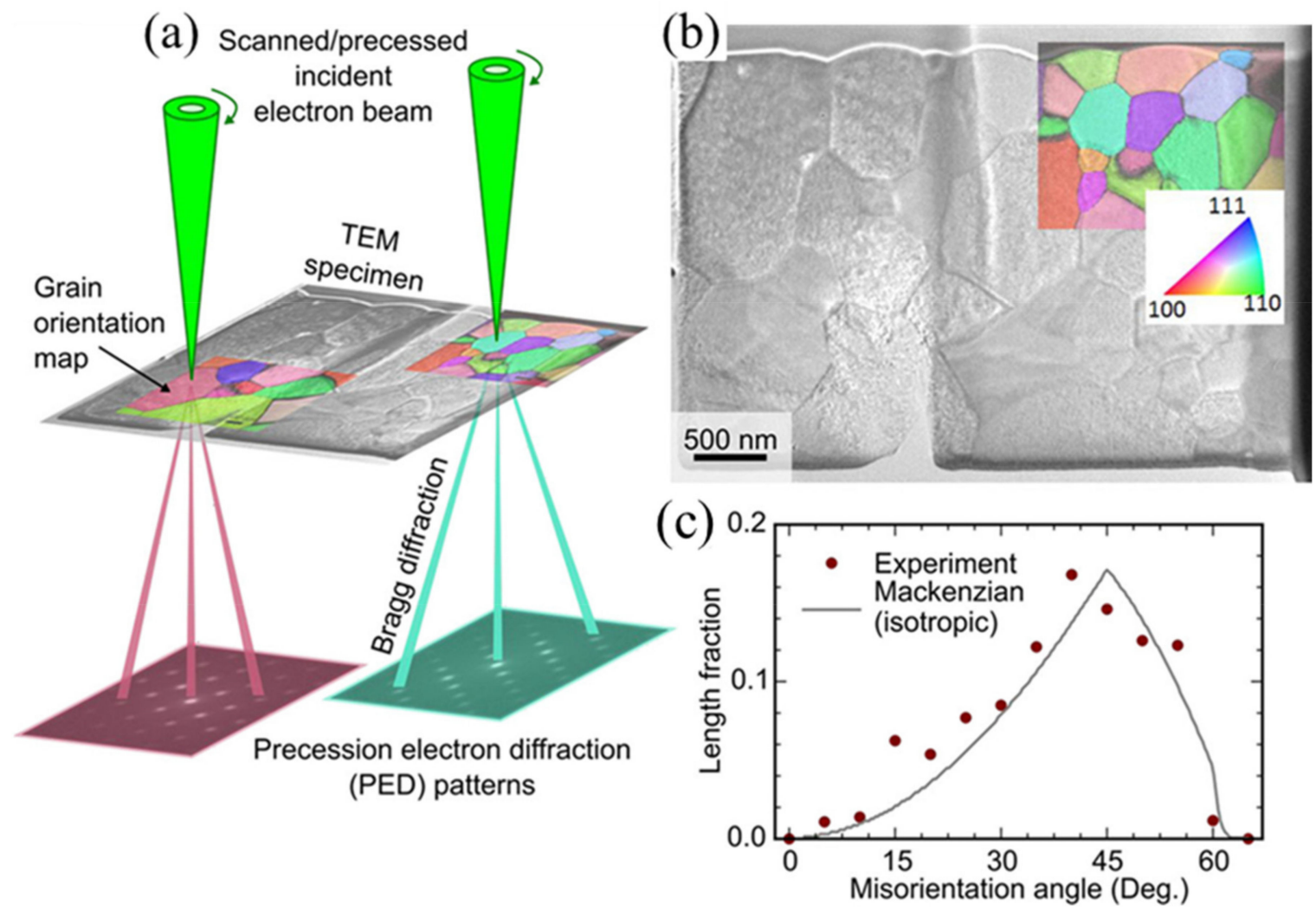

Figure 27. (a) Schematics representation of PEND in a TEM that enables grain and GB orientation mapping via precession of the electron beam. (b) Bright-field TEM image of Pr and Gd-co doped ceria (PGCO) specimen with overlaid inverse pole figures, grain orientation is indicated via color code corresponding to inset stereographic triangle. (c) Misorientation angle distribution and Mackenzian distribution [7]. Reprinted from Copyright (C) 2020 American Chemical Society.

In a work by Ikuhara et al. [211], STEM-EDXS was used to study segregation behavior in YSZ bicrystal at atomic scale. Figure 29 represents EDXS maps and line profiles of $\mathrm{Zr}$ and $Y$, respectively. From this data, chemically ordered segregation around the GB core is detected. $Y$ atoms are strongly segregated to the immediate left and right planes of the cation mirror plane $\left(\mathrm{M}_{\mathrm{c}}\right.$ in Figure $\left.29 \mathrm{c}, \mathrm{d}\right)$, whereas $\mathrm{Y}$ is depleted in the mirror plane and $\mathrm{Zr}$ tends to segregate on the mirror plane (Figure 29b). Such detailed observations in GBs of oxides can lead to a better understanding about defect chemistry and related properties. In this case, the interactions between $Y$ and oxygen vacancies govern segregation behavior by inducing a phase transition near the GB. Such characterization method capable of atomically mapping elements enables GB design at atomic scale, paving new avenues towards controlling and optimizing properties of oxides, particularly when supported by theoretical calculations such as Monte Carlo (MC), DFT, or phase field simulations [18,22,221].

Chemical doping is fundamental method of control and design GB functionality, and dopants are often added to ceramics improve sintering and control grain growth. Dopants or unwanted impurities in the system can segregate and modify GB properties. For instance, intergranular glassy phases are often observed in sintered ceramics $[74,200]$. It was elucidated in a work by Ishihara et al. [222], that small differences in the amounts of $\mathrm{Si}$ impurity led to distinct GB atomic structures in a Ti-doped $\Sigma 13 \alpha-\mathrm{Al}_{2} \mathrm{O}_{3}$ GB (Figure 30). In GB type-I, $\mathrm{Ti}^{3+}$ is replacing $\mathrm{Al}^{3+}$ while in type-II, $\mathrm{Ti}^{3+}$ oxidizes to $\mathrm{Ti}^{4+}$ and the $\mathrm{Al}$ vacancies were introduced to the GB to compensate for that leading to three-times larger structure units (oxidation states confirmed by EELS). 


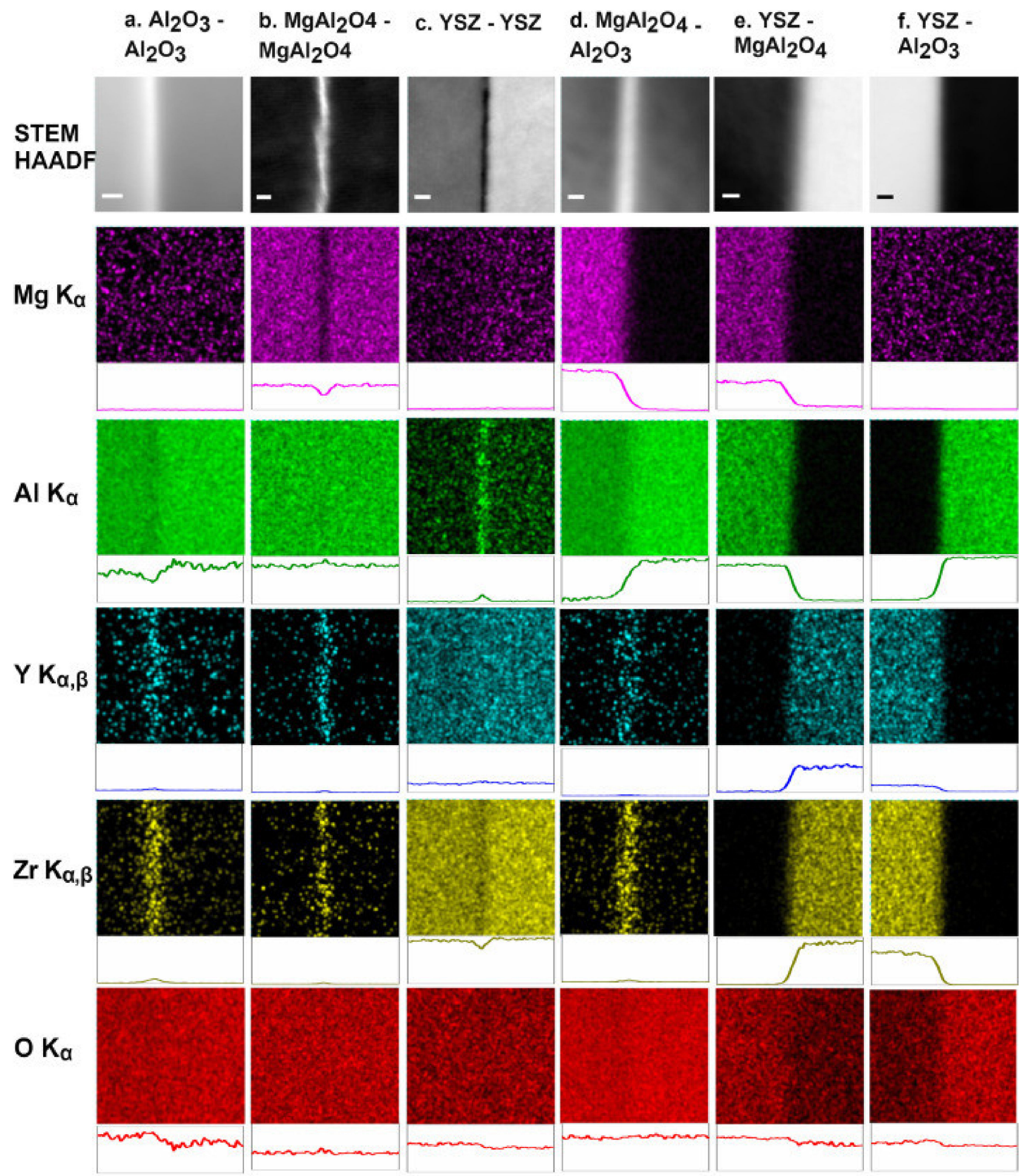

Figure 28. STEM HAADF images and EDXS maps for six (representative) interfaces in a flash-sintered $\mathrm{MgAl}_{2} \mathrm{O}_{4}-\mathrm{Al}_{2} \mathrm{O}_{3}-\mathrm{YSZ}$ ceramic. $\mathrm{Mg} \mathrm{K}_{\alpha}, \mathrm{Al} \mathrm{K} \mathrm{K}_{\alpha}, \mathrm{Y} \mathrm{K}_{\alpha, \beta}, \mathrm{Zr} \mathrm{K} \mathrm{K}_{\alpha, \beta}$ and $\mathrm{O} \mathrm{K}_{\alpha}$ elemental EDXS maps (net counts) and their corresponding intensity profiles (net counts normalized by the total counts) are shown. (a) Alumina-alumina GB shows depletion of Al and segregation of $\mathrm{Y} / \mathrm{Zr}$, (b) spinel-spinel GB shows depletion of $\mathrm{Mg}$ and segregation of $\mathrm{Y} / \mathrm{Zr}$, (c) $\mathrm{YSZ}$-YSZ GB shows depletion of $\mathrm{Zr}$ and segregation of $\mathrm{Al}$, (d) spinel-alumina GB shows segregation of $\mathrm{Y} / \mathrm{Zr}$, and (e) YSZ-spinel and (f) YSZ-alumina interfaces do not show any segregation. Scale bar is $2 \mathrm{~nm}$ [41]. Figure 28 reprinted from Acta Materialia, 14, Komal Syed, Mingjie Xu, Kenta K. Ohtaki, David Kok, Keyur K. Karandikar, Olivia A. Graeve, William J. Bowman, Martha L. Mecartney, Correlations of grain boundary segregation to sintering techniques in a three-phase ceramic, 100890, Copyright (2020), with permission from Elsevier. 
EELS is regularly employed in both TEM and STEM, and in addition to elemental concentrations can provide information about the electronic structure, bonding environment, chemistry, and oxidation states of atoms and ions at interfaces. While application of EELS can be very similar to EDXS, it acquires additional information mentioned, has higher detection efficiency, making it more promising for analysis and quantifications in e-beam sensitive materials and light weight elements. In a study by Saito et al. [223], segregation behavior of impurities to an $\mathrm{MgO}$ bicrystal was investigated. Some impurities tend to segregate to GB and interact with native structural defects, dominating the structures of the GB and hence determining many of its properties. A case study of the Cliff-Lorimer method for quantitative GB analysis in oxides is a work by Bowman et al. [8] that analyzes the cation concentrations at the GBs of a polycrystalline, oxygen conducting material, $\operatorname{Pr}_{0.04} \mathrm{Gd}_{0.11} \mathrm{Ce}_{0.85} \mathrm{O}_{2-\delta}$. Using the quantitative EELS analysis along with other characterization techniques, the authors concluded that the boundaries with higher solute concentrations have lower activation energy of ion conduction across GBs.

a

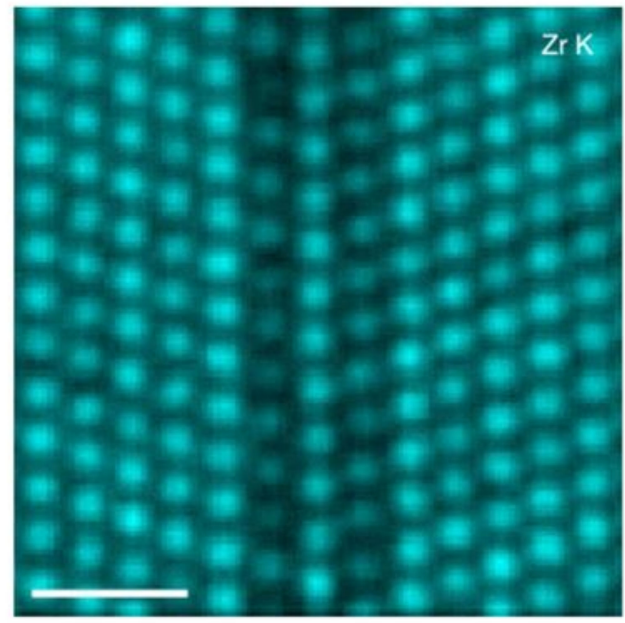

C

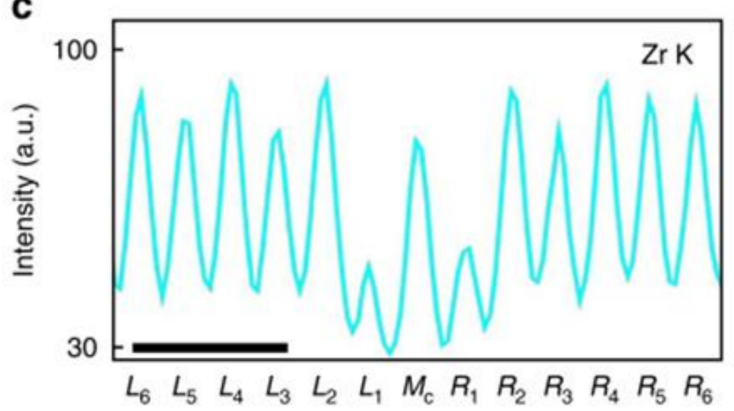

b

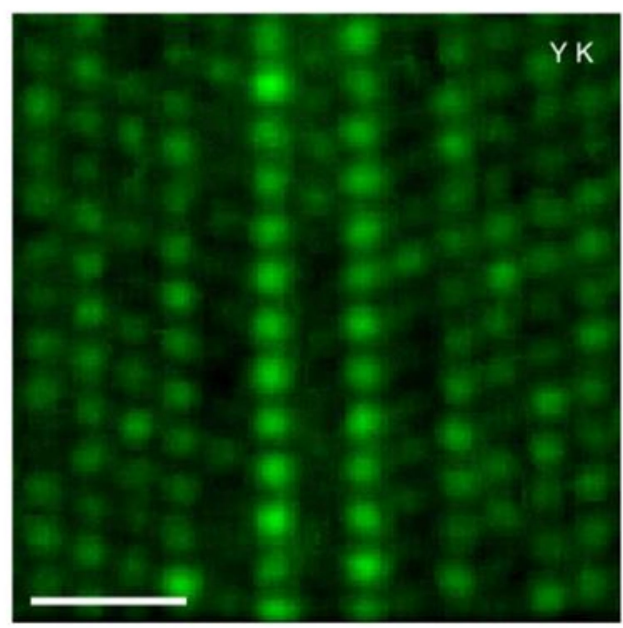

d

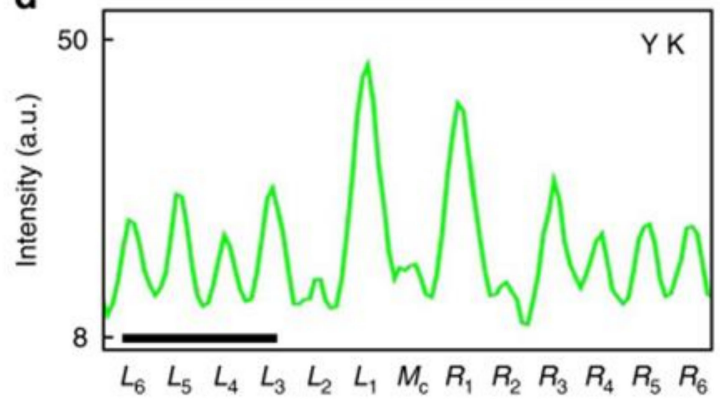

Figure 29. Energy-dispersive $X$-ray spectroscopy maps and intensity profiles. (a,b) EDXS elemental maps for a. Zr K and b. $\mathrm{Y} \mathrm{K}$ and (c,d). Intensity profiles by summing the X-ray counts in the maps in the direction parallel to the GB for (c) Zr-K and b. Y-K (normalized to the total Zr and Y counts). Reprinted from [212] under the terms of the Creative Commons CC BY license.

Yang et al. [224] published a study on GB segregation in Mn-doped $\mathrm{SrTiO}_{3}$. This material has promising magnetic and electric properties, which can be improved by engineering the GBs. It was found that $\mathrm{Mn}^{2+}$ segregates inside GBs both in $\mathrm{Sr}$ and interstitial sites, while $\mathrm{Mn}^{4+}$ is found to substitute Ti in bulk $\mathrm{SrTiO}_{3}$. Figure 31 represents the HAADF image, EELS elemental maps of (Figure 31a) Sr, (Figure 31b) Ti and (Figure 31c) Mn. The line profile in Figure 31e is extracted by averaging the compositions across the images shows an enrichment in Mn and $\mathrm{Sr}$ is accompanied by Sr deficiency at GB core. It is evident that $\mathrm{Sr}$ is roughly 50 at $\%$ away from the GB while the sum of Ti and Mn is also roughly 50 at $\%$. This would suggest that Mn substitutes for Ti and should, therefore, have a +4 
charge state [224]. This interface was also investigated by EDXS (Figure 31f,g). It is evident that there is significant difference between qualitative elemental maps (Figure 31b,d) and quantitative maps (Figure 31e,g) which proves the importance of quantitative analysis.

(a)

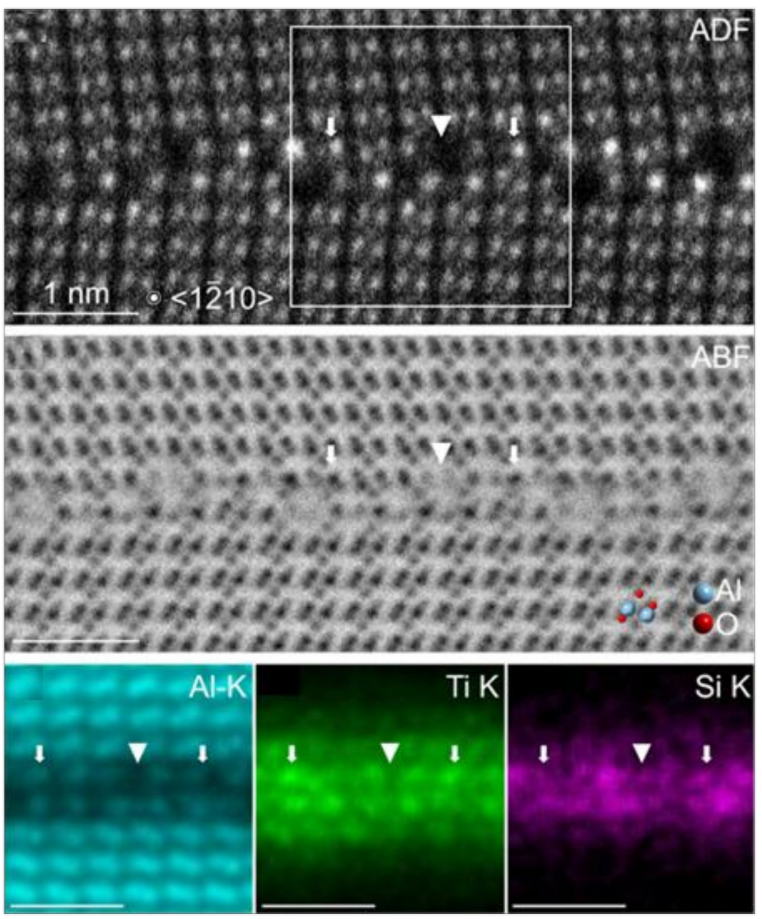

(b)
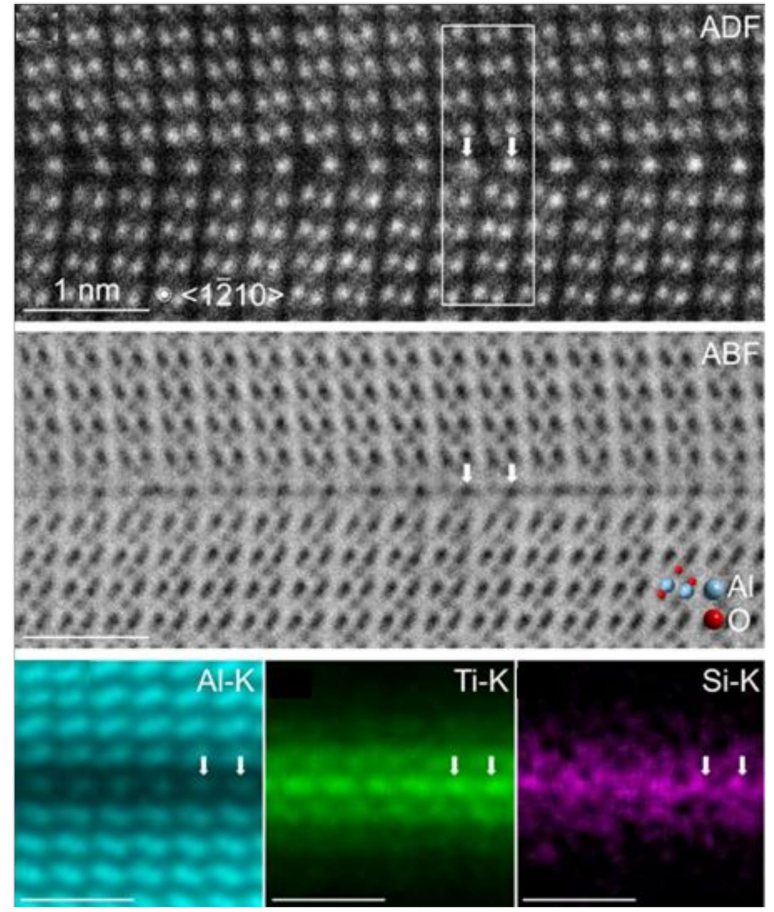

Figure 30. ADF-STEM, ABF-STEM and EDXS count maps of Al-K, Ti-K, and Si-K edges, respectively, obtained from (a) type-I and (b) type-II Ti-doped $\Sigma 13 \alpha-\mathrm{Al}_{2} \mathrm{O}_{3}$ GBs viewed along the [1210] direction. The white boxes on the ADF-STEM image indicates the size of the unit structure of pristine GB. The arrows indicate the positions of brighter Z-contrast in the GB core, and corresponding locations are also indicated in respective images. All the scale bars are $1 \mathrm{~nm}$. Reprinted from [222] under the terms of the Creative Commons CC BY license.

\subsection{In Situ S/TEM of GBs and HIs}

In-situ mechanical testing inside electron microscopes has been an effective approach to investigate interfacial deformation and fracture modes in ceramics. Among different techniques, in situ nanopillar compression is widely used to explore the mechanical behavior and deformation mechanisms, including dislocation motion, stacking fault formation and GB sliding, in ceramic materials at small scale $[225,226]$. Dynamic interactions between individual dislocations and well-controlled $\mathrm{GBs}$ in $\mathrm{SrTiO}_{3}$ can be directly observed under TEM during nanoindentation [227]. The dislocation impediment effect induced by high-angle or low-angle GBs was found to be related to both the geometric and structural stabilization effects of the GBs [227]. In another example, Kondo, et al. [228] conducted nanoindentation at a $\mathrm{Zr}$-segregated $\sum 13 \mathrm{~GB}$ in $\mathrm{Al}_{2} \mathrm{O}_{3}$ and observed the crack nucleation and propagation along the GB inside TEM. Post-mortem HAADF STEM revealed that atomic-scale cleavage path is along the center layer of the triple $\mathrm{Zr}$-rich layers, pointing to the importance of local oxygen coordination at the dopant-enriched GB core in determining the fracture path and therefore, toughness, of oxide ceramics. Combining localized laser heating inside TEM, in-situ mechanical testing at ultra-high temperatures up to the melting point of ceramics could be realized. Using this approach, Grosso et al. [229], investigated the temperature dependency of yield strength in nanocrystalline $\mathrm{Sc}_{2} \mathrm{O}_{3}$-stablized $\mathrm{ZrO}_{2}$ from room temperature to $2050{ }^{\circ} \mathrm{C}$. Their results cast doubt on the previous hypothesis that GB diffusion is the reason for Hall-Petch break down in nanocrystalline ceramics, at least 
in this material system. This approach has also been used to investigate GB and surface diffusivities in $\mathrm{ZrO}_{2}$ bicrystal by the same group of authors [230].
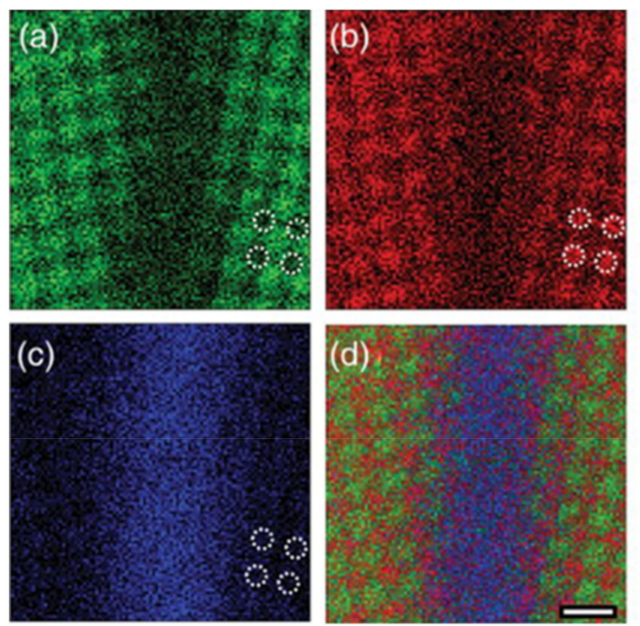

(e)
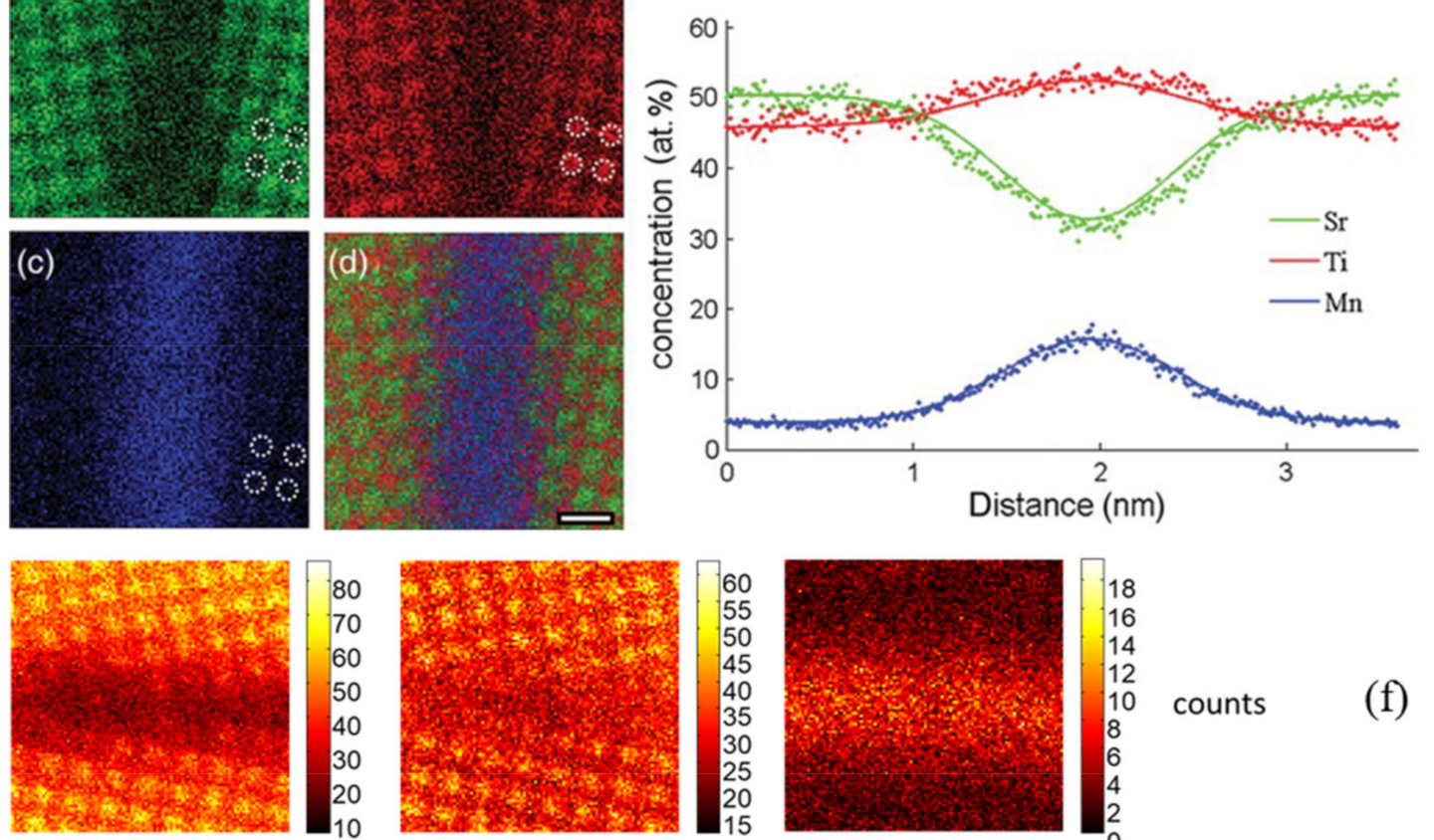

$\mathrm{Sr}$

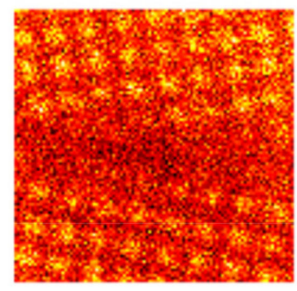

$\mathrm{Ti}$

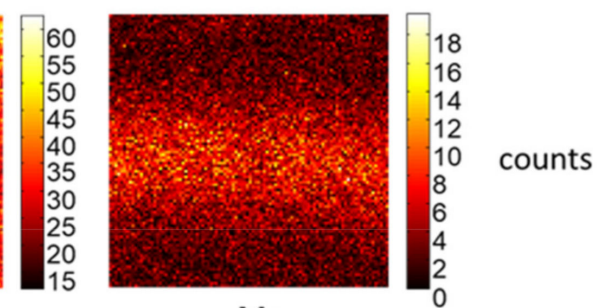

(f)
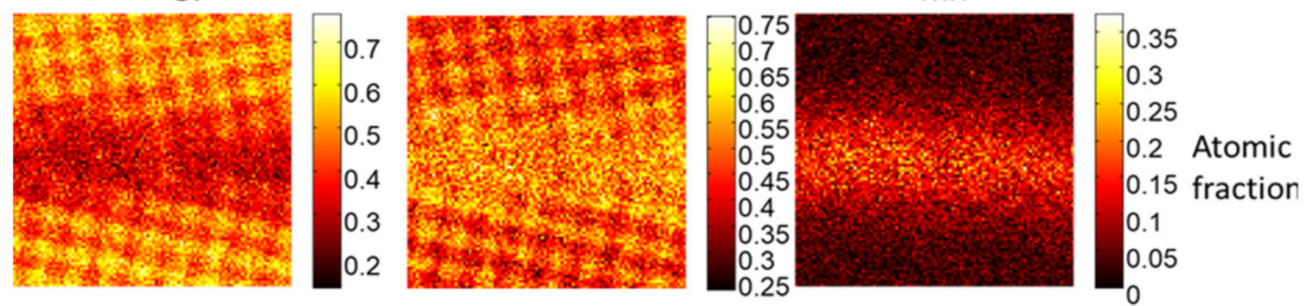

$\mathrm{Mn}$

(g)

Figure 31. Atomic resolution mapping of the Mn-doped $\mathrm{SrTiO}_{3} \mathrm{~GB}$. EELS compositional maps of (a) $\mathrm{Sr}$, (b) $\mathrm{Ti}$, (c) Mn, and (d) composite maps were obtained from the MSA with RGB false colors applied. The scale bar is $0.5 \mathrm{~nm}$. A few $\mathrm{nm}$ away from the GB core, Mn has a much lower but detectable concentration, and substitutes the Ti site as indicated by the coincident dashed circles in $(\mathbf{b}, \mathbf{c})$. The relative concentration profile (at \%) across the GB in (e) is obtained by concerting the vertically summed up EELS signal of the two-dimensional map using the Cliff-Lorimer factors of a $200 \mathrm{kV}$ microscope. Atomic EDXS mapping of the Mn-doped $\mathrm{SrTiO}_{3} \mathrm{~GB}$. (f) shows count maps of $\mathrm{Sr}$, $\mathrm{Ti}$ and $\mathrm{Mn}$, respectively. (g) shows the atomic fraction of elements normalized to1 (or 100\%) using the Cliff-Lorimer factors. As seen clearly in these maps, Ti shows reduced counts but increased concentration (or atomic fraction) as the concentration of Sr drops inside the GB. Reprinted from [224] under the terms of the Creative Commons CC BY license.

In addition to mechanical testing, in-situ characterization of other crystalline defects, such as oxygen vacancies under thermal or electrical stimulus is of great importance for a wide range of functional properties in ceramics. Klie, et al. [3] performed in-situ heating coupled with STEM-EELS on a series of perovskite oxides to capture changes in the structure, composition, and valence states. An excess of oxygen vacancies was observed at the GB before heating. At $724 \mathrm{~K}$, the amount of oxygen vacancies increased both in the bulk and at the GB, even though the GB cation structure did not change upon heating. According to the EELS data collected from the same GB upon cooling, oxygen diffusion occurs from the bulk into the GB plane which agrees with the increase of oxygen vacancies upon heating. In other words, the oxygen diffuses to the bulk upon heating and goes back to the GB upon cooling. The impact of electrical biasing on oxygen vacancy migration 
in $\mathrm{CeO}_{2}$ was studied by Gao, et al. [231] using STEM-EELS. The formation and ordering of oxygen vacancies in the $\mathrm{CeO}_{2}$ thin film within an $\mathrm{Au} / \mathrm{CeO}_{2} / \mathrm{Nb}-\mathrm{SrTiO}_{3}$ junction was directly observed by applying a positive voltage. These promising results have proven that the oxygen vacancy migration mechanism is responsible for the resistance switching in $\mathrm{CeO}_{2}$ and possibly other oxides with similar properties [231]. Such material systems can be used for next generation memories due to their small power consumption, high density, and other properties. It is important to understand and control the switching behavior of nanoscale oxide devices.

In-situ electron microscopy combined with electron loss near edge structure (ELNES) can be used to monitor changes in the electronic structure of many elements such as $3 \mathrm{~d}-$ transition and rare earth metal oxides, including Fe and Ce oxide [232,233]. Numerous experiments have suggested a strong correlation between changes in valence states of cations and the $\mathrm{L}_{3} / \mathrm{L}_{2}$ or the ionization edges (white lines) ratio and $\mathrm{O}-\mathrm{K}$ edge fine structure. In addition, the O-K pre-peak, which is caused due to transitions from the O1s state to the unoccupied hybridized $\mathrm{O} 2 \mathrm{p}$ in transition metal $3 \mathrm{~d}$ orbitals, helps quantify the transition metal valence and the concentration of mobile holes and the transition metal spin states [234-240].

In 2000, Wang, et al. [241], reported the $\mathrm{L}_{3} / \mathrm{L}_{2}$ ratio for direct measurement of $\mathrm{Co}$ and $\mathrm{Mn}$ valence states. Significant differences between O-K edges in $\mathrm{Co}_{3} \mathrm{O}_{4}$ and $\mathrm{CoO}$ allowed to distinguish Co oxidation state in these two structures [232,233].

In an in-situ heating experiment coupled with STEM-EELS, metallic cobalt was distinguished from cobalt in 2+ and 3+ oxidation states [237]. The ELNES used for this study are shown in Figure 32. A clear energy shift in the $\mathrm{Co}_{-} \mathrm{L}_{3}$ and $\mathrm{L}_{2}$ peaks of $\mathrm{CoO}$ (contains $\mathrm{Co}^{2+}$ ) compared to $\mathrm{Co}_{3} \mathrm{O}_{4}$ (contains $\mathrm{Co}^{2+}$ and $\mathrm{Co}^{3+}$ ) is observed which is related to transition of $2 \mathrm{p}^{3 / 2}$ to $2 \mathrm{p}^{1 / 2}$ core-shell electrons into unoccupied $3 \mathrm{~d}$ orbitals. In summary, the following techniques can be used to measure the oxidation state of each cation at the GBs and HIs, where defect chemistry at such interfaces plays an important role and it directly relevant to the concentration of such defects at the interface.

In-situ EM has proved to be beneficial in research of battery materials, particularly observing material degradation during electrochemical performance and cycling [242]. While lithium-ion batteries with Ni-rich layered oxides such as $\mathrm{LiNi}_{0.8} \mathrm{Co}_{0.15} \mathrm{Al}_{0.05} \mathrm{O}_{2}$ (NCA) are of interest as cathodes, they suffer from capacity fade hypothesized to be correlated to microcracks that initiate and grow through GBs [243,244]. These microcracks serve as pathways for electrolyte penetration into secondary NCA particle and grow with the electrolyte corrosion and mechanical strain during lithiation/delithiation [245]. These hypotheses are validated by the comparison ELNES in the bulk and GB. According to Figure $33 \mathrm{~b}, \mathrm{Ni}$ shows an increase in the $\mathrm{L}_{3} / \mathrm{L}_{2}$ ratio indicates the change of $\mathrm{Ni}$ oxidation state from the bulk to the GB, while the same thing did not occur for cobalt (Figure 33e). In addition, GB were observed to be preferential cites for in situ exsolution of metallic particles [246]. This phenomenon is related to the lower formation energy for vacancy and nucleation sites at GBs, which is ultimately important for controlling particle density and distribution. 


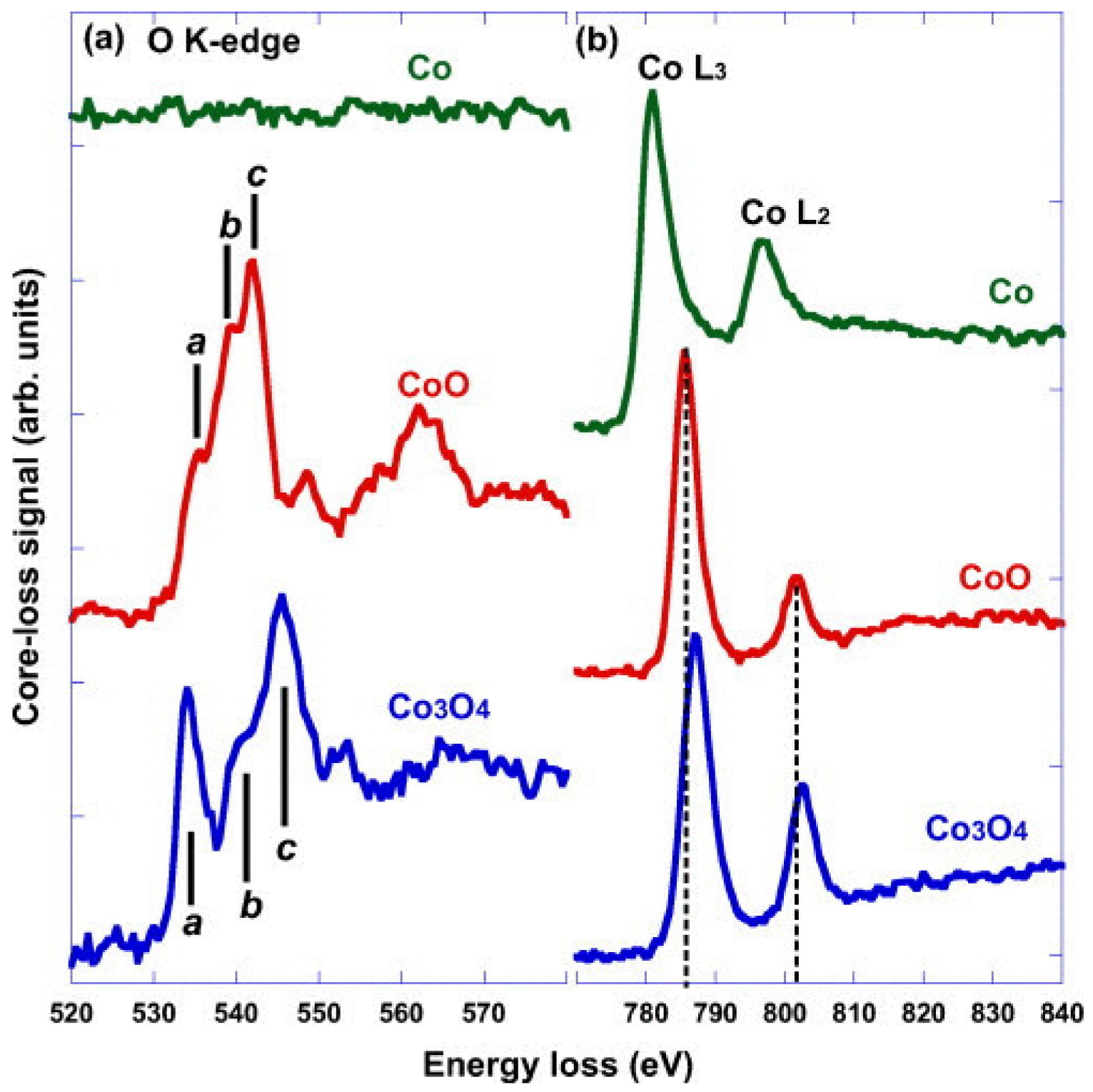

Figure 32. Comparison of (a) O K-edges and (b) $\mathrm{Co}-\mathrm{L}_{2,3}$ edges of metallic $\mathrm{Co}, \mathrm{CoO}$, and $\mathrm{Co}_{3} \mathrm{O}_{4}$ [237]. Reprinted from in situ electron energy loss spectroscopy study of metallic Co and Co oxides, Zhao, Y., Feltes, T.E., Regalbuto, J.R., Meyer, R.J., \& Klie, R.F., Journal of Applied Physics, 2010, 108(6), 063704, with the permission of AIP Publishing. 

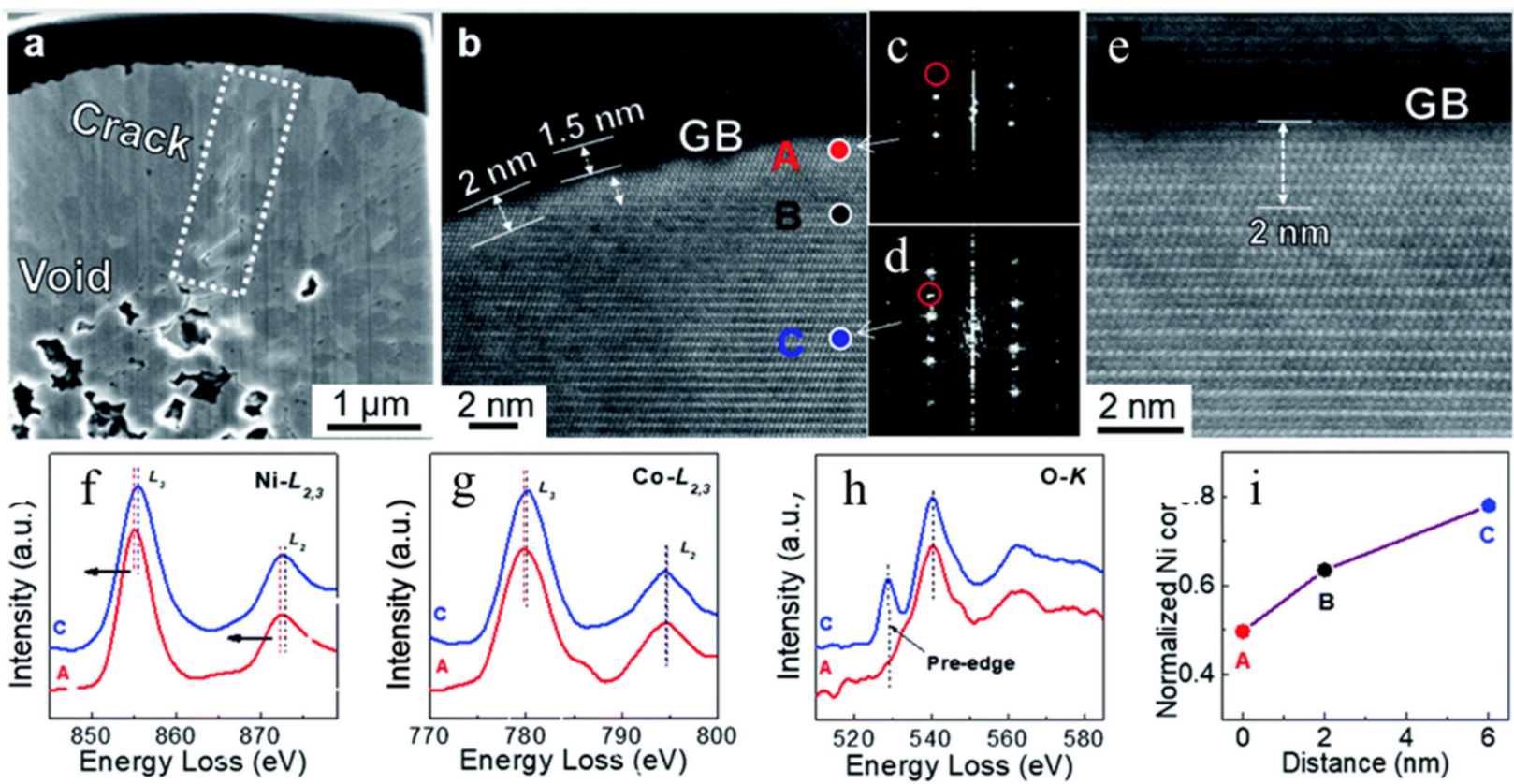

Figure 33. SEM and HAADF-STEM images of NCA after 1500 cycles. (a) Cross-section image of a secondary particle. (b) a representative GB at the microcrack line indicated in (a). Fast Fourier transform (FFT) pattens from (c) the GB and (d) the bulk. (e) a representative GB beyond the microcrack line indicated in (a). (f) the EELS spectra of Ni L-edge, (g) Co L-edge, and (h) O K-edge acquired at the points indicated in (b). (i) Normalized Ni concentration (relative to Co) from the GB to the bulk derived from EELS spectra [245]. Figure 33 reprinted with permission from the Royal Society of Chemistry Copyright 2021.

\section{Corelating GB Characterization with Properties \\ 4.1. Electrical Properties}

In polycrystalline oxides, GBs and HIs play an important role in functional properties such as ionic conductivity $[247,248]$. To measure these properties, techniques such as electrochemical impedance spectroscopy (EIS) are used that can measure conductivity of ions and distinguish the contribution of each component of the system to the measured conductivities $[249,250]$. It is common for GBs to behave different than the bulk and affect the conductivity values, whether reduce or increase them. For example, in many oxide systems GBs tend to hinder oxygen vacancy movement thereby drastically reducing the conductivity values. To better understand the mechanisms responsible for these observations, a comprehensive analysis of charge carriers responsible for conductivity or in other words defect chemistry at the GB is required and has been studied to good extent [71] Previously, an intrinsic space charge-layer was discovered that is localized at the GB which induces local redistribution of charge carriers in the vicinity of the GB core. This results in the depletion of charge carriers, reducing the conductivity at the GB [251]. In the following example, STEM- EELS was used to link nanoscale GB defect chemistry to the oxygen ion conductivity across the GBs Ca-doped ceria [21]. Figure 34a presents an ADF image of a GB where both grains are oriented near a zone axis orientation (Figure 34) [21]. The contrast is sensitive to the $\mathrm{Z}$ or atomic number of the elements. The decrease in ADF intensity at the GB is an indication of a decrease in high angle scattering of the electrons. This agrees with the EELS results shown on the side, presenting an increase in $\mathrm{Ca}^{2+}$ concentration at and near GB core compared to the bulk, as $\mathrm{Ca}^{2+}$ is lighter than $\mathrm{Ce}^{4+}$ therefore we expect lower signals where it segregates. The amount of Ca segregated at the GB was measured using EELS and is shown in Figure 34b. The segregation is maximized in the case of $5 \mathrm{~mol} \%$ Ca added to the system, which is also followed by a 2 times higher conductivity value (Figure 34c). 

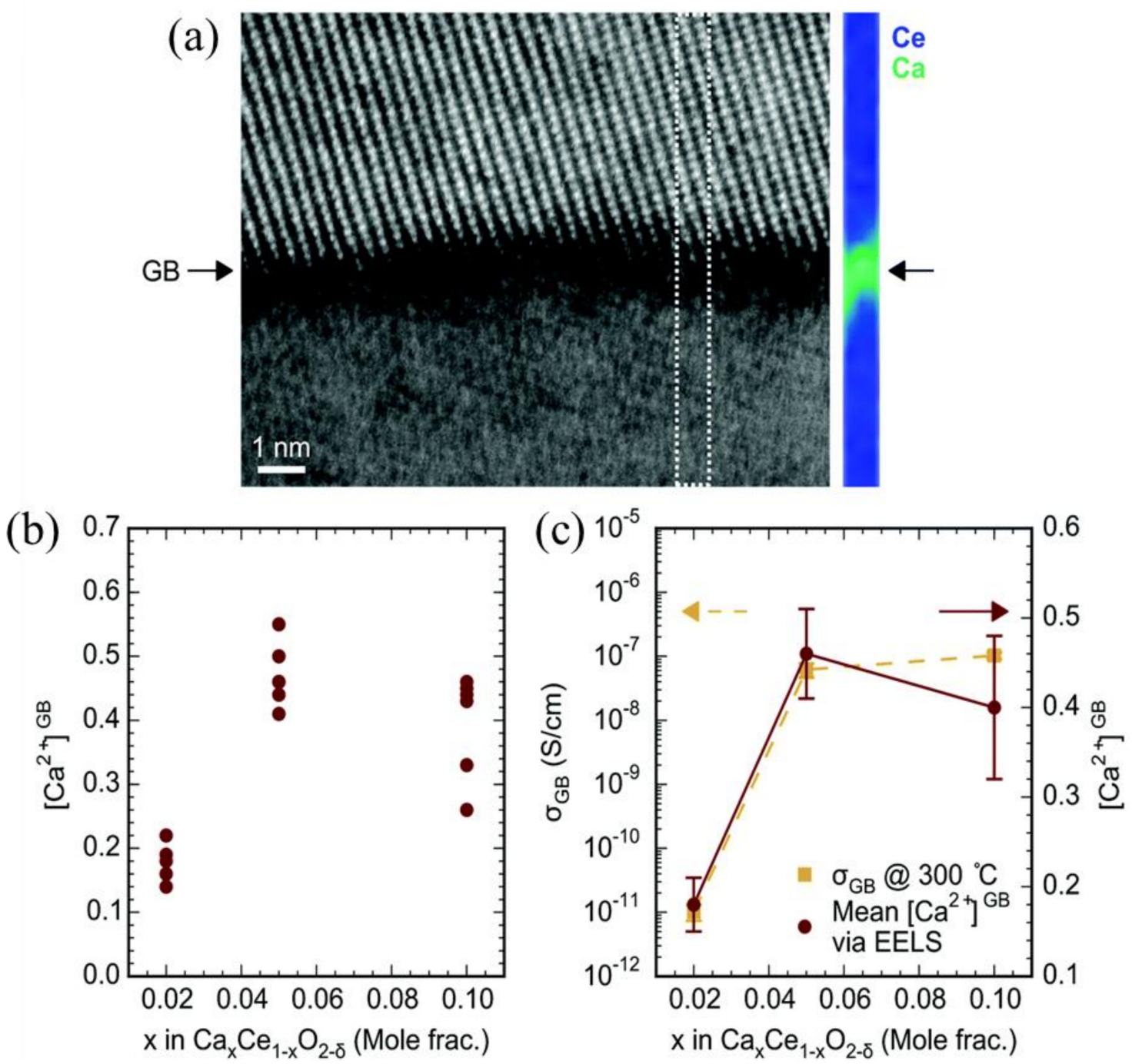

Figure 34. (a) ADF AC-STEM image of a GB in 5CCO, the associated elemental EELS map was acquired from the area in the dashed box and is on the right. (b) All EELS measurements of $\mathrm{GB} \mathrm{Ca}^{2+}$ concentration, (c) Influence of nominal Ca ${ }^{2+}$ concentration, $x$, on GB conductivity measured at $300{ }^{\circ} \mathrm{C}$ [21]. Reprinted from Nanoscale, Enhanced ionic conductivity in electroceramics by nanoscale enrichment of grain boundaries with high solute concentration, William J. Bowman, Madeleine N. Kelly, Gregory S. Rohrer, Cruz A. Hernandez and Peter A. Crozier, 2017, 9, 17293-17302, with permission from the Royal Society of Chemistry (2017).

Another major application of S/TEM characterization technique is the field of all solidstate lithium batteries, where ceramic oxides are employed as solid electrolytes [252]. These batteries are of interest for electrochemical energy storage applications due to their high energy density, safety, long cycle life and wide range of operation temperature. The candidate oxides include cubic garnet-type $\mathrm{Li}_{7} \mathrm{La}_{3} \mathrm{Zr}_{2} \mathrm{O}_{12}$ (LLZO), perovskite-type $\mathrm{Li}_{3} \times \mathrm{La}_{2 / 3}-\mathrm{TiO}$ (LLTO) and NASICON NLiM $2\left(\mathrm{PO}_{4}\right)_{3}(\mathrm{M}=\mathrm{Ti}, \mathrm{Ge}, \mathrm{Zr}, \mathrm{Hf})$ [253-258]. These structures are stable in air and with respect to Li metal and other high voltage cathodes. However, there are a few downsides including low ionic conductivity at various interfaces such as the anode/electrolyte/cathode, and GBs in the bulk. For example, the perovskite $\mathrm{Li}_{0.34} \mathrm{La}_{0.51} \mathrm{TiO}_{2.94}$ has shown bulk ionic conductivity of $1 \times 10^{-3} \mathrm{~S} \mathrm{~cm}^{-1}$ and total ionic conductivity of higher than $2 \times 10^{-5} \mathrm{~S} \mathrm{~cm}^{-1}$ at room temperature, meaning GBs tend to decrease conductivity [257]. Therefore, researchers began investigating this phenomenon to design new interfaces with higher efficiencies. Doping has been effective in improving total conductivity values in some oxides [259]. In general, doping of elements such as $\mathrm{Al}^{3+} / \mathrm{Ge}^{4+}$ at the $\mathrm{Li}$ sites and $\mathrm{Ta}^{5+} / \mathrm{Nb}^{5+}$ at the $\mathrm{Zr}$ sites has stabilized the cubic garnet and reduced Li ion migration activation energy 
thereby increasing the Li ion conductivity $[260,261]$. The substitution of the $\mathrm{Zr}^{4+}$ sites by Ge ${ }^{4+}$ improved ionic conductivity to be $4.78 \times 10^{-4} \mathrm{~S} \mathrm{~cm}^{-1}$ at $20^{\circ} \mathrm{C}$ with an activation energy of $0.29 \mathrm{eV}$ which are among the best in the field $[262,263]$. This dopant has also improved the sintering process by reducing the sintering temperature and increasing the density.

Another example is the poor GB conductivity in the Li-ion conducting solid electrolyte LLTO. Figure 35 shows HAADF-STEM image of GBs with dark contrast denoted as GB type I (upper portion) and normal contrast denoted as type II (lower portion). The difference between atomic structure of these types is evident in Figure 35b,c. While the GB type I has significantly deviated from the bulk and perovskite atomic structure disappeared, the GB type II experienced a much smaller lattice mismatch compared to that in type I and the perovskite structure remained. It is discovered using TEM that most GBs have severe structural and chemical changes from normal perovskite to compensate for the random orientation of the adjacent grains including such as reduction of $\mathrm{Ti}^{4+}$ to $\mathrm{Ti}^{3+}$, depletion of $\mathrm{Li}$, decrease in La content and deformation of Ti-O polyhedral (Figure 36). In addition, the structure of type I GB was schematically depicted in Figure 37 based on the HAADF-STEM and EELS analysis. The intensities of each element were defined by the atomic column intensity in the bulk. As seen in EELS results, the GB was filled with $\mathrm{O}$ and Ti and possessed a non-perovskite crystal structure. It was concluded that the existing GB is not energetically preferred for either Li accommodation or transport, giving rise to the poor GB conductivity. Papers including one by Ma et al. [20] perfectly demonstrates the correlation between atomic-scale GB structure and ionic conductivity in Li superionic conductors $[27,261,264]$.

The atomic structures and the band gaps of four typical GBs in $\alpha-\mathrm{Al}_{2} \mathrm{O}_{3}$ by stem and valence electron energy-loss spectroscopy. It was found that the band gaps of the GBs are narrowed by $0.5-2.1 \mathrm{eV}$ compared with that of $8.8 \mathrm{eV}$ in the bulk [161].

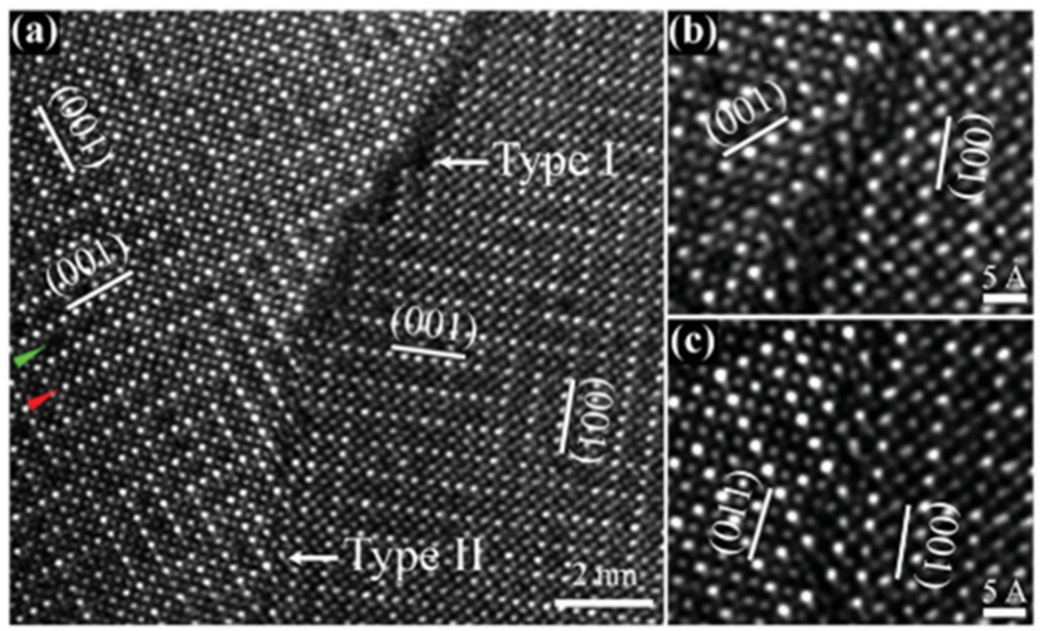

Figure 35. (a) HADDF-STEM of a GB exhibiting both dark and normal contrast regions, labelled as type I and type II, respectively. The $\{001\}$ planes of the alternating L-rich/La-poor layers of different regions in the grain were marked to highlight the existence of nanodomains (b) magnified type I GB feature. (c) magnified type II GB feature [20]. Reproduced from [20] with permission from the Royal Society of Chemistry, Copyright 2014. 

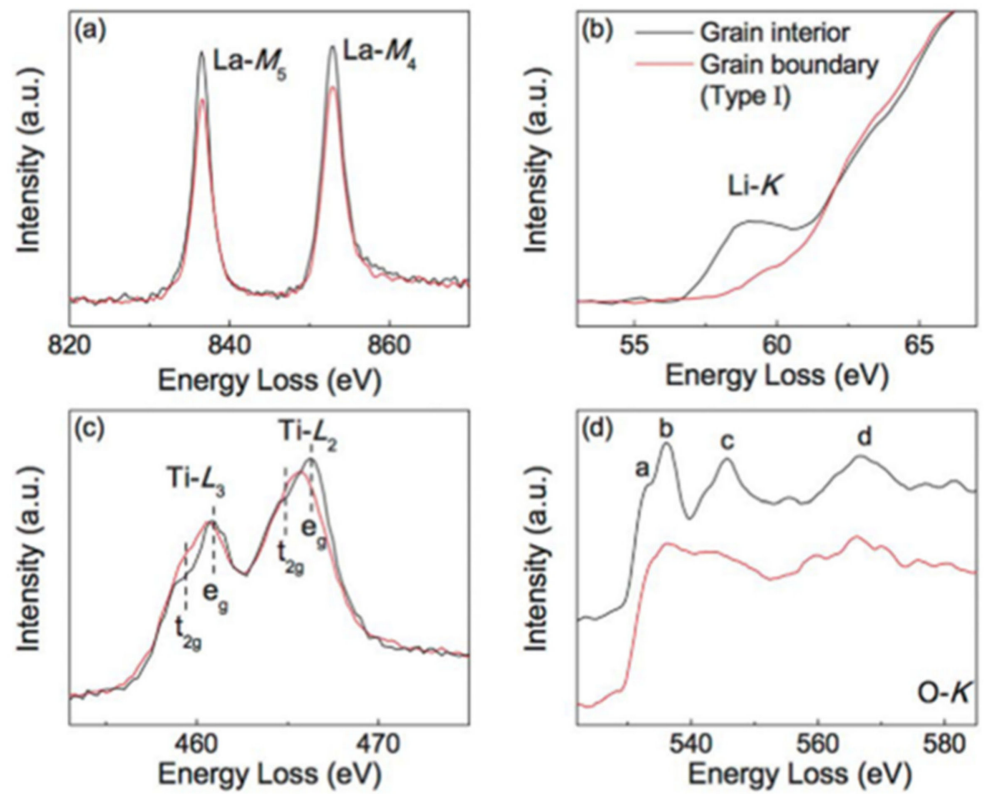

Figure 36. EELS data of (a) La-M $\mathrm{M}_{4,5}$, (b) Li-K, (c) Ti-L2,3, and (d) O-K edges for the type I GB and the bulk. The spectra were normalized to the integrated intensity of the Ti- $\mathrm{L}_{2,3}$ edge [20]. Reproduced from [20] with permission from the Royal Society of Chemistry, Copyright 2014.

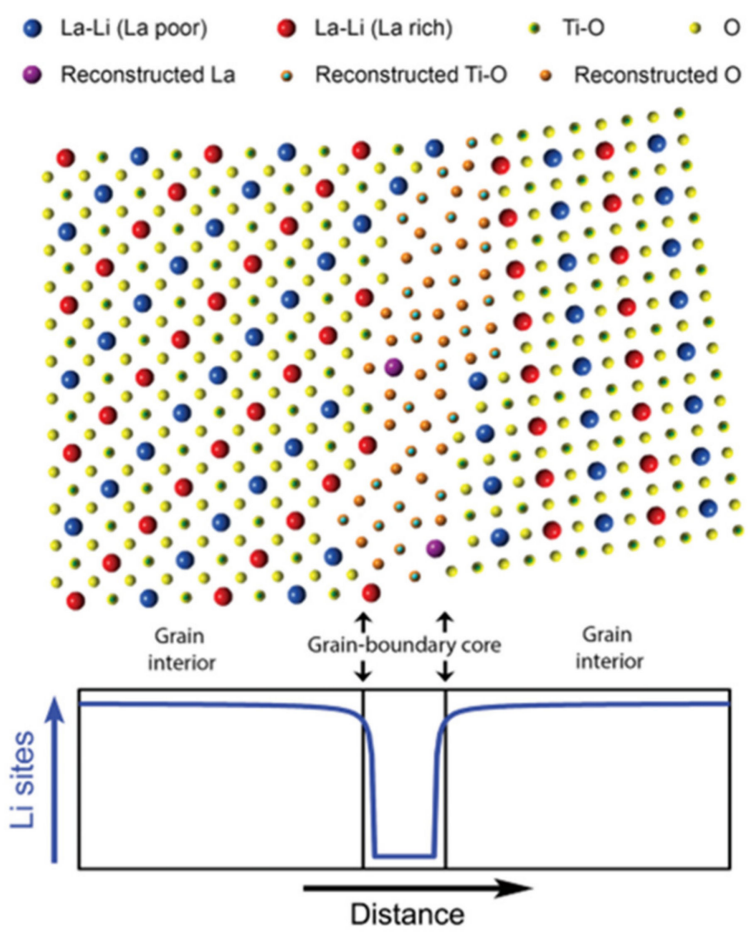

Figure 37. Schematic of the atomic configuration of the type I GB based on the HAADF-STEM images and EELS analysis, along with an illustration of the Li site distribution across type I GB [20]. Reproduced from [20] with permission from the Royal Society of Chemistry, Copyright 2014.

\subsection{Thermal Properties}

Another functional property that can be affected by the segregations at the GBs are thermal conductivity and thermoelectric characteristics. While most of the literature in this area is related to metals and non-oxide ceramics [265-267], there still exist a few studies that correlate thermal conductivity to segregation at the GB. In a work done by Boyle, et al. [268], it was proven that the addition of bismuth dopant to the calcium cobaltite structure, has 
improved Seebeck factor (a measure of the magnitude of an induced thermoelectric voltage in response to a temperature difference across the material [269]) and thermal conductivity, increasing the power factor in this material that can potentially be used as thermoelectric generators, coolers, etc. Segregation of bismuth at the GB plane is evident in Figure 38 captured using TEM and HAADF imaging [268].

Furthermore, it was shown previously that the combination of lattice dopants substitution and secondary phase segregation at the GB has dramatically increased the energy conversion efficiency in Bi-doped $\mathrm{CaMnO}_{3-\delta}$. In this case $\mathrm{CuO}$ segregates at the $\mathrm{GB}$, leading to a significant increase of both the Seebeck coefficient and electrical conductivity (Figure 39) [268].

Using S/TEM techniques, it is possible to learn about grain texture and orientations to correlate that to the properties, as done in a work by Shi et al. [271]. It has been demonstrated in the literature that GB has a huge impact on thermal conductivities of polycrystalline ceramics, including oxides $[270,272,273]$. GB engineering has shown to be a better way for improving thermal resistance of materials such as nanocrystalline yttria-stabilized zirconia and alumina ceramics and refractories [273]. While the impact of GBs is evident, a more comprehensive study of the nature of the structure and chemistry of the boundaries and their interaction with phonons is required to optimize such properties.
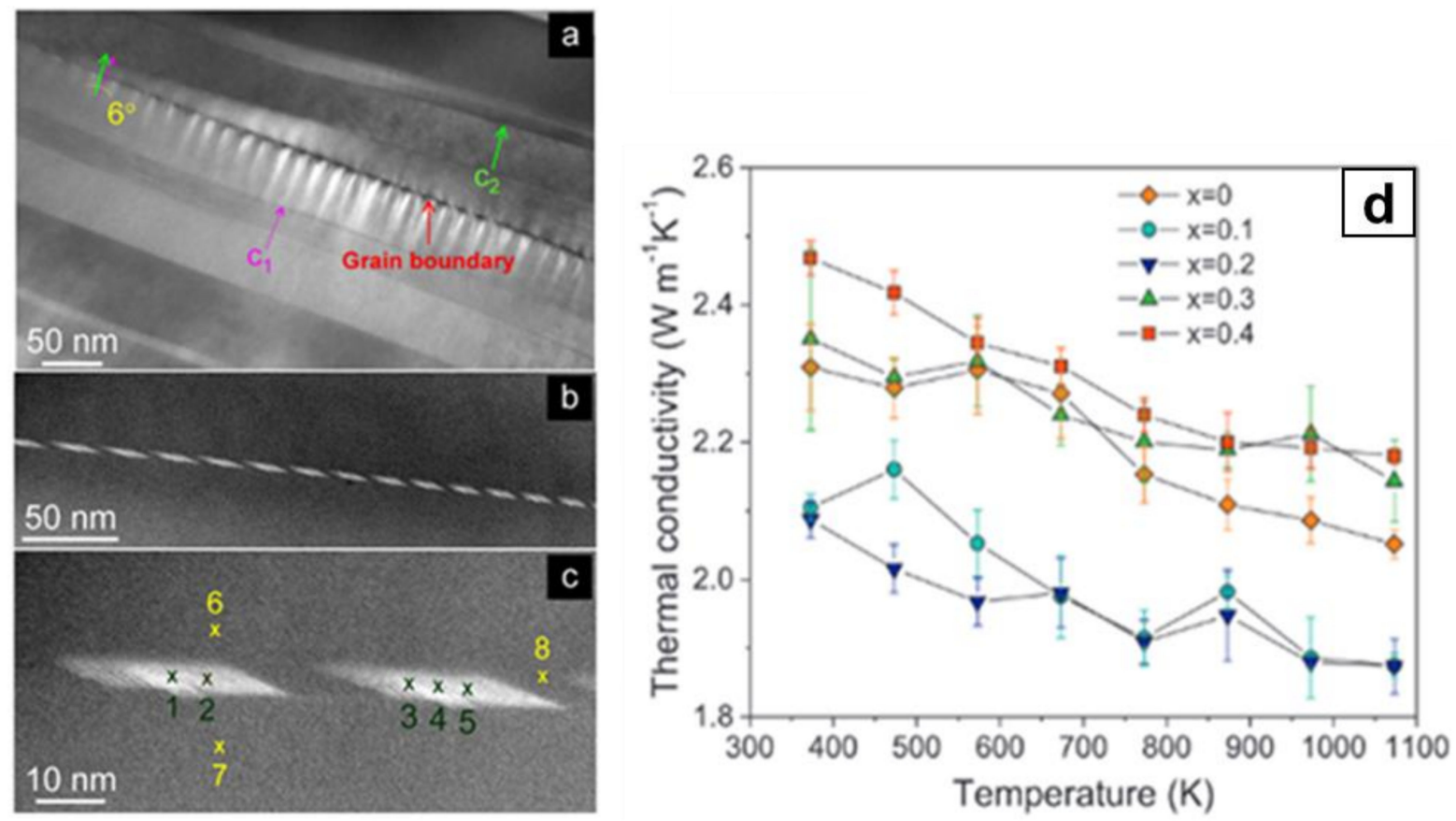

Figure 38. Nanostructure examination of $\mathrm{Ca}_{2.7} \mathrm{Bi}_{0.3} \mathrm{Co}_{4} \mathrm{O}_{9}$. (a) Low magnification TEM diffraction contrast image shows typical GB and the adjacent two grains. The pink arrow $C_{1}$ and the green arrows $C_{2}$ indicate the different c-axis orientations of such two neighboring grains and the misorientation angle is about $6^{\circ}$. (b), Low magnification STEM-Z contrast image from the same GB as indicated in (a). (c) High magnification STEM Z-contrast image of the same GB indicated in b, showing two segregation sites. (d)Temperature dependence of the thermal conductivity of $\mathrm{Ca}_{3-\mathrm{x}} \mathrm{Bi}_{\mathrm{x}} \mathrm{Co}_{4} \mathrm{O}_{9}$ with $\mathrm{x}=0,0.1,0.2,0.3$ and 0.4 [268]. Figure 38 reprinted from Journal of the European Ceramic Society, 36, Cullen Boyle, Paulo Carvillo, Yun Chen, Ever J. Barbero, DustinMcintyre, Xueyan Song, Grain boundary segregation and thermoelectric performance enhancement of bismuth doped calcium cobaltite, 601-607, Copyright (2015), with permission from Elsevier. 
(a)

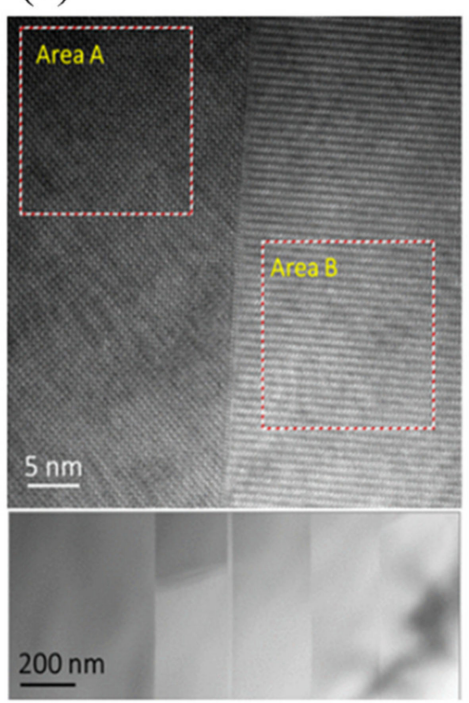

(b)

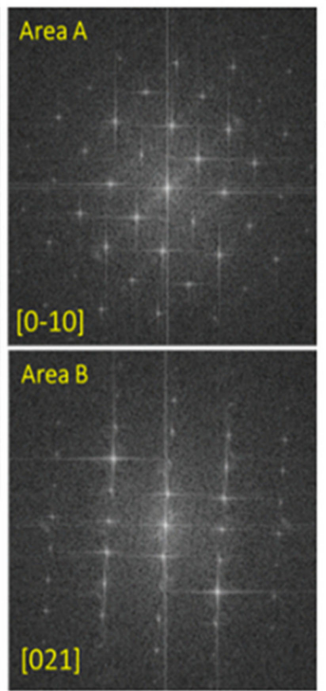

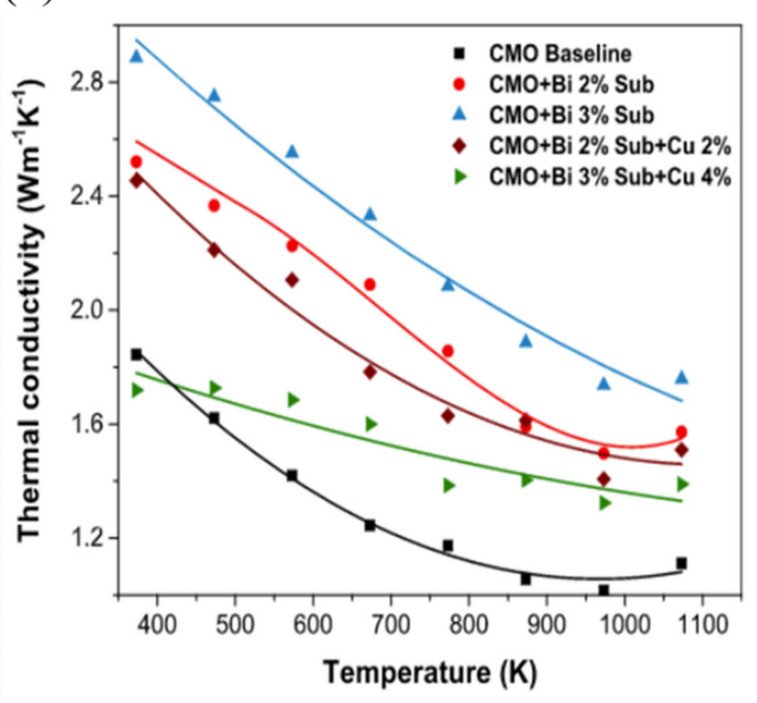

Figure 39. (a) HRTEM image taken from the $\mathrm{Cu}$-added Bi-doped $\mathrm{Ca} \mathrm{MnO}_{3-\delta}$ samples. Fourier transformation from the corresponding nanodomains with different orientation. (b)Temperature dependence of thermal conductivity in $\mathrm{Ca}_{1-\mathrm{x}} \mathrm{Bi}_{\mathrm{x}} \mathrm{MnCu}_{\mathrm{y}} \mathrm{O}_{3-\delta}$ [270]. Reprinted from ACS Applied Materials \& Interfaces, Grain Boundary Phase Segregation for Dramatic Improvement of the Thermoelectric Performance of Oxide Ceramics, Xueyan Song, Sergio A. Paredes Navia, Liang Liang, Cullen Boyle, Cesar-Octavio Romo-De-La-Cruz, Bryan Jackson, Alec Hinerman, Megan Wilt, Jacky Prucz, and Yun Chenwith, 2018, 10, 45, 39018-39024, with permission from American Chemical Society (2018).

\subsection{Mechanical Properties}

As a general type of planar defect, GBs in ceramics play an important role in their deformation mechanisms, such as GB sliding and intergranular fracture. Changes in the structure and chemistry of GBs could strongly influence the mechanical properties of ceramics. Tremendous research efforts have been devoted to enhancing the mechanical properties via GB engineering approaches that include controlling the grain size [90,274-277]; doping with dilute amount of rare earth elements [90,278,279]; forming glassy nanolayer films at GBs [200,280]; and optimizing the GB character distribution by introducing a high frequency of low-angle GBs [281]. Despite these important improvements, fundamental breakthroughs in the understanding of the correlations between GB structure and mechanical response is needed for the development of ceramic components with superior mechanical reliability.

Accurately determining the structure, chemical composition and bonding state at GBs is critical to unveil the structure-mechanical property relationships. GB non-stoichiometry often strongly influences the mechanical properties. As one of the most widely used structural ceramics, $\mathrm{Al}_{2} \mathrm{O}_{3}$ has a weak resistance to creep at high temperatures via GB sliding, while its creep resistance could be effectively improved by the addition of rare earth elements. Ikuhara, et al. [278,279] observed a segregation layer rich in Ln cations at GBs using HRTEM, EDXS and EELS. Such non-stoichiometry at GBs contributes to the dopant-dependent creep resistance in Ln oxide-doped $\mathrm{Al}_{2} \mathrm{O}_{3}$, although questions remain regarding its atomistic mechanisms (Figure 40). Later studies identified the atomicscale location of rare earth atoms at the expanded sites along GBs, which leads to an increase in the number of bonds and bond strength at GBs [200]. This finding suggests the enhancement in creep resistance could be affected by the ionic radii of rare earth dopants. Towards three-dimensional characterization of the GB segregation, a buried GB in Y-doped $\mathrm{Al}_{2} \mathrm{O}_{3}$ was studied under off-axis illumination condition using HAADF STEM, which revealed an ordered two-dimensional structure of $Y$ dopants on the GB with local disordering. In addition to dopant segregation, locations of oxygen vacancies on GBs were 
determined by HAADF and ADF STEM and EELS, underlining the importance of oxygen non-stoichiometry on the mechanical properties in oxides [7,282].

Furthermore, microstructural characterization of mechanically tested ceramics could shed light on their deformation mechanisms. Using HR-TEM, the atomic structure of $\mathrm{Al}_{2} \mathrm{O}_{3}$ recovered from shock loading was characterized, and a transition in deformation mechanisms from intergranular fracture and dislocation activities near GBs at low impact pressure to deformation twinning at high impact pressure has been observed [283]. In $B_{4} C$, which is an important super-hard lightweight ceramic, the deformation and failure mechanism has long been controversial. Acquiring experimental evidence on atomic structure of $\mathrm{B}_{4} \mathrm{C}$ is limited by its complex crystal structure with a C-B-C chain and $\mathrm{B}_{11} \mathrm{C}$ icosahedra and low Z-contrast of boron and carbon. Recent developments in aberration-corrected scanning transmission electron microscopy enables microstructural characterization with sub angstrom spatial resolution, particularly for light elements. Using ABF STEM imaging, detailed structure within the amorphous shear bands in nanoindentation tested $\mathrm{B}_{4} \mathrm{C}$ was investigated. Distorted icosahedra structures were found randomly distributed in the amorphous bands, offering insights into the deformation-induced amorphization mechanisms of $B_{4} C$ [284]. Guo et al. characterized the GB structure in nanocrystalline $B_{4} C$ after quasi-static bending tests of cantilever nanobeams. They reported $2 \mathrm{~nm}$ wide amorphous phase at GBs, which is likely induced by GB sliding and corresponds to the breakdown of Hall-Petch relationship in ceramics [181].

(a)

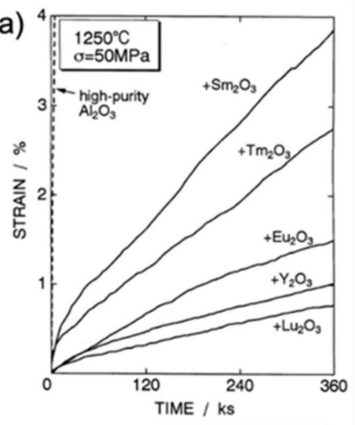

(b)

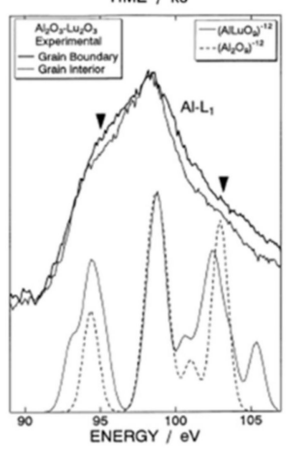

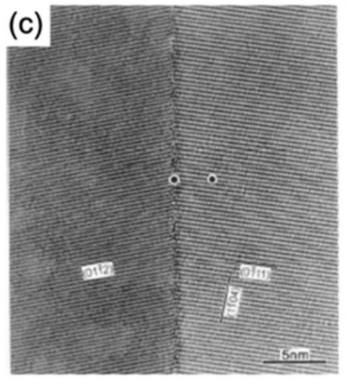

(d)

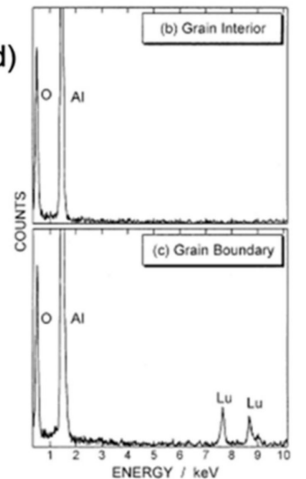

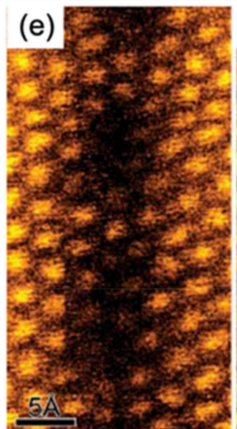

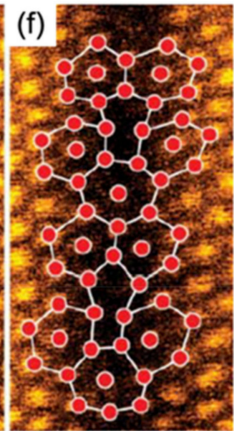

(g)

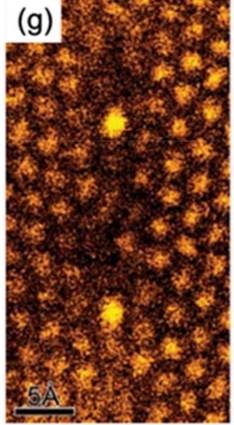

(h)

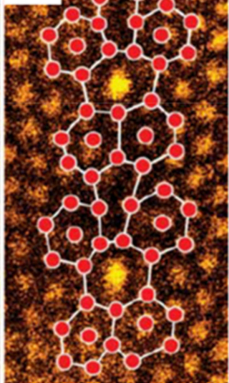

Figure 40. (a) High temperature creep properties of pure $\mathrm{Al}_{2} \mathrm{O}_{3}$ and different Ln oxides-doped $\mathrm{Al}_{2} \mathrm{O}_{3}$; (b) ELNES Al-L $\mathrm{L}_{1}$ edge peak for $\mathrm{Lu}_{2} \mathrm{O}_{3}$-doped $\mathrm{Al}_{2} \mathrm{O}_{3}$ in the grain interior and at a GB. (c) HRTEM micrograph of a GB in $\mathrm{Lu}_{2} \mathrm{O}_{3}$-doped $\mathrm{Al}_{2} \mathrm{O}_{3}$. (d) EDXS point spectra from the grain interior and the GB, corresponding to the two points in (c). (e,g) are HAADF STEM images of a $\Sigma 31$ [0001] tilt GB in pure $\mathrm{Al}_{2} \mathrm{O}_{3}, \mathrm{Y}$-doped $\mathrm{Al}_{2} \mathrm{O}_{3}$, respectively. Brighter columns in (g) are the locations of segregated $\mathrm{Y}$ atoms. $(\mathbf{f}, \mathbf{h})$ are the same images as in $(\mathbf{e}, \mathbf{g})$, respectively, and with schematic overlay to show the arrangement of atomic columns. It is observed that $\mathrm{Y}$ atoms are at the center of the seven-member ring units along the GB [200]. Figure 40a-d reprinted from Materials Science and Engineering: A, Impurity effects on grain boundary strength in structural ceramics, Yuichi Ikuhara, Hidehiro Yoshida, Taketo Sakuma, 2001, 24-30, with permission from Elsevier. Figure 40e-h reprinted from Grain Boundary Strengthening in Alumina by Rare Earth Impurities, J. P. Buban, K. Matsunaga, J. Chen, N. Shibata, W. Y. Ching, T. Yamamoto, Y. Ikuhara, Science 2006, 311, 212-215. Reprinted with permission from AAAS. 


\subsection{Magnetic Properties}

GBs and HIs can affect magnetic behavior of materials such as oxides. For example, lower magnetoresistance at $\mathrm{T} \ll \mathrm{T}_{\mathrm{C}}$ in a polycrystalline $\mathrm{La}_{0.67} \mathrm{Ba}_{0.33} \mathrm{MnO}_{2.99}$ compared to it is single crystal form is related to high volume of GBs present in the former [285]. In another example, ferromagnetic properties of nanocrystalline $\mathrm{Mn}$-doped $\mathrm{ZnO}$ thin films were improved due the existence of greater GB specific area compared to the critical values [286].BF-TEM studies show that the wurtzite lattice of $\mathrm{ZnO}$ is separated by amorphous layers whose thickness increases with the Mn concentration which is controllable (Figure 41). Amorphous phases at GBs and HIs can potentially affect other magnetic properties such as coercivity (resistance of a magnetic material to demagnetization). This is evident in a work by Sepehri-amin et al. [287], where B-enriched amorphous intergranular phases cause the domain wall pinning that is correlated to high coercivity observed in B-doped $\mathrm{Sm}\left(\mathrm{Fe}_{0.8} \mathrm{Co}_{0.2}\right)_{12}$. Lattice distortion and strain in HIs can affect magnetic flux pinning centers leading to high critical density in $\mathrm{SrZrO}_{3}$ [288].
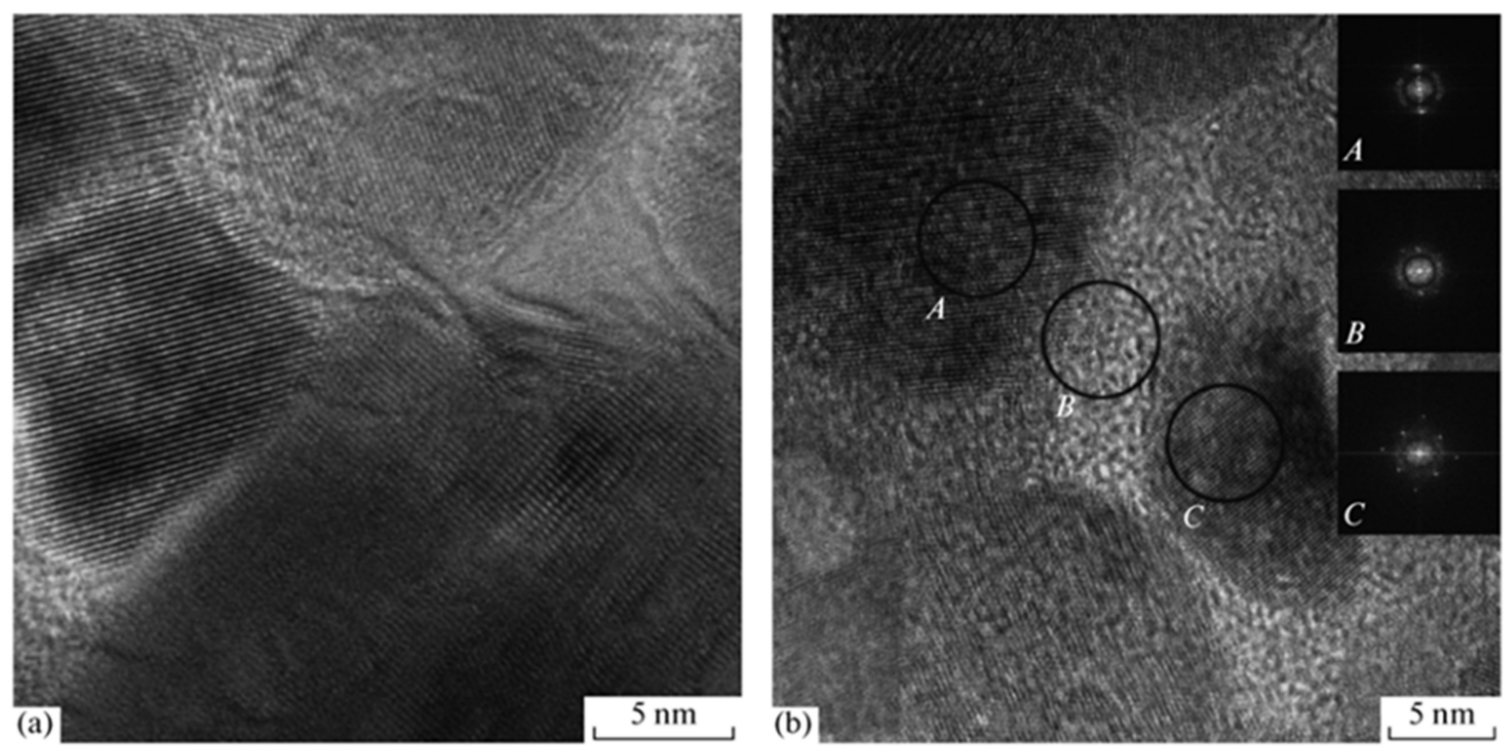

Figure 41. BF-TEM micrographs of doped $\mathrm{ZnO}$ thin films with (a) 10 at $\% \mathrm{Mn} \mathrm{ZnO}$ grains and (b) 15 at $\%$ Mn $\mathrm{ZnO}$ grains, surrounded by amorphous layers. The insets in $(\mathbf{b})$ show the fast Fourier transform patterns for crystalline and amorphous regions, A, B and C, respectively [289]. Figure 41 reprinted by permission from Springer Nature Customer Service Centre $\mathrm{GmbH}$ : Springer Nature, JETP Letters, Grain boundary layers in nanocrystalline ferromagnetic zinc oxide, Straumal, B.B.; Myatiev, A.A.; Straumal, P.B.; Mazilkin, A.A.; Protasova, S.G.; Goering, E.; Baretzky, B., M.H., Copyright @ 2010.

Figure 41 represents the BF-TEM image of Mn-doped $\mathrm{ZnO}$ films with (a) 10 and (b) 15 at $\%$ Mn concentration. The direct resolution of the lattice allows the observation of the crystalline $\mathrm{ZnO}$ grains in wurtzite structure, and it is clearly visible that amorphous phases lie at the areas between the grains or in other words, GBs [289].

The examples mentioned above and more in literature $[290,291]$ prove the importance of GBs and HIs in magnetic behavior of oxides, and therefore highlight the importance of their characterization.

\subsection{Optical Properties}

Polycrystalline ceramics can be transparent, translucent, or opaque [40]. Transparent polycrystalline ceramics have become of interest since Neodymium-doped yttrium aluminum garnet (Nd:YAG) was introduced as a lasing medium for solid state lasers in 1995 [201] and have applications in armors, opto-electrical devices such as solar cells, displays, and circuitries. Compared to single crystals, polycrystalline ceramics are costeffective, easier to produce, exhibit good mechanical, thermal and chemical stability, and 
shape-control availability [292,293]. However, certain defects such as impurities and porosity inside their microstructure scatter and refract light leading to optical losses, thus limiting wide employment of transparent polycrystalline ceramics [203,294]. GBs are one main area accommodating such defects and can impact properties of these materials. The GB structure can also control grain size and phase composition, thus playing a significant role in transmittance of polycrystalline ceramics. Some boundaries with higher doping concentrations show a low reflectance, whereas other boundaries with secondary phases show a bold difference in refractive index with respect to the bulk, becoming the major scattering sources [295]. In addition to impurities, grain size related birefringence also affects the transparency of polycrystalline ceramics based on Rayleigh approximation [296,297]. Therefore, it is important to characterize such defects and interfaces to achieve optimal properties in polycrystals [12-14] For example, S/TEM techniques can help detect the origin of light scattering at interface to improve optical quality. Segregation of elements at the GBs in polycrystalline oxides affect optical properties such as transmittance [148]. In a work by Trunec, et al. [298] polycrystalline alumina was doped with $\mathrm{Zr}$ and spinel nanoparticles to improve in-line transmittance. According to STEM EDXS results, Zr segregated at the GBs shown in Figure 42. According to this study, the segregation has impeded GB motion to achieve grain size refinement in dense alumina structure, thereby lowering light loss by birefringence.

(a)

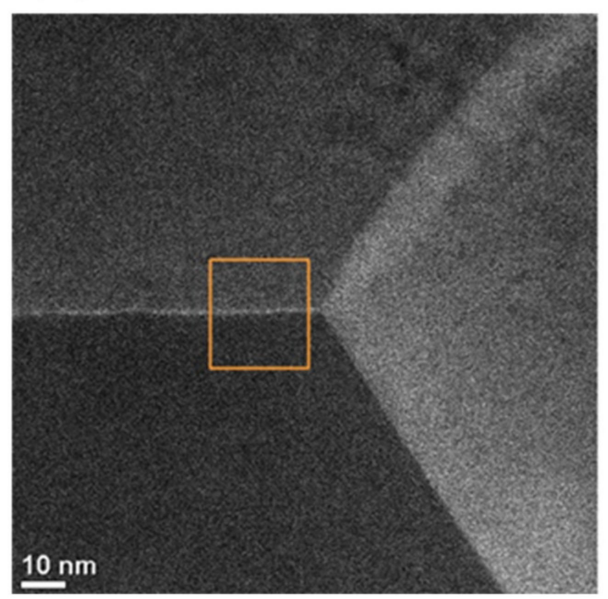

(b)
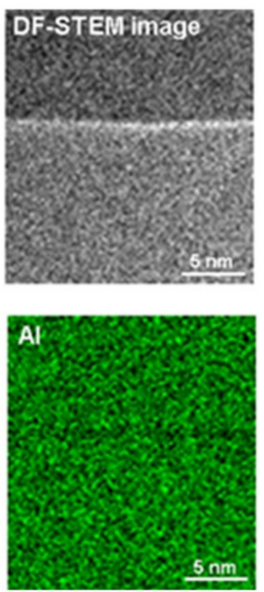
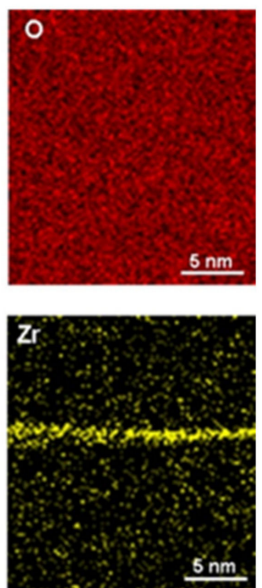

Figure 42. Morphology and element mapping of grain boundaries in $\mathrm{Zr}$-doped $\mathrm{Al}_{2} \mathrm{O}_{3}$. (a) STEM image of a triple junction; (b) DF-STEM image and STEM-EDXS elemental mapping of the selected GB area [298]. Figure 42 reprinted from Journal of the European Ceramic Society, 35, Martin Trunec, Karel Maca, Radim Chmelik, Polycrystalline alumina ceramics doped with nanoparticles forincreased transparency, 1001-1009, Copyright (2014), with permission from Elsevier.

In addition to intentional doping, small amounts of impurities in raw material can impact the microstructure and properties of transparent magnesium aluminate spinel $\left(\mathrm{MgAl}_{2} \mathrm{O}_{4}\right)$ [299]. Impurities such as carbon, sulfur and silicon tend to segregate and form amorphous phases at GBs and triple junctions (Figure 43a-c) and restrict grain growth by GB pinning and solute dragging mechanisms. Hence, sub-micrometer grains increase GB volume fraction and impurity segregation at GBs discontinues light transmittance by increase in light scattering, leading to opacity (Figure $43 \mathrm{f}$ ). LiF reacts with impurities, forming volatile species. These products can be easily removed in high temperature to clean $\mathrm{GB}$ and facilitate grain growth. Clean GBs greatly improve transparency of the $\mathrm{MgAl}_{2} \mathrm{O}_{4}$ that can be used as transparent armor and IR-seeking missile domes (Figure 43d-g). 

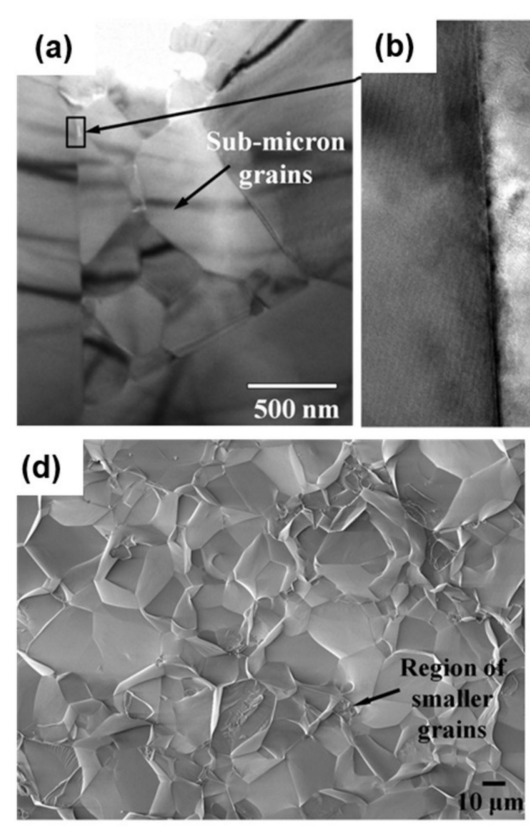

(b)

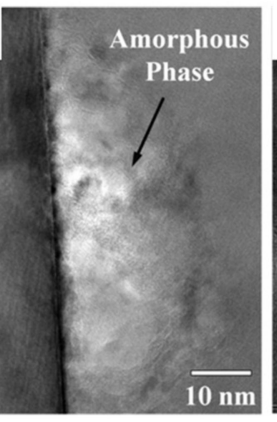

(e)

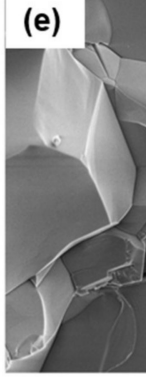

(c)

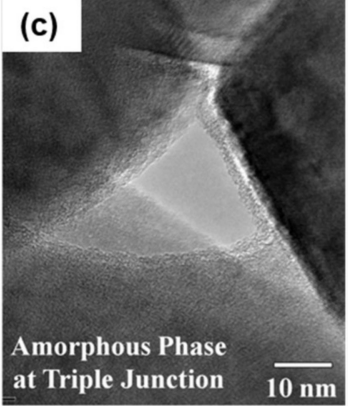

$\mathrm{MgAl}_{2} \mathrm{O}_{4}$ Pellets with $1.5 \mathrm{~g}$

$\sim 2 \mathrm{~mm}$ in thickness (f)

(g)

$1 \mathrm{wt} \%$

$\mathrm{LiF}$

(f)

No LiF

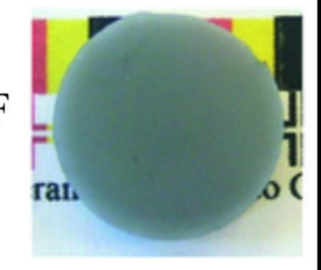

II

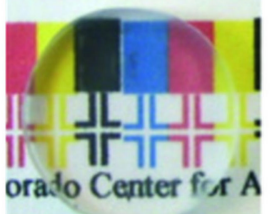

Figure 43. Microstructure of $\mathrm{MgAl}_{2} \mathrm{O}_{4}$ spinel by low-purity powder hot-pressed at $1200{ }^{\circ} \mathrm{C}$ without $\mathrm{LiF}$ (a-c,f) and with $1 \mathbf{w t} \% \operatorname{LiF}(\mathbf{d}, \mathbf{e}, \mathbf{g})$. (a) TEM image of sub-micrometer grains; (b) TEM image of amorphous phase at interface between matrix grains and sub-micrometer grains; (c) TEM image of amorphous phase at triple junctions; (d) SEM image of matrix grains (e) SEM image of micrometer grains; (f) digital image of a $\mathrm{MgAl}_{2} \mathrm{O}_{4}$ pellet without $\mathrm{LiF}$; (g) digital image of a $\mathrm{MgAl}_{2} \mathrm{O}_{4}$ pellet with $1 \mathrm{wt} \% \mathrm{LiF}$ [299]. Figure 43 reprinted from International Journal of the American Ceramic Society, 10, Marc Rubat $\mathrm{du}$ Merac and Ivar E. Reimanis, Effect of Impurities and LiF Additive in Hot-Pressed Transparent Magnesium Aluminate Spinel, E33-E48, Copyright (2012), with permission from John Wiley and Sons.

\section{Conclusions and Future Perspective}

Recent and continual advancements in electron microscopy hardware, data acquisition and processing algorithms, three-dimensional analyses, and innovative workflows provide enormous potential to the field of interfacial characterization. An overarching goal of high-resolution analysis is to such fine-scale data to develop models capable of predicting macroscopic structure-property relationships. However, it is indeed challenging to collect a statistically significant amount of observations/data using S/TEM, simply because one needs to prepare many samples and analyze tens, hundreds or even thousands of interfaces, all of which might vary slightly in their atomic scale nature (e.g., atomic structure and chemistry). Therefore, there is significant potential in automation of such measurements using machine learning and artificial intelligence.

It is imperative to consider the limitations of S/TEM while using and planning to use it. Direct observations made with the help of powerful electron microscopes give us valuable insights to the underlying science of interfaces. But these techniques focus on a small volume of material, likely subject to multiple specimen preparation steps as mentioned earlier, and by the time the specimen is observed, the material may be somewhat different than the material in bulk form. Thus, the authors strongly suggest that (potential) users keep this in mind and be aware of possible impacts of preparation steps.

There is a clear lack in literature on heterointerface characterization in multiphase polycrystalline ceramics. The added complexity of such systems due to existence of several phases and defects makes such studies more challenging and resource intensive. While the majority ceramics community focuses on single phase oxides due to their promising properties, mixed phase counterparts have proven to be of importance in various fields such as structural materials, thermoelectric materials, and mixed ion electron conductors (where one or more phases dominate the electron conduction while the other/others maintain ion conduction). It is expected that advancements in high-throughput automated 
EM, including the ones mentioned in this paper, will enable more investigation of GBs/HIs in multiphase polycrystalline systems.

Lastly, in-situ and in-operando studies of interfaces in functional materials, and those sensitive to our atmosphere and electron beam irradiation are very promising, even though there are limited studies at present. This will likely change with recent and future technological and workflow advancements in EM, such as sample preparation and cryo-EM methods for sensitive materials, such as alkali ion conductors. Such dynamic experiments on interfaces (and nanomaterials more generally) are particularly exciting due to the possibility of observing reactions, degradation, and mechanisms underlying interface functionality.

In closing, while there are many experimental and practical considerations to make when undertaking such a study, the authors hope this article paves the way for more scientists and engineers interested in using S/TEM techniques to study and develop interfacial sciences, particularly in ceramic oxides.

Author Contributions: H.V. and W.J.B. conceived the idea of the review. H.V. wrote most of the paper and H.V. and W.J.B. did critical revision. K.S. contributed to useful discussions and wrote part of the introduction and the EDXS technique section. X.W. wrote the mechanical properties and in-situ S/TEM sections. J.L.W. wrote the introduction to TEM and STEM with inputs from H.G. and J.M. H.G. wrote parts of the optical and magnetic properties sections. All authors have read and agreed to the published version of the manuscript.

Funding: This research was funded by the National Science Foundation Materials Research Science and Engineering Center program through the UC Irvine Center for Complex and Active Materials (NSF DMR-2011967).

Acknowledgments: H.V. and X.W. acknowledge funding by the National Science Foundation Materials Research Science and Engineering Center program through the UC Irvine Center for Complex and Active Materials (NSF DMR-2011967). K.S. acknowledges NSF DMR 1611457 and support from US Department of Education Graduate Assistance in Areas of National Need (GAANN) Fellowship. J.L.W. and W.J.B. acknowledge funding under the award NSF DMR-2042638. J.M. acknowledges funding under the award NSF Graduate Research Fellowship. H.G. and W.J.B. acknowledge funding from the American Chemical Society's Petroleum Research Fund Doctoral New Investigator Grant. W.J.B. acknowledges funding from the UC Irvine School of Engineering new faculty set-up funding.

Conflicts of Interest: The authors declare no conflict of interest.

\section{References}

1. Reynolds, W.T. Interfaces in Crystalline Materials By, A.P. Sutton (University of Oxford) and R. W. Balluffi (MIT). Oxford University Press: New York. 1995. xxvii + 819 pp. \$165. ISBN 0-19-851385-2. J. Am. Chem. Soc. 1997, 119, 2343-2343. [CrossRef]

2. Pryds, N.; Esposito, V.; Dk, N.; Dk, V. When two become one: An insight into 2D conductive oxide interfaces. J. Electroceramics 2017, 38, 1-23. [CrossRef]

3. Klie, R.F.; Ito, Y.; Stemmer, S.; Browning, N.D. Observation of oxygen vacancy ordering and segregation in Perovskite oxides. Ultramicroscopy 2001, 86, 289-302. [CrossRef]

4. Carter, C.B.; Norton, M.G. Ceramic Materials: Science and Engineering; Springer: Berlin/Heidelberg, Germany, $2007 ;$ Volume 716.

5. Lin, Y.; Fang, S.; Su, D.; Brinkman, K.S.; Chen, F. Enhancing grain boundary ionic conductivity in mixed ionic-electronic conductors. Nat. Commun. 2015, 6, 6824. [CrossRef]

6. Feng, B.; Lugg, N.R.; Kumamoto, A.; Ikuhara, Y.; Shibata, N. Direct Observation of Oxygen Vacancy Distribution across Yttria-Stabilized Zirconia Grain Boundaries. ACS Nano 2017, 11, 11376-11382. [CrossRef]

7. Bowman, W.J.; Darbal, A.; Crozier, P.A. Linking Macroscopic and Nanoscopic Ionic Conductivity: A Semiempirical Framework for Characterizing Grain Boundary Conductivity in Polycrystalline Ceramics. ACS Appl. Mater. Interfaces 2020, 12, 507-517. [CrossRef] [PubMed]

8. Bowman, W.J.; Zhu, J.; Sharma, R.; Crozier, P.A. Electrical conductivity and grain boundary composition of Gd-doped and Gd/Pr co-doped ceria. Solid State Ion. 2015, 272, 9-17. [CrossRef]

9. Orlovskaya, N.; Browning, N. (Eds.) Mixed Ionic Electronic Conducting Perovskites for Advanced Energy Systems; Springer Science \& Business Media: Secaucus, NJ, USA, 2012; Volume 173.

10. Dong, Y.; Zhang, Z.; Alvarez, A.; Chen, I.-W. Potential jumps at transport bottlenecks cause instability of nominally ionic solid electrolytes in electrochemical cells. Acta Mater. 2020, 199, 264-277. [CrossRef] 
11. Giuntini, D.; Torresani, E.; Chan, K.T.; Blankenburg, M.; Saviot, L.; Bor, B.; Domènech, B.; Shachar, M.; Müller, M.; Olevsky, E.A.; et al. Iron oxide-based nanostructured ceramics with tailored magnetic and mechanical properties: Development of mechanically robust, bulk superparamagnetic materials. Nanoscale Adv. 2019, 1, 3139-3150. [CrossRef]

12. Gilde, G.; Patel, P.; Sands, J.; Patterson, P.; Blodgett, D.; Duncan, D.; Hahn, D. Evaluation of hot isostatic pressing parameters on the optical and ballistic properties of spinel for transparent armor. Army Res. Lab. Aberd. Proving Ground Md 2006, 88, 2747-2751.

13. Sutorik, A.C.; Gilde, G.; Kilczewski, S.; Patel, P.; Sands, J.M. Development of transparent ceramic spinel (MgAl2O4) for armor applications. In Proceedings of the Optics InfoBase Conference Papers, Optical Society of America, Jackson Hole, WY, USA, 13-17 June 2010; p. OWA6.

14. Lange, F.F.; Clarke, D.R. Morphological Changes of an Intergranular Thin Film in a Poly crystalline Spinel. J. Am. Ceram. Soc. 1982, 65, 502-506. [CrossRef]

15. Smith, D.; Auvray, S.; Absi, J.; Kadiebu, S.; Fayette, S. Grain-boundary thermal resistance in polycrystalline oxides: Alumina, tin oxide, and magnesia. High. Temp. High. Press. 2003, 35-36, 93-99. [CrossRef]

16. Szot, K.; Rodenbücher, C.; Bihlmayer, G.; Speier, W.; Ishikawa, R.; Shibata, N.; Ikuhara, Y. Influence of dislocations in transition metal oxides on selected physical and chemical properties. Crystals 2018, 8, 241. [CrossRef]

17. Kingery, W.D.; Bowen, H.K.; Uhlmann, D.R. Introduction to Ceramics; John Wiley \& Sons: Hoboken, NJ, USA, 1976 ; Volume 17.

18. Mebane, D.S.; De Souza, R.A. A generalised space-charge theory for extended defects in oxygen-ion conducting electrolytes: From dilute to concentrated solid solutions. Energy Environ. Sci. 2015, 8, 2935-2940. [CrossRef]

19. Xu, X.; Liu, Y.; Wang, J.; Isheim, D.; Dravid, V.P.; Phatak, C.; Haile, S.M. Variability and origins of grain boundary electric potential detected by electron holography and atom-probe tomography. Nat. Mater. 2020, 19, 887-893. [CrossRef] [PubMed]

20. Ma, C.; Chen, K.; Liang, C.; Nan, C.W.; Ishikawa, R.; More, K.; Chi, M. Atomic-scale origin of the large grain-boundary resistance in perovskite Li-ion-conducting solid electrolytes. Energy Environ. Sci. 2014, 7, 1638-1642. [CrossRef]

21. Bowman, W.J.; Kelly, M.N.; Rohrer, G.S.; Hernandez, C.A.; Crozier, P.A. Enhanced ionic conductivity in electroceramics by nanoscale enrichment of grain boundaries with high solute concentration. Nanoscale 2017, 9, 17293-17302. [CrossRef]

22. Tong, X.; Bowman, W.J.; Mejia-Giraldo, A.; Crozier, P.A.; Mebane, D.S. New Data-Driven Interacting-Defect Model Describing Nanoscopic Grain Boundary Compositions in Ceramics. J. Phys. Chem. C 2020, 124, 23619-23625. [CrossRef]

23. Alekseeva, I.; Dymshits, O.; Tsenter, M.; Zhilin, A.; Golubkov, V.; Denisov, I.; Skoptsov, N.; Malyarevich, A.; Yumashev, K. Optical applications of glass-ceramics. J. Non Cryst. Solids 2010, 356, 3042-3058. [CrossRef]

24. Cao, X.Q.; Vassen, R.; Stoever, D. Ceramic materials for thermal barrier coatings. J. Eur. Ceram. Soc. 2004, 24, 1-10. [CrossRef]

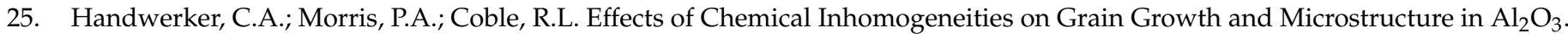
J. Am. Ceram. Soc. 1989, 72, 130-136. [CrossRef]

26. Shibata, N.; Findlay, S.D.; Azuma, S.; Mizoguchi, T.; Yamamoto, T.; Ikuhara, Y. Atomic-scale imaging of individual dopant atoms in a buried interface. Nat. Mater. 2009, 8, 654-658. [CrossRef]

27. An, J.; Park, J.S.; Koh, A.L.; Lee, H.B.; Jung, H.J.; Schoonman, J.; Sinclair, R.; Gür, T.M.; Prinz, F.B. Atomic scale verification of oxide-ion vacancy distribution near a single grain boundary in YSZ. Sci. Rep. 2013, 3, 1-6. [CrossRef] [PubMed]

28. Lu, X.; Xia, G.; Lemmon, J.P.; Yang, Z. Advanced materials for sodium-beta alumina batteries: Status, challenges and perspectives. J. Power Sources 2010, 195, 2431-2442. [CrossRef]

29. Yoon, H.; Choi, M.; Lim, T.W.; Kwon, H.; Ihm, K.; Kim, J.K.; Choi, S.Y.; Son, J. Reversible phase modulation and hydrogen storage in multivalent $\mathrm{VO}_{2}$ epitaxial thin films. Nat. Mater. 2016, 15, 1113-1119. [CrossRef]

30. Oshima, Y.; Lee, S.; Takayanagi, K. Visualization of lithium ions by annular bright field imaging. Microscopy 2017, 66, 15-24. [CrossRef]

31. Bowman, W.J.; Hernandez, C.A.; McGuinness, K.; Crozier, P.A. Quantifying and Correlating the Composition and Conductivity of Grain Boundaries in Ca-doped $\mathrm{CeO}_{2}$ Electrolytes, an AC-STEM EELS Study. Microsc. Microanal. 2015, 21, 1727-1728. [CrossRef]

32. Garvie, L.A.J.; Buseck, P.R. Determination of $\mathrm{Ce}^{4+} / \mathrm{Ce}^{3+}$ in electron-beam-damaged $\mathrm{CeO}_{2}$ by electron energy-loss spectroscopy. J. Phys. Chem. Solids 1999, 60, 1943-1947. [CrossRef]

33. Lei, Y.; Ito, Y.; Browning, N.D.; Mazanec, T.J. Segregation Effects at Grain Boundaries in Fluorite-Structured Ceramics. J. Am. Ceram. Soc. 2002, 85, 2359-2363. [CrossRef]

34. Hojo, H.; Mizoguchi, T.; Ohta, H.; Findlay, S.D.; Shibata, N.; Yamamoto, T.; Ikuhara, Y. Atomic structure of a CeO 2 grain boundary: The role of oxygen vacancies. Nano Lett. 2010, 10, 4668-4672. [CrossRef]

35. Dufour, L.; Monty, C. Surfaces and Interfaces of Ceramic Materials; Springer Science \& Business Media: Berlin/Heidelberg, Germany, 2012.

36. McGee, T.D. Grain boundaries in ceramic materials. In Materials Science Research; Springer: Berlin/Heidelberg, Germany, 1965; pp. 3-32.

37. Ernst, F.; Kienzle, O.; Rühle, M. Structure and Composition of Grain Boundaries in Ceramics. J. Eur. Ceram. Soc. 1999, 19, 665-673. [CrossRef]

38. Clarke, D. Grain Boundaries In Polycrystalline Ceramics. Annu. Rev. Mater. Sci. 2003, 17, 57-74. [CrossRef]

39. Kingery, W.D. The chemistry of ceramic grain boundaries. Pure Appl. Chem. 1984, 56, 1703-1714. [CrossRef]

40. Burgers, J.M. Geometrical considerations concerning the structural irregularities to be assumed in a crystal. Proc. Phys. Soc. 1940, 52, 23-33. [CrossRef] 
41. Syed, K.; Xu, M.; Ohtaki, K.K.; Kok, D.; Karandikar, K.K.; Graeve, O.A.; Bowman, W.J.; Mecartney, M.L. Correlations of grain boundary segregation to sintering techniques in a three-phase ceramic. Materialia 2020, 14, 100890. [CrossRef]

42. Smallman, R.E.; Ngan, A.H.W. Chapter 10-Surfaces, grain boundaries and interfaces. In Modern Physical Metallurgy, 8th ed.; Elsevier: Oxford, UK, 2014; pp. 415-442. ISBN 978-0-08-098204-5.

43. Porter, D.A.; Easterling, K.E. Phase Transformations in Metals and Alloys (Revised Reprint); CRC Press: Boca Raton, FL, USA, 2009.

44. Olmsted, D.L.; Foiles, S.M.; Holm, E.A. Survey of computed grain boundary properties in face-centered cubic metals: I. Grain boundary energy. Acta Mater. 2009, 57, 3694-3703. [CrossRef]

45. Randle, V. 'Special' boundaries and grain boundary plane engineering. Scr. Mater. 2006, 54, 1011-1015. [CrossRef]

46. Ghamarian, I.; Samimi, P.; Rohrer, G.S.; Collins, P.C. Determination of the five parameter grain boundary character distribution of nanocrystalline alpha-zirconium thin films using transmission electron microscopy. Acta Mater. 2017, 130, 164-176. [CrossRef]

47. Guziewski, M.; Banadaki, A.D.; Patala, S.; Coleman, S.P. Application of Monte Carlo techniques to grain boundary structure optimization in silicon and silicon-carbide. Comput. Mater. Sci. 2020, 182, 109771-109771. [CrossRef]

48. Echeverri Restrepo, S.; Tamayo Giraldo, S.; Thijsse, B.J. Using artificial neural networks to predict grain boundary energies. Comput. Mater. Sci. 2014, 86, 170-173. [CrossRef]

49. Kim, H.K.; Ko, W.S.; Lee, H.J.; Kim, S.G.; Lee, B.J. An identification scheme of grain boundaries and construction of a grain boundary energy database. Scr. Mater. 2011, 64, 1152-1155. [CrossRef]

50. Soifer, Y.M.; Verdyan, A.; Kazakevich, M.; Rabkin, E. Nanohardness of copper in the vicinity of grain boundaries. Scr. Mater. 2002, 47, 799-804. [CrossRef]

51. Han, J.; Thomas, S.L.; Srolovitz, D.J. Grain-Boundary Kinetics: A Unified Approach. Prog. Mater. Sci. 2018, 98, 386-476. [CrossRef]

52. Pérez-Pérez, F.J.; Smith, R. Structural changes at grain boundaries in bcc iron induced by atomic collisions. Nucl. Instrum. Methods Phys. Res. Sect. b Beam Interact. Mater. At. 2020, 164, 487-494. [CrossRef]

53. Dickey, E.C.; Fan, X.; Pennycook, S.J. Structure and chemistry of yttria-stabilized cubic-zirconia symmetric tilt grain boundaries. J. Am. Ceram. Soc. 2001, 84, 1361-1368. [CrossRef]

54. Tochigi, E.; Nakamura, A.; Shibata, N.; Ikuhara, Y. Dislocation Structures in Low-Angle Grain Boundaries of $\alpha-\mathrm{Al}_{2} \mathrm{O}_{3}$. Crystals 2018, 8, 133. [CrossRef]

55. Gottstein, G. Physical Foundations of Materials Science; Springer: Berlin Heidelberg, Germany, 2004; ISBN 978-3-540-40139-1.

56. Dillon, S.J.; Tang, M.; Carter, W.C.; Harmer, M.P. Complexion: A new concept for kinetic engineering in materials science. Acta Mater. 2007, 55, 6208-6218. [CrossRef]

57. Wang, Y.; Wang, C.; Yuan, L.; Cai, R.; Liu, X.; Li, C.; Zhou, G. Coincidence-site-lattice twist boundaries in bicrystalline $\alpha$-Fe ${ }_{2} \mathrm{O}_{3}$ nanoblades. J. Phys. Chem. C 2014, 118, 5796-5801. [CrossRef]

58. Sato, Y.; Buban, J.P.; Mizoguchi, T.; Shibata, N.; Yodogawa, M.; Yamamoto, T.; Ikuhara, Y. Role of Pr segregation in acceptor-state formation at ZnO grain boundaries. Phys. Rev. Lett. 2006, 97, 106802. [CrossRef] [PubMed]

59. Shibata, N.; Painter, G.S.; Satet, R.L.; Hoffmann, M.J.; Pennycook, S.J.; Becher, P.F. Rare-earth adsorption at intergranular interfaces in silicon nitride ceramics: Subnanometer observations and theory. Phys. Rev. B 2005, 72, 140101. [CrossRef]

60. Imai, H. Mesostructured crystals: Growth processes and features. Prog. Cryst. Growth Charact. Mater. 2016, 62, 212-226. [CrossRef]

61. Schuler, J.D.; Rupert, T.J. Materials selection rules for amorphous complexion formation in binary metallic alloys. Acta Mater. 2017, 140, 196-205. [CrossRef]

62. Cantwell, P.R.; Frolov, T.; Rupert, T.J.; Krause, A.R.; Marvel, C.J.; Rohrer, G.S.; Rickman, J.M.; Harmer, M.P. Grain boundary complexion transitions. In Annual Review of Materials Research; Annual Reviews Inc.: Palo Alto, CA, USA, 2020; Volume 50, pp. 465-492.

63. Mwema, F.; Akinlabi, E.; Oladijo, O. Sputtered Thin Films: Theory and Fractal Descriptions; CRC Press: Boca Raton, FL, USA, 2021.

64. Liu, H. Growth kinetics of thin film epitaxy. In 21st Century Surface Science-A Handbook; IntechOpen: London, UK, 2020.

65. Hubler, G.K. Pulsed Laser Deposition. MRS Bull. 1992, 17, 26-29. [CrossRef]

66. Sediva, E.; Bowman, W.J.; Gonzalez-Rosillo, J.C.; Rupp, J.L. Investigation of the eightwise switching mechanism and its suppression in $\mathrm{SrTiO}_{3}$ modulated by humidity and interchanged top and bottom platinum and $\mathrm{LaNiO}_{3}$ electrode contacts. Adv. Electron. Mater. 2019, 5, 1800566. [CrossRef]

67. Schweiger, S.; Pfenninger, R.; Bowman, W.J.; Aschauer, U.; Rupp, J.L. Designing strained interface heterostructures for memristive devices. Adv. Mater. 2017, 29, 1605049. [CrossRef] [PubMed]

68. Sheth, J.; Chen, D.; Kim, J.J.; Bowman, W.J.; Crozier, P.A.; Tuller, H.L.; Misture, S.T.; Zdzieszynski, S.; Sheldon, B.W.; Bishop, S.R Coupling of strain, stress, and oxygen non-stoichiometry in thin film $\operatorname{Pr}_{0.1} \mathrm{Ce}_{0.9} \mathrm{O}_{2-\delta}$. Nanoscale 2016, 8, 16499-16510. [CrossRef]

69. Garbayo, I.; Struzik, M.; Bowman, W.J.; Pfenninger, R.; Stilp, E.; Rupp, J.L. Glass-Type Polyamorphism in Li-Garnet Thin Film Solid State Battery Conductors. Adv. Energy Mater. 2018, 8, 1702265. [CrossRef]

70. Taylor, R.I.; Coad, J.P.; Brook, R.J. Grain Boundary Segregation in $\mathrm{Al}_{2} \mathrm{O}_{3}$. J. Am. Ceram. Soc. 1974, 57, 539-540. [CrossRef]

71. Gregori, G.; Merkle, R.; Maier, J. Ion conduction and redistribution at grain boundaries in oxide systems. Prog. Mater. Sci. 2017, 89, 252-305. [CrossRef]

72. Rohrer, G.S. Grain boundary energy anisotropy: A review. J. Mater. Sci. 2011, 46, 5881-5895. [CrossRef]

73. Krivanek, O.L.; Isoda, S.; Kobayashi, K. Lattice imaging of a grain boundary in crystalline germanium. Philos. Mag. 1977, 36, 931-940. [CrossRef] 
74. Gust, M.; Goo, G.; Wolfenstine, J.; Mecartney, M.L. Influence of Amorphous Grain Boundary Phases on the Superplastic Behavior of 3-mol\%-Yttria-Stabilized Tetragonal Zirconia Polycrystals (3Y-TZP). J. Am. Ceram. Soc. 1993, 76, 1681-1690. [CrossRef]

75. Steele, B.C.H. Mass transport in materials incorporated in electrochemical energy conversion systems. Solid State Ion. 1984, 12, 391-406. [CrossRef]

76. Guo, X.; Sigle, W.; Maier, J. Blocking Grain Boundaries in Yttria-Doped and Undoped Ceria Ceramics of High Purity. J. Am. Ceram. Soc. 2003, 86, 77-87. [CrossRef]

77. Kelly, T.F.; Miller, M.K. 2007. Atom probe tomography. Rev. Sci. Instrum. 2007, 78, 031101. [CrossRef] [PubMed]

78. von Harrach, H.S.; Klenov, D.; Freitag, B.; Schlossmacher, P.; Collins, P.C.; Fraser, H.L. Comparison of the detection limits of EDS and EELS in S/TEM. Microsc. Microanal. 2010, 16, 1312-1313. [CrossRef]

79. Diercks, D.R.; Tong, J.; Zhu, H.; Kee, R.; Baure, G.; Nino, J.C.; O’Hayre, R.; Gorman, B.P. Three-dimensional quantification of composition and electrostatic potential at individual grain boundaries in doped ceria. J. Mater. Chem. A 2016, 4, 5167-5175. [CrossRef]

80. Ross, F.M.; Minor, A.M. In situ transmission electron microscopy. In Springer Handbooks; Springer: Berlin/Heidelberg, Germany, 2019; pp. 101-187.

81. Vurpillot, F.; Lefebvre, W.; Cairney, J.M.; Oberdorfer, C.; Geiser, B.P.; Rajan, K. Advanced volume reconstruction and data mining methods in atom probe tomography. MRS Bull. 2016, 41, 46-51. [CrossRef]

82. Wu, Q.; Yu, Z.; Wang, Y.; Diercks, D.; Gorman, B.P.; Rickman, J.M.; Harmer, M.P.; Chan, H.M. Influence of codoping with Hf and La on grain-boundary transport in alumina. J. Am. Ceram. Soc. 2021, 104, 514-523. [CrossRef]

83. Burton, G.L.; Ricote, S.; Foran, B.J.; Diercks, D.R.; Gorman, B.P. Quantification of grain boundary defect chemistry in a mixed proton-electron conducting oxide composite. J. Am. Ceram. Soc. 2020, 103, 3217-3230. [CrossRef]

84. Mutas, S.; Klein, C. Importance of the Protective Layers and the Specimen Preparation for Reproducible APT Results. Microsc. Microanal. 2011, 17, 730-731. [CrossRef]

85. Gupta, D. Diffusion, solute segregations and interfacial energies in some material: An overview. Interface Sci. 2003, 11, 7-20. [CrossRef]

86. Foiles, S.M. Temperature dependence of grain boundary free energy and elastic constants. Scr. Mater. 2010, 62, 231-234. [CrossRef]

87. Munoz, N.E.; Gilliss, S.R.; Carter, C.B. Remnant grooves on alumina surfaces. Surf. Sci. 2004, 573, 391-402. [CrossRef]

88. Saylor, D.M.; Rohrer, G.S. Measuring the influence of grain-boundary misorientation on thermal groove geometry in ceramic polycrystals. J. Am. Ceram. Soc. 1999, 82, 1529-1536. [CrossRef]

89. Kelly, M.N.; Bojarski, S.A.; Rohrer, G.S. The temperature dependence of the relative grain-boundary energy of yttria-doped alumina. J. Am. Ceram. Soc. 2017, 100, 783-791. [CrossRef]

90. Yoshida, H.; Yokoyama, K.; Shibata, N.; Ikuhara, Y.; Sakuma, T. High-temperature grain boundary sliding behavior and grain boundary energy in cubic zirconia bicrystals. Acta Mater. 2004, 52, 2349-2357. [CrossRef]

91. Dillon, S.J.; Harmer, M.P.; Rohrer, G.S. The relative energies of normally and abnormally growing grain boundaries in alumina displaying different complexions. J. Am. Ceram. Soc. 2010, 93, 1796-1802. [CrossRef]

92. Williams, D.B.; Carter, C.B. Transmission Electron. Microscopy: A Textbook for Materials Science; Springer: Berlin/Heidelberg, Germany, 2009; p. 760. ISBN 978-0-387-76500-6.

93. Thomas, J.; Gemming, T. Analytical Transmission Electron. Microscopy: An Introduction for Operators; Springer Science \& Business Media: Secaucus, NJ, USA, 2014.

94. Ikuhara, Y. Towards new transmission electron microscopy in advanced ceramics. J. Ceram. Soc. Jpn. 2002, 110, 139-145. [CrossRef]

95. Rukari, T.; Babita, A. Review Article Transmission Electron Microscopy-An Overview. Int. Res. J. Invent. Pharm. Sci. 2013, 1, 1-7.

96. Winey, M.; Meehl, J.B.; O’Toole, E.T.; Giddings, T.H. Conventional transmission electron microscopy. Mol. Biol. Cell 2014, 25, 319-323. [CrossRef] [PubMed]

97. Hawkes, P.W.; Spence, J.C. Springer Handbook of Microscopy; Springer Nature: Berlin/Heidelberg, Germany, 2019.

98. Pennycook, S.J. A Scan Through the History of STEM. In Scanning Transmission Electron Microscopy; Springer: New York, NY, USA, 2011; pp. 1-90.

99. Pennycook, S.J.; Nellist, P.D. (Eds.) Scanning Transmission Electron Microscopy: Imaging and Analysis; Springer Science \& Business Media: Secaucus, NJ, USA, 2011; ISBN 978-1-4419-7200-2.

100. Bacon, N.J.; Corbin, G.J.; Dellby, N.; Hrncirik, P.; Krivanek, O.L.; McManama-Smith, A.; Murfitt, M.F.; Szilagyi, Z.S. Nion UltraSTEM: An aberration-corrected STEM for imaging and analysis. Microsc. Microanal. 2005, 11, 1422-1423. [CrossRef]

101. MacLaren, I.; Ramasse, Q.M. Aberration-corrected scanning transmission electron microscopy for atomic-resolution studies of functional oxides. Int. Mater. Rev. 2014, 59, 115-131. [CrossRef]

102. Botton, G.; Prabhudev, S. Analytical electron microscopy. In Springer Handbook of Microscopy; Springer: Cham, Switzerland, 2019; pp. 345-453.

103. Hren, J. Introduction to Analytical Electron. Microscopy; Springer Science \& Business Media: Secaucus, NJ, USA, 2013; ISBN 978-1-4757-5581-7.

104. Shindo, D.; Oikawa, T. Analytical Electron. Microscopy for Materials Science; Springer Science \& Business Media: Secaucus, NJ, USA, 2013; ISBN 978-4-431-66988-3. 
105. Joy, D.C.; Roming, A.D., Jr.; Goldstein, J.; Goldstein, J.I. Principles of Analytical Electron. Microscopy; Springer Science \& Business Media: Secaucus, NJ, USA, 1986; ISBN 978-0-306-42387-1.

106. Scott, M.C.; Chen, C.C.; Mecklenburg, M.; Zhu, C.; Xu, R.; Ercius, P.; Dahmen, U.; Regan, B.C.; Miao, J. Electron tomography at 2.4-ångström resolution. Nature 2012, 483, 444-447. [CrossRef] [PubMed]

107. De, L.O.; Roglie, B.; Lecture, N. The wave nature of the electron. Nobel Lect. 1929, 12, 244-256.

108. Ruska, E. The Development of the Electron Microscope and of Electron Microscopy (Nobel Lecture). Angew. Chem. Int. Ed. Engl. 1987, 26, 595-605. [CrossRef]

109. Haider, M.; Rose, H.; Uhlemann, S.; Schwan, E.; Kabius, B.; Urban, K. A spherical-aberration-corrected 200 kV transmission electron microscope. Ultramicroscopy 1998, 75, 53-60. [CrossRef]

110. Batson, P.E.; Dellby, N.; Krivanek, O.L. Sub-ångstrom resolution using aberration corrected electron optics. Nature 2002, 418, 617-620. [CrossRef]

111. Yamashita, S.; Kikkawa, J.; Yanagisawa, K.; Nagai, T.; Ishizuka, K.; Kimoto, K. Atomic number dependence of Z contrast in scanning transmission electron microscopy. Sci. Rep. 2018, 8, 12325-12325. [CrossRef]

112. Hawkes, P.W. The correction of electron lens aberrations. Ultramicroscopy 2015, 156, A1-A64. [CrossRef]

113. Hart, J.L.; Lang, A.C.; Leff, A.C.; Longo, P.; Trevor, C.; Twesten, R.D.; Taheri, M.L. Direct detection electron energy-loss spectroscopy: A method to push the limits of resolution and sensitivity. Sci. Rep. 2017, 7, 8243. [CrossRef] [PubMed]

114. Zou, X.; Hovmöller, S.; Oleynikov, P. Electron Crystallography: Electron Microscopy and Electron Diffraction; Oxford University Press: Oxford, UK, 2012; p. 344. ISBN 978-0-19-173121-1.

115. Abelson, A.; Qian, C.; Salk, T.; Luan, Z.; Fu, K.; Zheng, J.G.; Wardini, J.L.; Law, M. Collective topo-epitaxy in the self-assembly of a 3D quantum dot superlattice. Nat. Mater. 2020, 19, 49-55. [CrossRef]

116. Plapcianu, C.; Valsangiacom, C.; Schaffer, J.E.; Wieg, A.; Garay, J.; Stanciu, L. Spark plasma sintering studies of nanosize lanthanide-doped ceria obtained by sol-gel method. J. Optoelectron. Adv. Mater. 2011, 13, 1101.

117. Fultz, B.; Howe, J.M. Transmission Electron. Microscopy and Diffractometry of Materials; Springer Science \& Business Media: Secaucus, NJ, USA, 2012.

118. Kotaka, Y. Direct visualization method of the atomic structure of light and heavy atoms with double-detector Cs-corrected scanning transmission electron microscopy. Appl. Phys. Lett. 2012, 101, 133107. [CrossRef]

119. Krivanek, O.L.; Chisholm, M.F.; Nicolosi, V.; Pennycook, T.J.; Corbin, G.J.; Dellby, N.; Murfitt, M.F.; Own, C.S.; Szilagyi, Z.S.; Oxley, M.P.; et al. Atom-by-atom structural and chemical analysis by annular dark-field electron microscopy. Nature 2010, 464, 571-574. [CrossRef]

120. Findlay, S.D.; Shibata, N.; Sawada, H.; Okunishi, E.; Kondo, Y.; Ikuhara, Y. Dynamics of annular bright field imaging in scanning transmission electron microscopy. Ultramicroscopy 2010, 110, 903-923. [CrossRef] [PubMed]

121. Findlay, S.D.; Saito, T.; Shibata, N.; Sato, Y.; Matsuda, J.; Asano, K.; Akiba, E.; Hirayama, T.; Ikuhara, Y. Direct imaging of hydrogen within a crystalline environment. Appl. Phys. Express 2010, 3, 116603-116603. [CrossRef]

122. Hirsch, S.G.; Walck, S.D.; LaSalvia, J.C.; Swab, J.J. Transmission Electron Microscopy Characterization of Knoop Indentation Inelastic Deformation Regions in Three Commercial Silicon Carbides; US Army Research Laboratory: Adelphi, MD, USA, 2018.

123. Giannuzzi, L.A.; Stevie, F.A. A review of focused ion beam milling techniques for TEM specimen preparation. Micron 1999, 30, 197-204. [CrossRef]

124. Ayache, J.; Beaunier, L.; Boumendil, J.; Ehret, G.; Laub, D. Sample Preparation Handbook for Transmission Electron. Microscopy: Techniques; Springer Science \& Business Media: Secaucus, NJ, USA, 2020; Volume 2.

125. Rigort, A.; Plitzko, J.M. Cryo-focused-ion-beam applications in structural biology. Arch. Biochem. Biophys. 2015, 581, 122-130. [CrossRef] [PubMed]

126. Zachman, M.J.; Asenath-Smith, E.; Estroff, L.A.; Kourkoutis, L.F. Site-specific preparation of intact solid-liquid interfaces by label-free in situ localization and Cryo-focused ion beam lift-out. Microsc. Microanal. 2016, 22, 1338-1349. [CrossRef]

127. Barna, Á.; Pécz, B.; Menyhard, M. TEM sample preparation by ion milling/amorphization. Micron 1999, 30, 267-276. [CrossRef]

128. Ünlü, N. Preparation of high quality Al TEM specimens via a double-jet electropolishing technique. Mater. Charact. 2008, 59, 547-553. [CrossRef]

129. Pourbabak, S.; Orekhov, A.; Schryvers, D. Twin-jet electropolishing for damage-free transmission electron microscopy specimen preparation of metallic microwires. Microsc. Res. Tech. 2021, 84, 298-304. [CrossRef] [PubMed]

130. Baena, V.; Schalek, R.L.; Lichtman, J.W.; Terasaki, M. Serial-section electron microscopy using automated tape-collecting ultramicrotome (ATUM). In Methods in Cell Biology; Academic Press Inc.: London, UK, 2019; Volume 152, pp. 41-67. ISBN 978-0-12-817018-2.

131. Schrand, A.M.; Schlager, J.J.; Dai, L.; Hussain, S.M. Preparation of cells for assessing ultrastructural localization of nanoparticles with transmission electron microscopy. Nat. Protoc. 2010, 5, 744-757. [CrossRef] [PubMed]

132. Sugar, J.D.; El Gabaly, F.; Chueh, W.C.; Fenton, K.R.; Tyliszczak, T.; Kotula, P.G.; Bartelt, N.C. High-resolution chemical analysis on cycled $\mathrm{LiFePO}_{4}$ battery electrodes using energy-filtered transmission electron microscopy. J. Power Sources 2014, $246,512-521$. [CrossRef]

133. Fischione, P.E.; Williams, R.E.; Genç, A.; Fraser, H.L.; Dunin-Borkowski, R.E.; Luysberg, M.; Bonifacio, C.S.; Kovács, A. A small spot, inert gas, ion milling process as a complementary technique to focused ion beam specimen preparation. Microsc. Microanal. 2017, 23, 782-793. [CrossRef] [PubMed] 
134. Van Mierlo, W.; Geiger, D.; Robins, A.; Stumpf, M.; Ray, M.L.; Fischione, P.; Kaiser, U. Practical aspects of the use of the X2 holder for HRTEM-quality TEM sample preparation by FIB. Ultramicroscopy 2014, 147, 149-155. [CrossRef]

135. Wang, H.; Srot, V.; Fenk, B.; Laskin, G.; Mannhart, J.; van Aken, P.A. An optimized TEM specimen preparation method of quantum nanostructures. Micron 2021, 140, 102979-102979. [CrossRef]

136. Liu, S.-S.; Toh, S.; Daio, T.; Koyama, M.; Matsumura, S. Microstructure Observation of Ni/YSZ Boundary by TEM and STEM. ECS Trans. 2013, 57, 1401-1405. [CrossRef]

137. Srot, V.; Wang, Y.; Salzberger, U.; Fenk, B.; Kelsch, M.; Minola, M.; Salluzzo, M.; De Luca, G.M.; Keimer, B.; van Aken, P.A. Improved sample preparation of beam-sensitive ultra-thin cuprate films. Microsc. Microanal. 2019, 25, 686-687. [CrossRef]

138. Aitkaliyeva, A.; Madden, J.W.; Miller, B.D.; Cole, J.I.; Gan, J. Comparison of preparation techniques for nuclear materials for transmission electron microscopy (TEM). J. Nucl. Mater. 2015, 459, 241-246. [CrossRef]

139. Ennos, A.E. The origin of specimen contamination in the electron microscope. Br. J. Appl. Phys. 1953, 101-106. [CrossRef]

140. Isabell, T.C.; Fischione, P.E.; O’Keefe, C.; Guruz, M.U.; Dravid, V.P. Plasma cleaning and its applications for electron microscopy. Microsc. Microanal. 1999, 5, 126-135. [CrossRef]

141. Bennett, J.C.; Egerton, R.F. NiO Test Specimens for Analytical Electron Microscopy: Round-Robin Results. Microsc. Microanal. 1995, 1, 143-149. [CrossRef]

142. Egerton, R.F. An introduction to EELS. In Electron Energy-Loss Spectroscopy in the Electron Microscope; Springer: Berlin/Heidelberg, Germany, 2011; pp. 1-28.

143. Krivanek, O.L.; Ahn, C.C.; Keeney, R.B. Parallel detection electron spectrometer using quadrupole lenses. Ultramicroscopy 1987, 22, 103-115. [CrossRef]

144. Menon, N.K.; Krivanek, O.L. Synthesis of Electron Energy Loss Spectra for the Quantification of Detection Limits. Microsc. Microanal. 2002, 8, 203-215. [CrossRef] [PubMed]

145. Crozier, P.A. Quantitative elemental mapping of materials by energy-filtered imaging. Ultramicroscopy 1995, 58, 157-174. [CrossRef]

146. Egerton, R.F.; Cheng, S.C. Measurement of local thickness by electron energy-loss spectroscopy. Ultramicroscopy 1987, 21, 231-244. [CrossRef]

147. Malis, T.; Cheng, S.C.; Egerton, R.F. EELS log-ratio technique for specimen-thickness measurement in the TEM. J. Electron. Microsc. Tech. 1988, 8, 193-200. [CrossRef]

148. Zhang, F.; Vanmeensel, K.; Batuk, M.; Hadermann, J.; Inokoshi, M.; van Meerbeek, B.; Naert, I.; Vleugels, J. Highly-translucent, strong and aging-resistant 3Y-TZP ceramics for dental restoration by grain boundary segregation. Acta Biomater. 2015, 16, 215-222. [CrossRef] [PubMed]

149. Zhang, Z.; Rauch, E.F.; Véron, M. Twinning analyses in a magnesium alloy with tilting series scanning method using a TEM based orientation mapping system. Mater. Lett. 2013, 111, 192-196. [CrossRef]

150. Overwijk, M.H.F.; Reefman, D. Maximum-entropy deconvolution applied to electron energy-loss spectroscopy. Micron 2000, 31, 325-331. [CrossRef]

151. Egerton, R.F. Limits to the spatial, energy and momentum resolution of electron energy-loss spectroscopy. Ultramicroscopy 2007, 107, 575-586. [CrossRef]

152. Nelayah, J.; Kociak, M.; Stéphan, O.; de Abajo, F.J.G.; Tencé, M.; Henrard, L.; Taverna, D.; Pastoriza-Santos, I.; Liz-Marzán, L.M.; Colliex, C. Mapping surface plasmons on a single metallic nanoparticle. Nat. Phys. 2007, 3, 348-353. [CrossRef]

153. Kimoto, K.; Kothleitner, G.; Grogger, W.; Matsui, Y.; Hofer, F. Advantages of a monochromator for bandgap measurements using electron energy-loss spectroscopy. Micron 2005, 36, 185-189. [CrossRef]

154. Eccles, J.W.L.; Bangert, U.; Bromfield, M.; Christian, P.; Harvey, A.J.; Thomas, P. UV-Vis plasmon studies of metal nanoparticles. J. Phys. Conf. Ser. 2010, 241, 012090. [CrossRef]

155. Aguiar, J.A.; Reed, B.W.; Ramasse, Q.M.; Erni, R.; Browning, N.D. Quantifying the low-energy limit and spectral resolution in valence electron energy loss spectroscopy. Ultramicroscopy 2013, 124, 130-138. [CrossRef] [PubMed]

156. Jeangros, Q.; Faes, A.; Wagner, J.B.; Hansen, T.W.; Aschauer, U.; Hessler-Wyser, A.; Dunin-Borkowski, R.E. In situ redox cycle of a nickel-YSZ fuel cell anode in an environmental transmission electron microscope. Acta Mater. 2010, 58, 4578-4589. [CrossRef]

157. Rouviere, J.L.; Béché, A.; Martin, Y.; Denneulin, T.; Cooper, D. Improved strain precision with high spatial resolution using nanobeam precession electron diffraction. Appl. Phys. Lett. 2013, 103, 241913-241913. [CrossRef]

158. Cizek, P.; Sankaran, A.; Rauch, E.F.; Barnett, M.R. Observation of (sub)grain clusters in the as-deposited and in situ annealed nanocrystalline nickel using automated crystal orientation mapping. Scr. Mater. 2012, 67, 685-688. [CrossRef]

159. Krivanek, O.L.; Lovejoy, T.C.; Dellby, N.; Aoki, T.; Carpenter, R.W.; Rez, P.; Soignard, E.; Zhu, J.; Batson, P.E.; Lagos, M.J.; et al. Vibrational spectroscopy in the electron microscope. Nature 2014, 514, 209-212. [CrossRef] [PubMed]

160. Bowman, W.J.; March, K.; Hernandez, C.A.; Crozier, P.A. Measuring bandgap states in individual non-stoichiometric oxide nanoparticles using monochromated STEM EELS: The Praseodymium-ceria case. Ultramicroscopy 2016, 167, 5-10. [CrossRef]

161. Wei, J.; Ogawa, T.; Feng, B.; Yokoi, T.; Ishikawa, R.; Kuwabara, A.; Matsunaga, K.; Shibata, N.; Ikuhara, Y. Direct measurement of electronic band structures at oxide grain boundaries. Nano Lett. 2020, 20, 2530-2536. [CrossRef]

162. Krivanek, O.L.; Paterson, J.H. Elnes of 3d transition-metal oxides. I. Variations across the periodic table. Ultramicroscopy 1990, 32, 313-318. [CrossRef] 
163. Manoubi, T.; Colliex, C.; Rez, P. Quantitative electron energy loss spectroscopy on M45 edges in rare earth oxides. J. Electron. Spectrosc. Relat. Phenom. 1990, 50,1-18. [CrossRef]

164. Colliex, C.; Cosslett, V.E.; Leapman, R.D.; Trebbia, P. Contribution of electron energy loss spectroscopy to the development of analytical electron microscopy. Ultramicroscopy 1976, 1, 301-315. [CrossRef]

165. Vincent, R.; Midgley, P.A. Double conical beam-rocking system for measurement of integrated electron diffraction intensities Ultramicroscopy 1994, 53, 271-282. [CrossRef]

166. Frechero, M.A.; Rocci, M.; Sánchez-Santolino, G.; Kumar, A.; Salafranca, J.; Schmidt, R.; Díaz-Guillén, M.R.; Durá, O.J.; Rivera-Calzada, A.; Mishra, R.; et al. Paving the way to nanoionics: Atomic origin of barriers for ionic transport through interfaces. Sci. Rep. 2015, 5, 17229. [CrossRef]

167. Stöger-Pollach, M.; Bukvišová, K.; Schwarz, S.; Kvapil, M.; Šamořil, T.; Horák, M. Fundamentals of cathodoluminescence in a STEM: The impact of sample geometry and electron beam energy on light emission of semiconductors. Ultramicroscopy 2019, 200, 111-124. [CrossRef] [PubMed]

168. Beck, G. Contribution to the Theory of the Cherenkov Effect. Phys. Rev. 1948, 74, 795-802. [CrossRef]

169. Chen, J.; Sekiguchi, T.; Yang, D.; Yin, F.; Kido, K.; Tsurekawa, S. Electron-beam-induced current study of grain boundaries in multicrystalline silicon. J. Appl. Phys. 2004, 96, 5490-5495. [CrossRef]

170. Chernyak, L.; Osinsky, A.; Temkin, H.; Yang, J.W.; Chen, Q.; Asif Khan, M. Electron beam induced current measurements of minority carrier diffusion length in gallium nitride. Appl. Phys. Lett. 1996, 69, 2531-2533. [CrossRef]

171. Leach, C. Grain boundary structures in zinc oxide varistors. Acta Mater. 2005, 53, 237-245. [CrossRef]

172. Leach, C. Crystal plane influence of the EBIC contrast in zinc oxide varistors. J. Eur. Ceram. Soc. 2001, 21, 2127-2130. [CrossRef]

173. Bhattacharyya, A.; Reimer, J.D.; Ritz, K.N. Breakdown voltage characteristics of thin oxides and their correlation to defects in the oxide as observed by the EBIC technique. IEEE Electron. Device Lett. 1986, 7, 58-60. [CrossRef]

174. Midgley, P.A.; Eggeman, A.S. Precession electron diffraction-A topical review. IUCr] 2015, 2, 126-136. [CrossRef] [PubMed]

175. Ophus, C. Four-Dimensional Scanning Transmission Electron Microscopy (4D-STEM): From Scanning Nanodiffraction to Ptychography and Beyond. Microsc. Microanal. 2019, 25, 563-582. [CrossRef]

176. Watanabe, M.; Williams, D. Development of Diffraction Imaging for Orientation Analysis of Grains in Scanning Transmission Electron Microscopy. Microsc. Microanal. 2007, 13, 962-963. [CrossRef]

177. Bober, D.B.; Kumar, M.; Rupert, T.J. Nanocrystalline grain boundary engineering: Increasing $\Sigma 3$ boundary fraction in pure Ni with thermomechanical treatments. Acta Mater. 2015, 86, 43-54. [CrossRef]

178. Izadi, E.; Darbal, A.; Sarkar, R.; Rajagopalan, J. Grain rotations in ultrafine-grained aluminum films studied using in situ TEM straining with automated crystal orientation mapping. Mater. Des. 2017, 113, 186-194. [CrossRef]

179. Idrissi, H.; Kobler, A.; Amin-Ahmadi, B.; Coulombier, M.; Galceran, M.; Raskin, J.P.; Godet, S.; Kübel, C.; Pardoen, T.; Schryvers, D. Plasticity mechanisms in ultrafine grained freestanding aluminum thin films revealed by in-situ transmission electron microscopy nanomechanical testing. Appl. Phys. Lett. 2014, 104, 101903. [CrossRef]

180. Garner, A.; Gholinia, A.; Frankel, P.; Gass, M.; MacLaren, I.; Preuss, M. The microstructure and microtexture of zirconium oxide films studied by transmission electron backscatter diffraction and automated crystal orientation mapping with transmission electron microscopy. Acta Mater. 2014, 80, 159-171. [CrossRef]

181. Guo, D.; Song, S.; Luo, R.; Goddard, W.A., III; Chen, M.; Reddy, K.M.; An, Q. Grain boundary sliding and amorphization are responsible for the reverse Hall-Petch relation in superhard nanocrystalline boron carbide. Phys. Rev. Lett. 2018, 121, 145504-145504. [CrossRef]

182. Harks, P.P.R.M.L.; Mulder, F.M.; Notten, P.H.L. In situ methods for Li-ion battery research: A review of recent developments. J. Power Sources 2015, 288, 92-105. [CrossRef]

183. Wu, F.; Yao, N. Advances in windowed gas cells for in-situ TEM studies. Nano Energy 2015, 13, 735-756. [CrossRef]

184. Miller, B.K. Development and Application of Operando TEM to a Ruthenium Catalyst for CO Oxidation; Arizona State University: Phoenix, AR, USA, 2016.

185. Jiang, N. Electron beam damage in oxides: A review. Rep. Prog. Phys. 2015, 79, 016501. [CrossRef] [PubMed]

186. Egerton, R.F. Radiation damage to organic and inorganic specimens in the TEM. Micron 2019, 119, 72-87. [CrossRef]

187. Jiang, N.; Spence, J.C.H. Electronic ionization induced atom migration in spinel $\mathrm{MgAl}_{2} \mathrm{O}_{4}$. J. Nucl. Mater. 2010, 403, $147-151$. [CrossRef]

188. Smith, R.; Bacorisen, D.; Uberuaga, B.P.; Sickafus, K.E.; Ball, J.A.; Grimes, R.W. Dynamical simulations of radiation damage in magnesium aluminate spinel, $\mathrm{MgAl}_{2} \mathrm{O}_{4}$. J. Phys. Condens. Matter 2005, 17, 875-891. [CrossRef]

189. Ishimaru, M.; Afanasyev-Charkin, I.V.; Sickafus, K.E. Ion-beam-induced spinel-to-rocksalt structural phase transformation in $\mathrm{MgAl}_{2} \mathrm{O}_{4}$. Appl. Phys. Lett. 2000, 76, 2556-2558. [CrossRef]

190. Bouchet, D.; Colliex, C. Experimental study of ELNES at grain boundaries in alumina: Intergranular radiation damage effects on Al-L23 and O-K edges. Ultramicroscopy 2003, 96, 139-152. [CrossRef]

191. Nakamura, R.; Ishimaru, M.; Yasuda, H.; Nakajima, H. Atomic rearrangements in amorphous $\mathrm{Al}_{2} \mathrm{O}_{3}$ under electron-beam irradiation. J. Appl. Phys. 2013, 113, 064312. [CrossRef]

192. Yao, L.; Majumdar, S.; Äkäslompolo, L.; Inkinen, S.; Qin, Q.H.; van Dijken, S. Electron-Beam-Induced Perovskite-BrownmilleritePerovskite Structural Phase Transitions in Epitaxial $\mathrm{La}_{2 / 3} \mathrm{Sr}_{1 / 3} \mathrm{MnO}_{3}$ Films. Adv. Mater. 2014, 26, 2789-2793. [CrossRef] 
193. Nord, M.; Vullum, P.E.; Hallsteinsen, I.; Tybell, T.; Holmestad, R. Assessing electron beam sensitivity for SrTiO 3 and $\mathrm{La}_{0.7} \mathrm{Sr}_{0.3} \mathrm{MnO}_{3}$ using electron energy loss spectroscopy. Ultramicroscopy 2016, 169, 98-106. [CrossRef]

194. Lin, Y.; Wen, J.; Hu, L.; McCarthy, J.A.; Wang, S.; Poeppelmeier, K.R.; Marks, L.D. Electron-induced Ti-rich surface segregation on $\mathrm{SrTiO}_{3}$ nanoparticles. Micron 2015, 68, 152-157. [CrossRef]

195. West, G.D.; Perkins, J.M.; Lewis, M.H. Characterisation of fine-grained oxide ceramics. J. Mater. Sci. 2004, 39, 6687-6704. [CrossRef]

196. Winterstein, J.P.; Carter, C.B. Electron-beam damage and point defects near grain boundaries in cerium oxide. J. Eur. Ceram. Soc. 2014, 34, 3007-3018. [CrossRef]

197. Yoshida, H.; Kuwabara, A.; Yamamoto, T.; Ikuhara, Y.; Sakuma, T. High temperature plastic flow and grain boundary chemistry in oxide ceramics. J. Mater. Sci. 2005, 40, 3129-3135. [CrossRef]

198. Dillon, S.J.; Harmer, M.P. Multiple grain boundary transitions in ceramics: A case study of alumina. Acta Mater. 2007, 55, 5247-5254. [CrossRef]

199. Höche, T.; Kenway, P.R.; Kleebe, H.-J.; Rühle, M.; Morris, P.A. High-Resolution Transmission Electron Microscopy Studies of a Near $\Sigma 11$ Grain Boundary in $\alpha$-Alumina. J. Am. Ceram. Soc. 1994, 77, 339-348. [CrossRef]

200. Matsunaga, K.; Nishimura, H.; Hanyu, S.; Muto, H.; Yamamoto, T.; Ikuhara, Y. HRTEM study on grain boundary atomic structures related to the sliding behavior in alumina bicrystals. Appl. Surf. Sci. 2005, 241, 75-79. [CrossRef]

201. Matsui, K.; Yoshida, H.; Ikuhara, Y. Nanocrystalline, Ultra-Degradation-Resistant Zirconia: Its Grain Boundary Nanostructure and Nanochemistry. Sci. Rep. 2014, 4, 4758. [CrossRef]

202. Stemmer, S.; Vleugels, J.; Van Der Biest, O. Grain boundary segregation in high-purity, yttria-stabilized tetragonal zirconia polycrystals (Y-TZP). J. Eur. Ceram. Soc. 1998, 18, 1565-1570. [CrossRef]

203. Sokol, M.; Ratzker, B.; Kalabukhov, S.; Dariel, M.P.; Galun, E.; Frage, N. Transparent polycrystalline magnesium aluminate spinel fabricated by spark plasma sintering. Adv. Mater. 2018, 30, 1706283. [CrossRef]

204. Nuns, N.; Béclin, F.; Crampon, J. Grain-Boundary Characterization in a Nonstoichiometric Fine-Grained Magnesium Aluminate Spinel: Effects of Defect Segregation at the Space-Charge Layers. J. Am. Ceram. Soc. 2009, 92, 870-875. [CrossRef]

205. Avila-Paredes, H.J.; Kim, S. The effect of segregated transition metal ions on the grain boundary resistivity of gadolinium doped ceria: Alteration of the space charge potential. Solid State Ion. 2006, 177, 3075-3080. [CrossRef]

206. Bueno, P.R.; Leite, E.R.; Oliveira, M.M.; Orlandi, M.O.; Longo, E. Role of oxygen at the grain boundary of metal oxide varistors: A potential barrier formation mechanism. Appl. Phys. Lett. 2001, 79, 48-50. [CrossRef]

207. Zhang, Z.; Sigle, W.; Rühle, M.; Jud, E.; Gauckler, L.J. Microstructure characterization of a cobalt-oxide-doped cerium-gadoliniumoxide by analytical and high-resolution TEM. Acta Mater. 2007, 55, 2907-2917. [CrossRef]

208. Merkle, K.L.; Smith, D.J. Atomic Structure of Symmetric Tilt Grain Boundaries in NiO. Phys. Rev. Lett. 1987, 59, 2887-2890. [CrossRef] [PubMed]

209. Sternlicht, H.; Bojarski, S.A.; Rohrer, G.S.; Kaplan, W.D. Quantitative differences in the Y grain boundary excess at boundaries delimiting large and small grains in $\mathrm{Y}$ doped $\mathrm{Al}_{2} \mathrm{O}_{3}$. J. Eur. Ceram. Soc. 2018, 38, 1829-1835. [CrossRef]

210. Sternlicht, H.; Rheinheimer, W.; Mehlmann, A.; Rothschild, A.; Hoffmann, M.J.; Kaplan, W.D. The mechanism of grain growth at general grain boundaries in $\mathrm{SrTiO}_{3}$. Scr. Mater. 2020, 188, 206-211. [CrossRef]

211. Jia, C.L.; Urban, K. Atomic-Resolution Measurement of Oxygen Concentration in Oxide Materials. Science 2004, 303, 2001-2004. [CrossRef]

212. Feng, B.; Yokoi, T.; Kumamoto, A.; Yoshiya, M.; Ikuhara, Y.; Shibata, N. Atomically ordered solute segregation behaviour in an oxide grain boundary. Nat. Commun. 2016, 7, 11079. [CrossRef] [PubMed]

213. Chiang, Y.; Wang, H.; Lee, J. HREM and STEM of intergranular films at zinc oxide varistor grain boundaries. J. Microsc. 1998, 191, 275-285. [CrossRef] [PubMed]

214. Winnubst, A.J.A.; Kroot, P.J.M.; Burggraaf, A.J. AES/STEM grain boundary analysis of stabilized zirconia ceramics. J. Phys. Chem. Solids 1983, 44, 955-960. [CrossRef]

215. Pyrz, W.D.; Blom, D.A.; Sadakane, M.; Kodato, K.; Ueda, W.; Vogt, T.; Buttrey, D.J. Atomic-level imaging of Mo-VO complex oxide phase intergrowth, grain boundaries, and defects using HAADF-STEM. Proc. Natl. Acad. Sci. USA 2010, 107, 6152-6157. [CrossRef] [PubMed]

216. Schusteritsch, G.; Ishikawa, R.; Elmaslmane, A.R.; Inoue, K.; McKenna, K.P.; Ikuhara, Y.; Pickard, C.J. Anataselike Grain Boundary Structure in Rutile Titanium Dioxide. Nano Lett. 2021, 21, 2745-2751. [CrossRef]

217. Ikuhara, Y. Grain boundary atomic structures and light-element visualization in ceramics: Combination of Cs-corrected scanning transmission electron microscopy and first-principles calculations. Electron. Microsc. 2011, 60, S173-S188. [CrossRef]

218. Gale, J.D. GULP: A computer program for the symmetry-adapted simulation of solids. J. Chem. Soc. Faraday Trans. 1997, 93, 629-637. [CrossRef]

219. Tong, W.; Yang, H.; Moeck, P.; Nandasiri, M.I.; Browning, N.D. General schema for [0 001 1] tilt grain boundaries in dense packing cubic crystals. Acta Mater. 2013, 61, 3392-3398. [CrossRef]

220. Yuan, R.; Zhang, J.; He, L.; Zuo, J.-M. Training Artificial Neural Networks for Precision Orientation and Strain Mapping Using 4D Electron. Diffraction Datasets; Elsevier: Amesterdam, The Netherlands, 2021.

221. Boland, T.M.; Rez, P.; Crozier, P.A.; Singh, A.K. Impact of Aliovalent Alkaline-Earth metal solutes on Ceria Grain Boundaries: A density functional theory study. Acta Mater. 2021, 205, 116481. [CrossRef] 
222. Ishihara, S.; Tochigi, E.; Ishikawa, R.; Shibata, N.; Ikuhara, Y. Atomic structures of Ti-doped $\alpha-\mathrm{Al}_{2} \mathrm{O}_{3} \Sigma 13$ grain boundary with a small amount of Si impurity. J. Am. Ceram. Soc. 2020, 103, 6659-6665. [CrossRef]

223. Saito, M.; Wang, Z.; Ikuhara, Y. Selective impurity segregation at a near- $\Sigma 5$ grain boundary in MgO. J. Mater. Sci. 2014, 49 , 3956-3961. [CrossRef]

224. Yang, H.; Kotula, P.G.; Sato, Y.; Chi, M.; Ikuhara, Y.; Browning, N.D. Segregation of $\mathrm{Mn}^{2+}$ dopants as interstitials in $\mathrm{SrTiO}_{3}$ grain boundaries. Mater. Res. Lett. 2014, 2, 16-22. [CrossRef]

225. Song, Z.; Xie, Z.H. A literature review of in situ transmission electron microscopy technique in corrosion studies. Micron 2018, 112, 69-83. [CrossRef]

226. Cho, J.; Phuah, X.L.; Li, J.; Shang, Z.; Wang, H.; Charalambous, H.; Tsakalakos, T.; Mukherjee, A.K.; Wang, H.; Zhang, X. Temperature effect on mechanical response of flash-sintered ZnO by in-situ compression tests. Acta Mater. 2020, 200, 699-709. [CrossRef]

227. Kondo, S.; Shibata, N.; Mitsuma, T.; Tochigi, E.; Ikuhara, Y. Dynamic observations of dislocation behavior in $\mathrm{SrTiO}_{3}$ by in situ nanoindentation in a transmission electron microscope. Appl. Phys. Lett. 2012, 100, 181906. [CrossRef]

228. Kondo, S.; Mitsuma, T.; Shibata, N.; Ikuhara, Y. Direct observation of individual dislocation interaction processes with grain boundaries. Sci. Adv. 2016, 2, 1-8. [CrossRef]

229. Grosso, R.L.; Muccillo, E.N.; Muche, D.N.; Jawaharram, G.S.; Barr, C.M.; Monterrosa, A.M.; Castro, R.H.; Hattar, K.; Dillon, S.J. In situ transmission electron microscopy for ultrahigh temperature mechanical testing of $\mathrm{ZrO}_{2}$. Nano Lett. 2020, 20, 1041-1046. [CrossRef]

230. Vikrant, K.S.N.; Grosso, R.L.; Feng, L.; Muccillo, E.N.; Muche, D.N.; Jawaharram, G.S.; Barr, C.M.; Monterrosa, A.M.; Castro, R.H.; García, R.E.; et al. Ultrahigh temperature in situ transmission electron microscopy based bicrystal coble creep in zirconia I: Nanowire growth and interfacial diffusivity. Acta Mater. 2020, 199, 530-541. [CrossRef]

231. Gao, P.; Wang, Z.; Fu, W.; Liao, Z.; Liu, K.; Wang, W.; Bai, X.; Wang, E. In situ TEM studies of oxygen vacancy migration for electrically induced resistance change effect in cerium oxides. Micron 2010, 41, 301-305. [CrossRef]

232. Zhang, Z. Surface effects in the energy loss near edge structure of different cobalt oxides. Ultramicroscopy 2007, 107, 598-603. [CrossRef] [PubMed]

233. Stemmer, S.; Sane, A.; Browning, N.D.; Mazanec, T.J. Characterization of oxygen-deficient $\mathrm{SrCoO}_{3-\delta}$ by electron energy-loss spectroscopy and Z-contrast imaging. Solid State Ion. 2000, 130, 71-80. [CrossRef]

234. Klie, R.F.; Zheng, J.C.; Zhu, Y.; Varela, M.; Wu, J.; Leighton, C. Direct measurement of the low-temperature spin-state transition in $\mathrm{LaCoO}_{3}$. Phys. Rev. Lett. 2007, 99, 047203-047203. [CrossRef]

235. Klie, R.F.; Buban, J.P.; Varela, M.; Franceschetti, A.; Jooss, C.; Zhu, Y.; Browning, N.D.; Pantelides, S.T.; Pennycook, S.J. Enhanced current transport at grain boundaries in high-T c superconductors. Nature 2005, 435, 475-478. [CrossRef] [PubMed]

236. Browning, N.D.; Buban, J.P.; Nellist, P.D.; Norton, D.P.; Chisholm, M.F.; Pennycook, S.J. The atomic origins of reduced critical currents at [001] tilt grain boundaries in $\mathrm{YBa}_{2} \mathrm{Cu}_{3} \mathrm{O}_{7-\delta}$ thin films. Phys. C Supercond. Its Appl. 1998, 294, 183-193. [CrossRef]

237. Zhao, Y.; Feltes, T.E.; Regalbuto, J.R.; Meyer, R.J.; Klie, R.F. In Situ Electron Energy Loss Spectroscopy Study of Metallic Co and Co Oxides; American Institute of Physics AIP: College Park, MD, USA, 2010; Volume 108, p. 063704.

238. Song, X.; Daniels, G.; Feldmann, D.M.; Gurevich, A.; Larbalestier, D. Electromagnetic, atomic structure and chemistry changes induced by Ca-doping of low-angle $\mathrm{YBa}_{2} \mathrm{Cu}_{3} \mathrm{O}_{7-\delta}$ grain boundaries. Nat. Mater. 2005, 4, 470-475. [CrossRef] [PubMed]

239. Bischoff, J.; Motta, A.T. EFTEM and EELS analysis of the oxide layer formed on HCM12A exposed to SCW. J. Nucl. Mater. 2012, 430, 171-180. [CrossRef]

240. Jiang, N.; Spence, J.C.H. Interpretation of Oxygen K pre-edge peak in complex oxides. Ultramicroscopy 2006, 106, $215-219$. [CrossRef]

241. Wang, Z.L.; Yin, J.S.; Jiang, Y.D. EELS analysis of cation valence states and oxygen vacancies in magnetic oxides. Micron 2000, 31, 571-580. [CrossRef]

242. Yuan, Y.; Amine, K.; Lu, J.; Shahbazian-Yassar, R. Understanding materials challenges for rechargeable ion batteries with in situ transmission electron microscopy. Nat. Commun. 2017, 8, 15806. [CrossRef]

243. Sun, Y.Y.; Hou, P.Y.; Zhang, L.C. Mitigating the Microcracks of High-Ni Oxides by in Situ Formation of Binder between Anisotropic Grains for Lithium-Ion Batteries. ACS Appl. Mater. Interfaces 2020, 12, 13923-13930. [CrossRef]

244. Park, K.J.; Hwang, J.Y.; Ryu, H.H.; Maglia, F.; Kim, S.J.; Lamp, P.; Yoon, C.S.; Sun, Y.K. Degradation mechanism of Ni-enriched NCA cathode for lithium batteries: Are microcracks really critical? ACS Energy Lett. 2019, 4, 1394-1400. [CrossRef]

245. Liu, X.; Zhan, X.; Hood, Z.D.; Li, W.; Leonard, D.N.; Manthiram, A.; Chi, M. Essential effect of the electrolyte on the mechanical and chemical degradation of $\mathrm{LiNi}_{0.8} \mathrm{Co}_{0.15} \mathrm{Al}_{0.05} \mathrm{O}_{2}$ cathodes upon long-term cycling. J. Mater. Chem. A 2021, 9, $2111-2119$. [CrossRef]

246. Jo, Y.R.; Koo, B.; Seo, M.J.; Kim, J.K.; Lee, S.; Kim, K.; Han, J.W.; Jung, W.; Kim, B.J. Growth kinetics of individual Co particles Ex-solved on $\mathrm{SrTi}_{0.75} \mathrm{Co}_{0.25} \mathrm{O}_{3-\delta}$ polycrystalline perovskite thin films. J. Am. Chem. Soc. 2019, 141, 6690-6697. [CrossRef] [PubMed]

247. Zajac, W.; Molenda, J. Electrical conductivity of doubly doped ceria. Solid State Ion. 2008, 179, 154-158. [CrossRef]

248. Guo, X.; Waser, R. Electrical properties of the grain boundaries of oxygen ion conductors: Acceptor-doped zirconia and ceria. Prog. Mater. Sci. 2006, 51, 151-210. [CrossRef]

249. Steele, B.C.H.; Heinzel, A. Materials for fuel-cell technologies. Nature 2001, 414, 345-352. [CrossRef] 
250. Mogensen, M.; Sammes, N.M.; Tompsett, G.A. Physical, chemical and electrochemical properties of pure and doped ceria. Solid State Ion. 2000, 129, 63-94. [CrossRef]

251. Avila-Paredes, H.J.; Choi, K.; Chen, C.T.; Kim, S. Dopant-concentration dependence of grain-boundary conductivity in ceria: A space-charge analysis. J. Mater. Chem. 2009, 19, 4837-4842. [CrossRef]

252. Luo, J. Interfacial engineering of solid electrolytes. J. Mater. 2015, 1, 22-32. [CrossRef]

253. Murugan, R.; Thangadurai, V.; Weppner, W. Fast Lithium Ion Conduction in Garnet-Type $\mathrm{Li}_{7} \mathrm{La}_{3} \mathrm{Zr}_{2} \mathrm{O}_{12}$. Angew. Chem. Int. Ed. 2007, 46, 7778-7781. [CrossRef]

254. Li, Y.; Han, J.T.; Wang, C.A.; Xie, H.; Goodenough, J.B. Optimizing $\mathrm{Li}^{+}$conductivity in a garnet framework. J. Mater. Chem. 2012, 22, 15357-15361. [CrossRef]

255. Liu, Y.; Chen, J.; Gao, J. Preparation and chemical compatibility of lithium aluminum germanium phosphate solid electrolyte. Solid State Ion. 2018, 318, 27-34. [CrossRef]

256. Inaguma, Y.; Liquan, C.; Itoh, M.; Nakamura, T.; Uchida, T.; Ikuta, H.; Wakihara, M. High ionic conductivity in lithium lanthanum titanate. Solid State Commun. 1993, 86, 689-693. [CrossRef]

257. Kimura, K.; Wagatsuma, K.; Tojo, T.; Inada, R.; Sakurai, Y. Effect of composition on lithium-ion conductivity for perovskite-type lithium-strontium-tantalum-zirconium-oxide solid electrolytes. Ceram. Int. 2016, 42, 5546-5552. [CrossRef]

258. Cui, Y.; Mahmoud, M.M.; Rohde, M.; Ziebert, C.; Seifert, H.J. Thermal and ionic conductivity studies of lithium aluminum germanium phosphate solid-state electrolyte. Solid State Ion. 2016, 289, 125-132. [CrossRef]

259. Sharafi, A. Microstructural and Interface Engineering of Garnet-Type Fast Ion-Conductor for Use in Solid-State Batteries. Ph.D. Thesis, Horace H. Rackham School of Graduate Studies, University of Michigan, Ann Arbor, MI, USA, 2007. Available online: https: / / deepblue.lib.umich.edu/handle/2027.42/140865 (accessed on 19 May 2021).

260. Allen, J.L.; Wolfenstine, J.; Rangasamy, E.; Sakamoto, J. Effect of substitution (Ta, Al, Ga) on the conductivity of $\mathrm{Li}_{7} \mathrm{La}_{3} \mathrm{Zr}_{2} \mathrm{O}_{12}$. J. Power Sources 2012, 206, 315-319. [CrossRef]

261. Hu, S.; Li, Y.F.; Yang, R.; Yang, Z.; Wang, L. Structure and ionic conductivity of $\mathrm{Li}_{7} \mathrm{La}_{3} \mathrm{Zr}_{2-x} \mathrm{Gei}_{x} \mathrm{O}_{12}$ garnet-like solid electrolyte for all solid state lithium ion batteries. Ceram. Int. 2018, 44, 6614-6618. [CrossRef]

262. Thompson, T.; Yu, S.; Williams, L.; Schmidt, R.D.; Garcia-Mendez, R.; Wolfenstine, J.; Allen, J.L.; Kioupakis, E.; Siegel, D.J.; Sakamoto, J. Electrochemical window of the Li-ion solid electrolyte $\mathrm{Li}_{7} \mathrm{La}_{3} \mathrm{Zr}_{2} \mathrm{O}_{12}$. ACS Energy Lett. 2017, 2, 462-468. [CrossRef]

263. Thangadurai, V.; Narayanan, S.; Pinzaru, D. Garnet-type solid-state fast Li ion conductors for Li batteries: Critical review. Chem. Soc. Rev. 2014, 43, 4714-4727. [CrossRef]

264. Ahmad, M.M. Estimation of the concentration and mobility of mobile $\mathrm{Li}_{+}$in the cubic garnet-type $\mathrm{Li}_{7} \mathrm{La}_{3} \mathrm{Zr}_{2} \mathrm{O}_{12}$. RSC Adv. 2015, 5, 25824-25829. [CrossRef]

265. Pickett, W.E.; Feldman, J.L.; Deppe, J. Thermal transport across boundaries in diamond structure materials. Model. Simul. Mater. Sci. Eng. 1996, 4, 409-419. [CrossRef]

266. Sood, A.; Cheaito, R.; Bai, T.; Kwon, H.; Wang, Y.; Li, C.; Yates, L.; Bougher, T.; Graham, S.; Asheghi, M.; et al. Direct visualization of thermal conductivity suppression due to enhanced phonon scattering near individual grain boundaries. Nano Lett. 2018, 18, 3466-3472. [CrossRef] [PubMed]

267. Kinoshita, T.; Munekawa, S. Effect of grain boundary segregation on thermal conductivity of hot-pressed silicon carbide. Acta Mater. 1997, 45, 2001-2012. [CrossRef]

268. Boyle, C.; Carvillo, P.; Chen, Y.; Barbero, E.J.; Mcintyre, D.; Song, X. Grain boundary segregation and thermoelectric performance enhancement of bismuth doped calcium cobaltite. J. Eur. Ceram. Soc. 2016, 36, 601-607. [CrossRef]

269. Blundell, S.J.; Blundell, K.M. Concepts in Thermal Physics; Oxford University Press: Oxford, UK, 2010; p. 512. ISBN 978-0-19171823-6.

270. Song, X.; Paredes Navia, S.A.; Liang, L.; Boyle, C.; Romo-De-La-Cruz, C.O.; Jackson, B.; Hinerman, A.; Wilt, M.; Prucz, J.; Chen, Y. Grain boundary phase segregation for dramatic improvement of the thermoelectric performance of oxide ceramics. ACS Appl. Mater. Interfaces 2018, 10, 39018-39024. [CrossRef] [PubMed]

271. Shi, Z.; Su, T.; Zhang, P.; Lou, Z.; Qin, M.; Gao, T.; Xu, J.; Zhu, J.; Gao, F. Enhanced thermoelectric performance of $\mathrm{Ca}_{3} \mathrm{Co}_{4} \mathrm{O}_{9}$ ceramics through grain orientation and interface modulation. J. Mater. Chem. A 2020, 8, 19561-19572. [CrossRef]

272. Yang, H.S.; Bai, G.R.; Thompson, L.J.; Eastman, J.A. Interfacial thermal resistance in nanocrystalline yttria-stabilized zirconia. Acta Mater. 2002, 50, 2309-2317. [CrossRef]

273. Smith, D.S.; Fayette, S.; Grandjean, S.; Martin, C.; Telle, R.; Tonnessen, T. Thermal resistance of grain boundaries in alumina ceramics and refractories. J. Am. Ceram. Soc. 2003, 86, 105-111. [CrossRef]

274. Watanabe, T. Grain boundary engineering: Historical perspective and future prospects. J. Mater. Sci. 2011, 46, 4095-4115. [CrossRef]

275. Krause, A.R.; Cantwell, P.R.; Marvel, C.J.; Compson, C.; Rickman, J.M.; Harmer, M.P. Review of grain boundary complexion engineering: Know your boundaries. J. Am. Ceram. Soc. 2019, 102, 778-800. [CrossRef]

276. Maehara, Y.; Langdon, T.G. Superplasticity in ceramics. J. Mater. Sci. 1990, 25, 2275-2286. [CrossRef]

277. Ryou, H.; Drazin, J.W.; Wahl, K.J.; Qadri, S.B.; Gorzkowski, E.P.; Feigelson, B.N.; Wollmershauser, J.A. Below the hall-petch limit in nanocrystalline ceramics. ACS Nano 2018, 12, 3083-3094. [CrossRef] [PubMed]

278. Ikuhara, Y.; Yoshida, H.; Sakuma, T. Impurity effects on grain boundary strength in structural ceramics. Mater. Sci. Eng. A 2001, 319-321, 24-30. [CrossRef] 
279. Matsunaga, K.; Nishimura, H.; Muto, H.; Yamamoto, T.; Ikuhara, Y. Direct measurements of grain boundary sliding in yttriumdoped alumina bicrystals. Appl. Phys. Lett. 2003, 82, 1179-1181. [CrossRef]

280. Kondo, S.; Ishihara, A.; Tochigi, E.; Shibata, N.; Ikuhara, Y. Direct observation of atomic-scale fracture path within ceramic grain boundary core. Nat. Commun. 2019, 10, 2112. [CrossRef]

281. Coleman, S.P.; Hernandez-Rivera, E.; Behler, K.D.; Synowczynski-Dunn, J.; Tschopp, M.A. Challenges of Engineering Grain Boundaries in Boron-Based Armor Ceramics. JOM 2016, 68, 1605-1615. [CrossRef]

282. Watanabe, T.; Tsurekawa, S. Control of brittleness and development of desirable mechanical properties in polycrystalline systems by grain boundary engineering. Acta Mater. 1999, 47, 4171-4185. [CrossRef]

283. Chen, M.W.; McCauley, J.W.; Dandekar, D.P.; Bourne, N.K. Dynamic plasticity and failure of high-purity alumina under shock loading. Nat. Mater. 2006, 5, 614-618. [CrossRef]

284. Reddy, K.M.; Liu, P.; Hirata, A.; Fujita, T.; Chen, M.W. Atomic structure of amorphous shear bands in boron carbide. Nat. Commun. 2013, 4, 1-5. [CrossRef]

285. Ju, H.L.; Sohn, H. Role of grain boundaries in double exchange manganite oxides $\mathrm{La}_{1-x} \mathrm{~A}_{x} \mathrm{MnO}_{3}(\mathrm{~A}=\mathrm{Ba}, \mathrm{Ca})$. Solid State Commun 1997, 102, 463-466. [CrossRef]

286. Straumal, B.B.; Mazilkin, A.A.; Protasova, S.G.; Myatiev, A.A.; Straumal, P.B.; Schütz, G.; Van Aken, P.A.; Goering, E.; Baretzky, B. Magnetization study of nanograined pure and Mn-doped ZnO films: Formation of a ferromagnetic grain-boundary foam. Phys. Rev. B Condens. Matter Mater. Phys. 2009, 79, 205206-205206. [CrossRef]

287. Sepehri-Amin, H.; Tamazawa, Y.; Kambayashi, M.; Saito, G.; Takahashi, Y.K.; Ogawa, D.; Ohkubo, T.; Hirosawa, S.; Doi, M.; Shima, T.; et al. Achievement of high coercivity in $\mathrm{Sm}\left(\mathrm{Fe}_{0.8} \mathrm{Co}_{0.2}\right) 12$ anisotropic magnetic thin film by boron doping. Acta Mater. 2020, 194, 337-342. [CrossRef]

288. Zhang, J.; Wang, W.; Wang, T.; Jiang, L.; Wang, N.; Sun, D.; Zhao, X.; Wang, M.; Qi, Y. Nanoscale characterization of the doped $\mathrm{SrZrO}_{3}$ nanoparticles distribution and its influence on the microstructure of $\mathrm{Bi}_{2} \mathrm{Sr}_{2} \mathrm{CaCu}_{2} \mathrm{O}_{8+\delta}$ film. J. Alloys Compd. 2021, 858, 157650. [CrossRef]

289. Straumal, B.B.; Myatiev, A.A.; Straumal, P.B.; Mazilkin, A.A.; Protasova, S.G.; Goering, E.; Baretzky, B. Grain boundary layers in nanocrystalline ferromagnetic zinc oxide. JETP Lett. 2010, 92, 396-400. [CrossRef]

290. Park, Y.J.; Kang, J.H.; Kim, A.H.; Kim, T.H.; Lim, T.Y.; Kim, D.H. Structural, electrical, and magnetic properties of $\mathrm{BiFeO}_{3}-\mathrm{Y}_{3} \mathrm{Fe}_{5} \mathrm{O}_{12}$ bulk ceramics and sputtered thin films. J. Magn. Magn. Mater. 2021, 535, 168058. [CrossRef]

291. Li, S.; Pan, J.; Gao, F.; Zeng, D.; Qin, F.; He, C.; Dodbiba, G.; Wei, Y.; Fujita, T. Structure and magnetic properties of coprecipitated nickel-zinc ferrite-doped rare earth elements of Sc, Dy, and Gd. J. Mater. Sci. Mater. Electron. 2021, 1-16. [CrossRef]

292. Chen, C.F.; Brennecka, G.L.; Synowicki, R.A.; Tegtmeier, E.L.; Brand, M.J.; Montalvo, J.D.; Ivy, J.; Cherepy, N.J.; Seeley, Z.; Payne, S.A. Transparent polycrystalline $\mathrm{Gd}_{2} \mathrm{Hf}_{2} \mathrm{O}_{7}$ ceramics. J. Am. Ceram. Soc. 2018, 101, 3797-3807. [CrossRef]

293. Zhao, W.; Anghel, S.; Mancini, C.; Amans, D.; Boulon, G.; Epicier, T.; Shi, Y.; Feng, X.Q.; Pan, Y.B.; Chani, V.; et al. Ce $3+$ dopant segregation in $\mathrm{Y}_{3} \mathrm{Al}_{5} \mathrm{O}_{12}$ optical ceramics. Opt. Mater. 2011, 33, 684-687. [CrossRef]

294. Palmero, P.; Bonelli, B.; Fantozzi, G.; Spina, G.; Bonnefont, G.; Montanaro, L.; Chevalier, J. Surface and mechanical properties of transparent polycrystalline YAG fabricated by SPS. Mater. Res. Bull. 2013, 48, 2589-2597. [CrossRef]

295. Lyberis, A.; Patriarche, G.; Gredin, P.; Vivien, D.; Mortier, M. Origin of light scattering in ytterbium doped calcium fluoride transparent ceramic for high power lasers. J. Eur. Ceram. Soc. 2011, 31, 1619-1630. [CrossRef]

296. Klimke, J.; Trunec, M.; Krell, A. Transparent tetragonal yttria-stabilized zirconia ceramics: Influence of scattering caused by birefringence. J. Am. Ceram. Soc. 2011, 94, 1850-1858. [CrossRef]

297. Zhang, Y. Making yttria-stabilized tetragonal zirconia translucent. Dent. Mater. 2014, 30, 1195-1203. [CrossRef] [PubMed]

298. Trunec, M.; Maca, K.; Chmelik, R. Polycrystalline alumina ceramics doped with nanoparticles for increased transparency. J. Eur. Ceram. Soc. 2015, 35, 1001-1009. [CrossRef]

299. Merac, M.R.; Reimanis, I.E.; Smith, C.; Kleebe, H.-J.; Müller, M.M. Effect of Impurities and LiF Additive in Hot-Pressed Transparent Magnesium Aluminate Spinel. Int. J. Appl. Ceram. Technol. 2013, 10, E33-E48. [CrossRef] 